\title{
NUMERICALLY SIMULATED COMPARATIVE PERFORMANCE OF A SCRAMJET AND SHCRAMJET AT MACH 11
}

\section{Jonathan Chan}

A thesis submitted in conformity with the requirements for the degree of Masters of Applied Science, Graduate Department of Aerospace Science and Engineering, University of Toronto. Copyright (c) 2010 by Jonathan Chan.

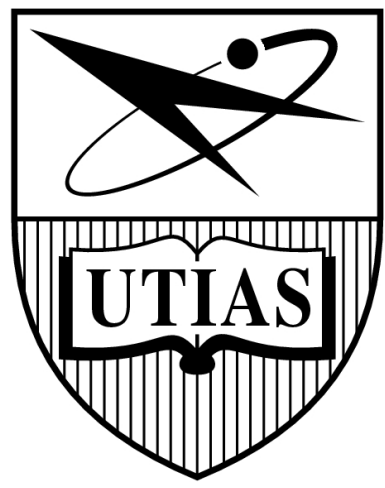




\title{
NUMERICALLY SIMULATED COMPARATIVE \\ PERFORMANCE OF A SCRAMJET AND \\ SHCRAMJET AT MACH 11
}

\author{
by Jonathan Chan \\ Masters of Applied Science \\ Graduate Department of Aerospace Science and Engineering \\ University of Toronto, 2010 \\ jonny. chan@utoronto.ca
}

\section{Abstract}

This study investigates the design and aeropropulsive performance of a complete, hydrogen powered, shock-induced combustion ramjet (shcramjet) at a flight Mach number of 11 and altitude of $34.5 \mathrm{~km}$. The design includes a Prandtl-Meyer compression inlet, cantilevered ramp fuel injectors, a shock-inducing wedge and a divergent nozzle. Numerical studies are undertaken using the WARP code that solves the three-dimensional Favre-averaged Navier-Stokes equations closed by the Wilcox $k$ - $\omega$ turbulence model and the Jachimowski $H_{2} /$ air chemical kinetics model. Studies of fuel injection properties, mixing duct length, combustor wedge and nozzle geometry are completed to maximize the overall performance of the vehicle. The final shcramjet configuration generates a specific impulse of $1110 \mathrm{~s}$. A comparison is undertaken with a scramjet vehicle at identical flight conditions and using many of the same components. The comparable scramjet generates a higher specific impulse of $1450 s$ although it is significantly larger and therefore heavier. 


\section{Acknowledgements}

First and foremost, I am truly thankful for my supervisor, Prof. J.P. Sislian, for his patience and guidance. Without his knowledge and encouragement, this thesis would not have been possible. His advice extended beyond my studies and helped with my career and life in general. I would also like to thank the faculty and staff at the University of Toronto Institute for Aerospace Studies for their help and support.

I would like to extend my gratitude to my lab mates for their companionship. Specifically, I would like to thank Yen, Yu and Derrick for all their help during my studies.

Last but not least, I would like to thank my family and Emily, for their continual moral support during all my years of study. 


\section{Contents}

Acknowledgements

List of Tables

List of Figures

ix

Nomenclature

xii

Chapter 1. INTRODUCTION

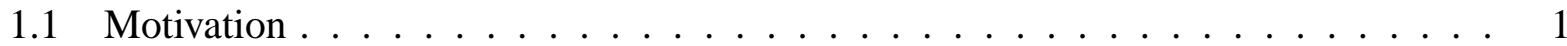

1.2 Types of Hypersonic Airbreathing Propulsion . . . . . . . . . . . . . . . 2

1.2 .1 Scramjet . . . . . . . . . . . . . . . . . 2

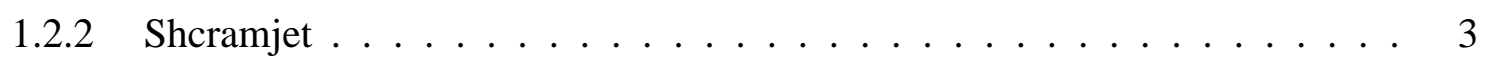

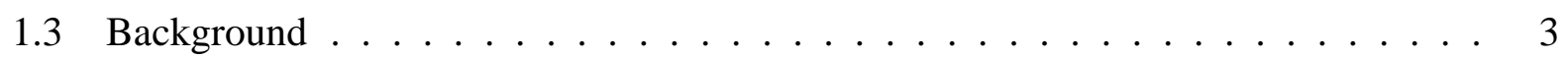

1.3.1 Fuel / Air Premixing . . . . . . . . . . . . . . . 3

1.3.2 Shock-Induced Combustion .................. 4

1.4 Scope of Present Study . . . . . . . . . . . . . . . . . . . . . . . . . 5

1.4.1 Thesis Objectives and Outline . . . . . . . . . . . . . . 7

Chapter 2. NUMERICAL METHOD $\quad 8$

2.1 Governing Equations . . . . . . . . . . . . . . . . 8

2.2 Numerical Method . . . . . . . . . . . . . . . . . . . 11 
2.3 Freestream Conditions . . . . . . . . . . . . . . . . . . . . . 12

$\begin{array}{lr}\text { Chapter 3. METHOD OF ANALYSIS } & \mathbf{1 4}\end{array}$

3.1 Analysis Tools . . . . . . . . . . . . . . . . . . . . . . . . . . 14

3.1 .1 Thrust Potential . . . . . . . . . . . . . . . . . . . . . . . . . . . 14

3.1 .2 Mixing Efficiency $\ldots \ldots \ldots \ldots \ldots \ldots$

3.1 .3 Thrust Forces . . . . . . . . . . . . . . . . . . . . 15

$3.1 .4 \quad$ Specific Impulse $\ldots \ldots \ldots \ldots$

3.2 Method of Comparative Analysis . . . . . . . . . . . . . . . . . . . . 16

3.3 Domain . . . . . . . . . . . . . . . . . . . 18

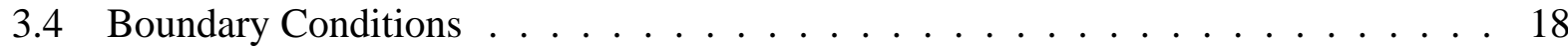

Chapter 4. SHCRAMJET INLET 20

4.1 Inlet Configuration . . . . . . . . . . . . . . . . . . . 20

4.2 Inlet Flowfield . . . . . . . . . . . . . . . . . . . . . . 22

$4.2 .1 \quad$ Pressure Wave Study . . . . . . . . . . . . . . . . . . . . . . 25

4.2.2 Comparison with 2-Shock Inlet . . . . . . . . . . . . . . . . . 25

Chapter 5. SHCRAMJET INJECTORS 27

5.1 Injector Configuration . . . . . . . . . . . . . . . . . . . . . . . 27

5.2 Injector Cases . . . . . . . . . . . . . . . . . . . . . . 28

5.3 Injector Flowfields . . . . . . . . . . . . . . . . . . . . . 30

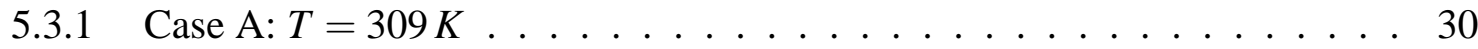

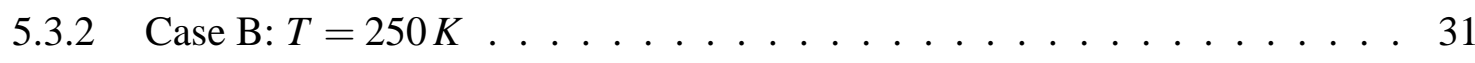

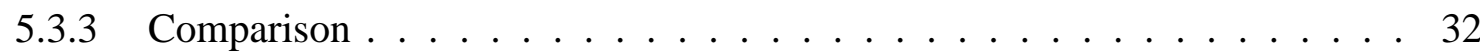

Chapter 6. SHCRAMJET COMBUSTOR 34

6.1 Combustor Configuration . . . . . . . . . . . . . . . . . . . . . 34

6.2 Combustor Flowfield $\ldots \ldots \ldots \ldots \ldots$

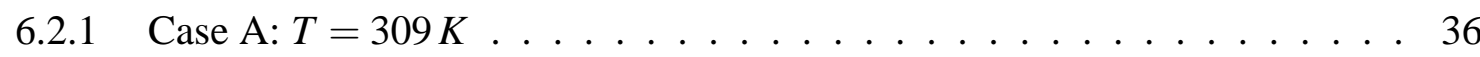

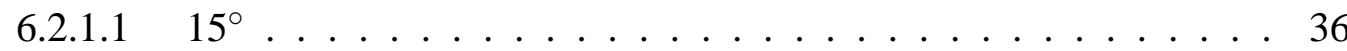

$6.2 .1 .2 \quad 15^{\circ}$ Short $\ldots \ldots \ldots \ldots \ldots \ldots \ldots \ldots$

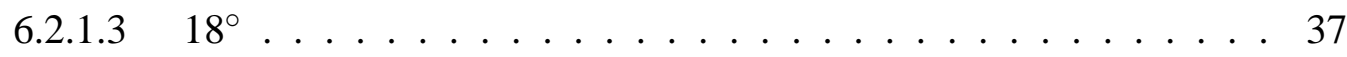

6.2.1.4 Case Comparison . . . . . . . . . . . . . . . 38

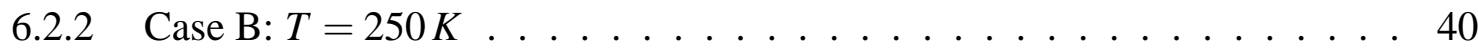

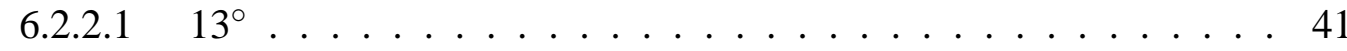

$6.2 .2 .217^{\circ} \ldots \ldots \ldots \ldots \ldots \ldots \ldots \ldots \ldots \ldots \ldots \ldots \ldots$

6.2.2.3 Case Comparison . . . . . . . . . . . . . . . . 42 
Chapter 7. SHCRAMJET NOZZLE $\mathbf{4 4}$

7.1 Nozzle Configuration . . . . . . . . . . . . . . . . . . . . . . . 44

7.1.1 Method of Characteristics . . . . . . . . . . . . . . . . 45

7.1.1.1 Unit Process . . . . . . . . . . . . . . . . . . 47

7.1 .2 Dual Wall Method . . . . . . . . . . . . . . . . . . . . . 47

7.1.2.1 Mach Region . . . . . . . . . . . . . . . . 48

7.1.2.2 Kernel Region . . . . . . . . . . . . . . . . . . . . 48

7.1.2.3 Transition Region . . . . . . . . . . . . . . . . . . 49

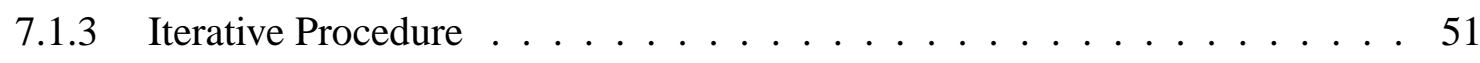

7.1 .4 Choosing an Initial Data Line . . . . . . . . . . . . . . . 51

7.1 .5 Effects on Nozzle Wall Geometry $\ldots \ldots \ldots$. . . . . . . . 53

7.1 .6 Outer Cowl Design . . . . . . . . . . . . . . . . . . . 55

7.2 Nozzle Flowfield . . . . . . . . . . . . . . . . . . . 55

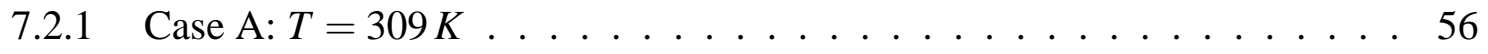

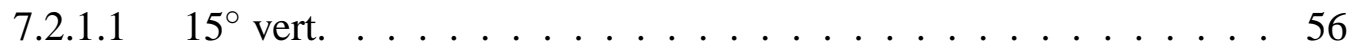

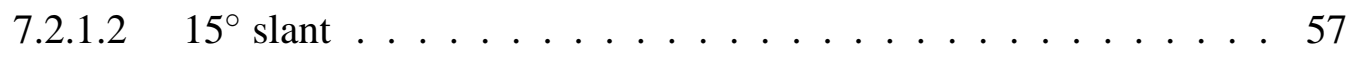

$7.2 .1 .3 \quad 15^{\circ}$ slant multitemp $\ldots \ldots \ldots \ldots \ldots \ldots$

$7.2 .1 .418^{\circ}$ slant $\ldots \ldots \ldots \ldots \ldots \ldots$

$7.2 .2 \quad$ Case B: $T=250 K \ldots \ldots \ldots \ldots \ldots$

$7.2 .2 .1 \quad 13^{\circ}$ vert. . . . . . . . . . . . . . . 59

7.2 .3 Case Comparison . . . . . . . . . . . . . . . . . . . . 60

7.2.3.1 Chosen Case . . . . . . . . . . . . . . . . . . 62

7.2.3.2 Cowl Length Optimization . . . . . . . . . . . . . . . 62

7.3 Final Vehicle Configuration . . . . . . . . . . . . . . . . . . 63

Chapter 8. COMPARISON WITH SCRAMJET $\mathbf{6 5}$

8.1 Scramjet Configuration . . . . . . . . . . . . . . . . 65

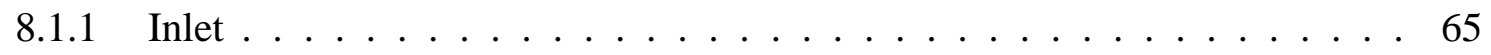

8.1 .2 Injectors . . . . . . . . . . . . . . . . 66

8.1 .3 Combustor . . . . . . . . . . . . . . . 66

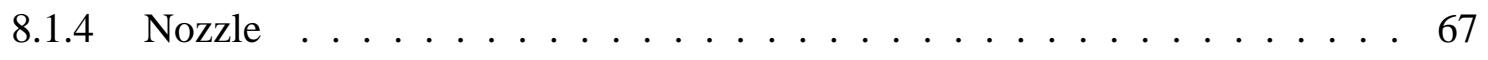

8.1.4.1 False-Wall Method . . . . . . . . . . . . . . . 67

8.2 Component Comparison . . . . . . . . . . . . . . . . . . . . . 69

$8.2 .1 \quad$ Inlet $\ldots \ldots \ldots \ldots \ldots$

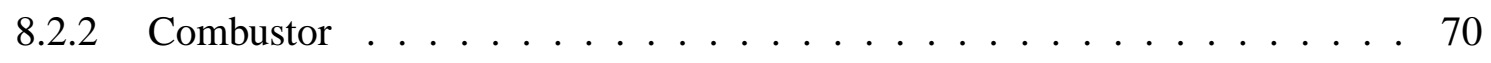

8.2.2.1 Scramjet No Burning . . . . . . . . . . . . . 73

8.2 .3 Nozzle . . . . . . . . . . . . . . . . . . . . . . . . . . . . 75

8.3 Vehicle Comparison . . . . . . . . . . . . . . . . . . . . . . 78 
8.3 .1 Pressure Flowfields ......................... 78

8.3 .2 Vehicle Surface Forces . . . . . . . . . . . . . . . . 80

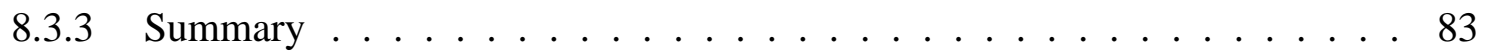

Chapter 9. CONCLUSIONS AND RECOMMENDATIONS 84

Appendix A. Vehicle Forces
$\mathbf{8 6}$

$\begin{array}{lr}\text { Bibliography } & \mathbf{8 9}\end{array}$ 


\section{List of Tables}

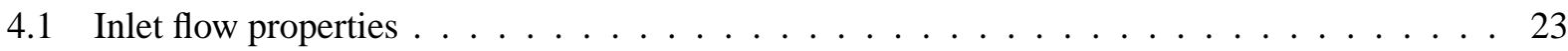

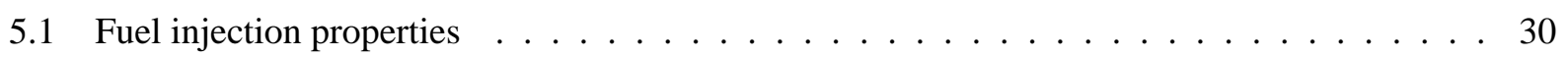

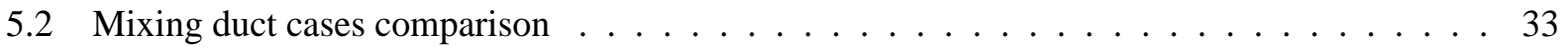

8.1 Fuel injection parameters $\ldots \ldots \ldots \ldots \ldots \ldots$

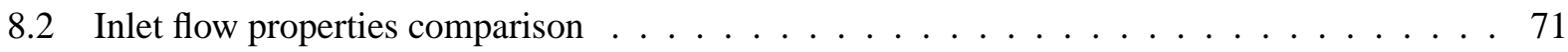

8.3 Combustor flow properties comparison $\ldots \ldots \ldots \ldots \ldots \ldots$

8.4 Overall vehicle performance characteristics $\ldots \ldots \ldots \ldots$

A.1 Overall vehicle performance (Thrust) $\ldots \ldots \ldots \ldots$. . . . . . . . . . 87

A.2 Overall vehicle performance $\left(I_{s p}\right) \ldots \ldots \ldots \ldots \ldots$ 


\section{List of Figures}

1.1 Hypersonic air-breathing engine schematics $\ldots \ldots \ldots \ldots$

3.1 Isometric view of simulation domain $\ldots \ldots \ldots \ldots$

3.2 Front view of simulation domain $\ldots \ldots \ldots \ldots \ldots$

4.13 shock mixed-compression inlet configuration . . . . . . . . . . . . 21

4.2 Compression ramp inlet configuration $\ldots \ldots \ldots \ldots \ldots \ldots \ldots \ldots$

4.3 Shcramjet inlet pressure flowfield . . . . . . . . . . . . . . . 22

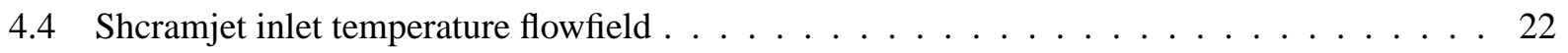

4.5 Shcramjet inlet exit velocity profile . . . . . . . . . . . . . . . 24

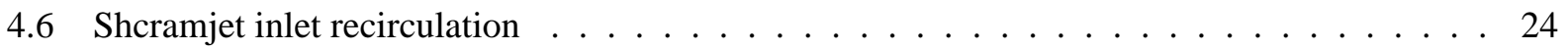

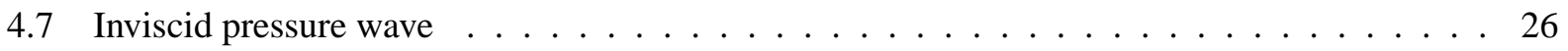

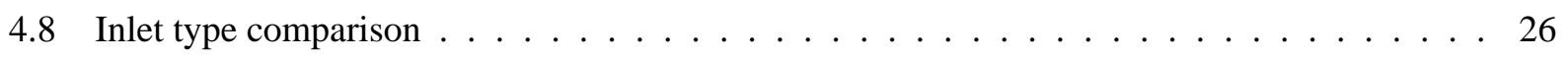

5.1 Cantilevered ramp injector array geometry $\ldots \ldots \ldots \ldots \ldots$

5.2 Injector region grid (reduced density) $\ldots \ldots \ldots \ldots \ldots$

5.3 Case A mixing duct water mass fraction $\ldots \ldots \ldots \ldots \ldots \ldots \ldots$

5.4 Hydrogen mass fraction contours in Case A's mixing duct $\ldots \ldots \ldots \ldots \ldots \ldots$

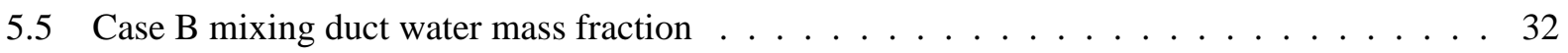

5.6 Hydrogen mass fraction contours in Case B's mixing duct . . . . . . . . . . . . . 32

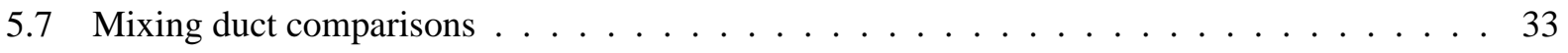

6.1 Combustor temperature flowfield for Case $\mathrm{A}: 15^{\circ} \ldots \ldots \ldots$ 
6.2 Combustor $\mathrm{H}_{2} \mathrm{O}$ level flowfield for Case A: $15^{\circ} \ldots \ldots \ldots \ldots \ldots$

6.3 Combustor temperature flowfield for Case A: $18^{\circ} \ldots \ldots \ldots$

6.4 Combustor $\mathrm{H}_{2} \mathrm{O}$ level flowfield for Case A: $18^{\circ} \ldots \ldots \ldots \ldots \ldots \ldots$

6.5 Case A combustor flowfield properties comparison . . . . . . . . . . . . . . 40

6.6 Combustor temperature flowfield for Case $\mathrm{B}: 13^{\circ} \ldots \ldots \ldots \ldots$

6.7 Combustor $\mathrm{H}_{2} \mathrm{O}$ level flowfield for Case B: $13^{\circ} \ldots \ldots \ldots \ldots \ldots \ldots$

6.8 Combustor temperature flowfield for Case B: $17^{\circ} \ldots \ldots \ldots \ldots$

6.9 Combustor $\mathrm{H}_{2} \mathrm{O}$ level flowfield for Case B: $17^{\circ} \ldots \ldots \ldots \ldots \ldots$. . . . . . . . 42

6.10 Case B combustor flowfield properties comparison $\ldots \ldots \ldots$. . . . . . . . 43

7.1 Nozzle gridding with every $4^{\text {th }}$ line shown $\ldots \ldots \ldots \ldots$

7.2 Method of characteristics solution schematic of point 4 from information at points 1 and $2 \quad . \quad 47$

7.3 Schematic of dual wall nozzle design $\ldots \ldots \ldots \ldots$

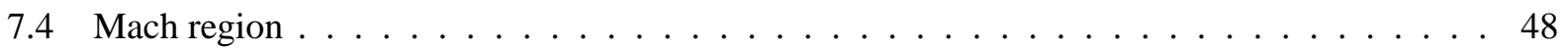

7.5 Method of characteristics process in the Kernel region . . . . . . . . . . . . . . . . 49

$7.6 C^{+}$and $C^{-}$characteristics in the completed Kernel region . . . . . . . . . . . . . 49

7.7 Method of characteristics process in the upper Transition region $\ldots \ldots \ldots$. . . . . 50

7.8 Typical Transition region $\ldots \ldots \ldots \ldots \ldots \ldots$

7.9 Step 3: Reduce length of nozzle walls $\ldots \ldots \ldots \ldots \ldots$

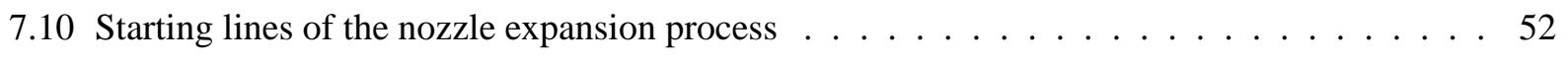

7.11 Effect of flow direction and starting line on MOC generated nozzle wall geometry . . . . . 54

7.12 Cowl geometry . . . . . . . . . . . . . . . . . . . 55

7.13 Regions of the simulation $($ Blue $=2 \mathrm{D}$, Green=3D) $\ldots \ldots \ldots \ldots$

7.14 Case A $15^{\circ}$ nozzle pressure flowfield $\ldots \ldots \ldots \ldots \ldots \ldots$

7.15 Case A $15^{\circ}$ slant nozzle pressure flowfield $\ldots \ldots \ldots \ldots \ldots$

7.16 Case A $18^{\circ}$ slant nozzle pressure flowfield . . . . . . . . . . . . . . . . 59

7.17 Case B $13^{\circ}$ nozzle pressure flowfield $\ldots \ldots \ldots \ldots \ldots$

7.18 Nozzle flowfield properties comparison ( ${ }^{*}$ Case B shifted in $x$ to start with Case A) . . . . . 61

7.19 Case A $15^{\circ}$ slant nozzle pressure flowfield with optimized cowl $\ldots \ldots \ldots 3$

7.20 Full shcramjet vehicle temperature flowfield $\ldots \ldots \ldots$. . . . . . . . . . 64

8.1 General cantilevered ramp injector array geometry $\ldots \ldots \ldots 6$

8.2 Schematic of nozzle design $\ldots \ldots \ldots \ldots \ldots$

8.3 Starting line of the nozzle expansion process $\ldots \ldots \ldots \ldots$

8.4 Scramjet inlet pressure flowfield $\ldots \ldots \ldots \ldots \ldots \ldots \ldots$ 
8.5 Scramjet inlet temperature flowfield $\ldots \ldots \ldots \ldots \ldots \ldots$

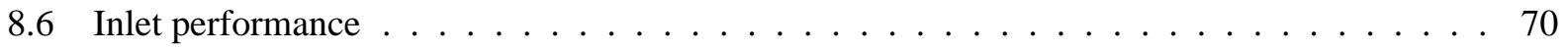

8.7 Shcramjet combustor Mach number flowfields at $z=0.01 \mathrm{~m} \ldots \ldots \ldots \ldots$

8.8 Temperature contour plots at $z=0.01 \mathrm{~m}$ in the scramjet combustor . . . . . . . . 72

$8.9 \mathrm{H}_{2} \mathrm{O}$ mass fraction contour plots at $z=0.01 \mathrm{~m}$ in the scramjet combustor $\ldots \ldots \ldots 72$

8.10 Water mass fraction contours in the scramjet combustor $\ldots \ldots \ldots \ldots$

8.11 Combustor flowfield properties comparison $\ldots \ldots \ldots \ldots \ldots$

8.12 Scramjet (no burning) vs shcramjet mixing efficiency . . . . . . . . . . . . . 75

8.13 Scramjet nozzle flowfields at $z=0.01 \mathrm{~m} \ldots \ldots \ldots \ldots$

8.14 Shcramjet nozzle flowfields at $z=0.01 \mathrm{~m} \ldots \ldots \ldots \ldots \ldots$

8.15 Nozzle species mass fractions $\ldots \ldots \ldots \ldots \ldots \ldots \ldots$

8.16 Scramjet vehicle pressure flowfield at $z=0.01 \mathrm{~m} \ldots \ldots \ldots$

8.17 Shcramjet vehicle pressure flowfield at $z=0.01 \mathrm{~m} \ldots \ldots \ldots \ldots$

8.18 Mass-averaged pressure variations along the engine $\ldots \ldots \ldots \ldots$

8.19 Forces on scramjet inner wall surfaces $\ldots \ldots \ldots \ldots \ldots$

8.20 Forces on shcramjet inner wall surfaces $\ldots \ldots \ldots \ldots$. . . . . . . . . . . . 81

8.21 Variations of the fuel specific impulse along the vehicles $\ldots \ldots \ldots . \ldots \ldots$

8.22 Scaled vehicle geometry comparison $\ldots \ldots \ldots \ldots$ 


\section{Nomenclature}

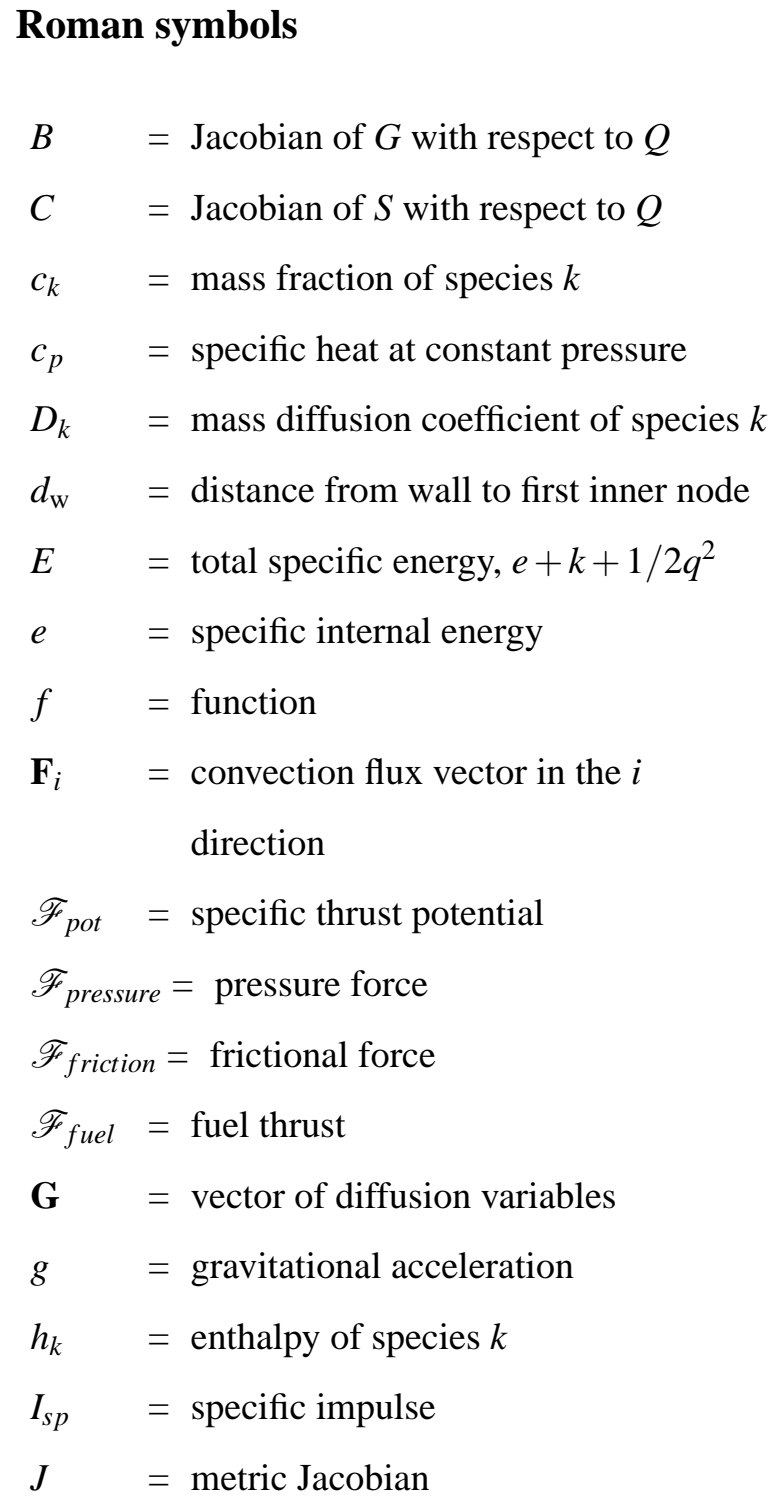

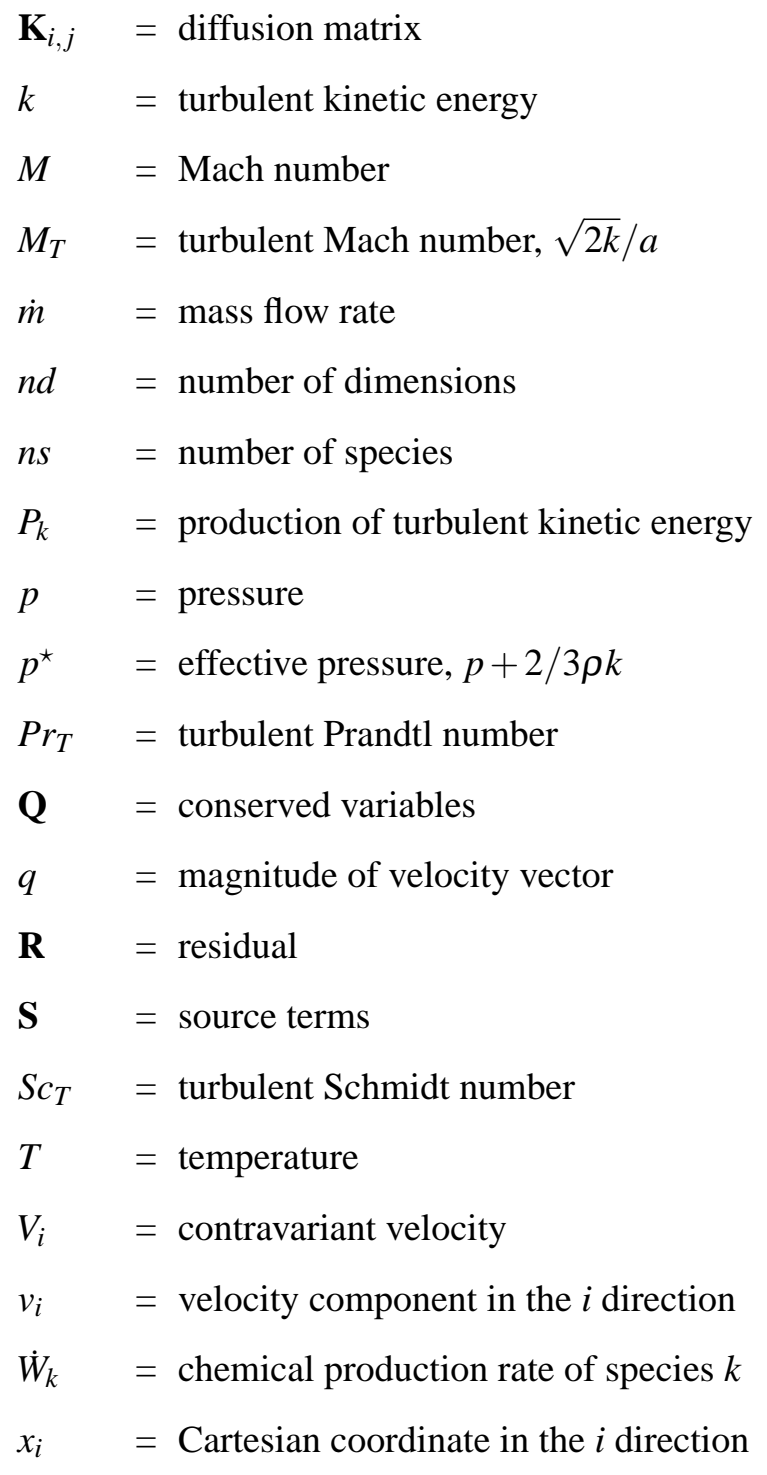




$$
\begin{aligned}
X_{i}= & \text { curvilinear coordinate in the } i \\
& \text { direction } \\
X_{i, j}= & \partial X_{i} / \partial x_{j} \\
y^{+}= & \text {non-dimensional wall distance, } \\
& d_{\mathrm{w}} \rho \sqrt{\tau_{\mathrm{w}} / \rho_{\mathrm{w}}} / \mu
\end{aligned}
$$

\section{Greek symbols}

$\alpha_{i, j} \quad=$ intermediate $K_{i, j}$ term,

$$
J^{-1} \sum_{m=1}^{n d} X_{i, m} X_{j, m}
$$$$
\beta_{i, j}^{r, s}=\alpha_{i, j} \delta_{r, s}+J^{-1} X_{i, s} X_{j, r}-2 / 3 J^{-1} X_{i, r} X_{j, s}
$$

$\delta_{i j} \quad=$ Kronecker delta

$\delta_{X_{i}} \quad=$ discrete derivative with respect to $X_{i}$

$$
\begin{array}{ll}
\eta_{m} & =\text { mixing efficiency } \\
\kappa & =\text { thermal conductivity } \\
\mu & =\text { viscosity } \\
\mu_{T} & =\text { turbulent eddy viscosity } \\
\phi & =\text { equivalence ratio } \\
\xi & =\text { convergence criterion } \\
\omega & =\text { dissipation rate per unit of turbulent } \\
& \text { kinetic energy } \\
\rho & =\text { density } \\
\sigma_{k} & =\text { Wilcox turbulent closure coefficient } \\
\sigma_{\omega} & =\text { Wilcox turbulent closure coefficient } \\
\tau & =\text { pseudo time } \\
\tau_{\mathrm{w}} & =\text { wall shear stress }
\end{array}
$$




\section{INTRODUCTION}

\subsection{Motivation}

Since the beginning of space access 50 years ago, the rocket has been the sole means of reaching space. The design of the rocket is simple yet effective and may still be used for many decades to come. Currently space access is reserved for high level missions or for large scale systems like GPS and satellite systems. However the demand for space access is ever increasing, specially with the commencement of space tourism. With more and more missions to space, the high cost development for newer and more efficient modes of transportation will be worthwhile and more complex systems will arise. One such technology is hypersonic airbreathing propulsion. As rocket technology requires both the fuel and oxidizer to be carried onboard, this can lead to large portions

of the takeoff mass to be just oxygen. In the current Shuttle system, about $65 \%$ of the take-off weight is oxygen. Using an airbreathing propulsion system, there will be no need to carry this oxygen load.

There are a few reasons why the rocket is still being used for space access. The most important reason is that rockets provide thrust from take-off to escape velocity ( $\approx$ Mach 26 ). Hypersonic airbreathing propulsion systems like the scramjet cannot provide thrust at take off or at low speeds. Furthermore, it has not been developped in the high Mach regime and its limit is still unknown. Currently the record is Mach 9.8 set by NASA's X-43 scramjet test vehicle.

Until further development into expanding hypersonic airbreathing propulsion across the entire Mach regime, a more realistic goal would be to implement airbreathing propulsion onto the current rocket based propulsion systems. In this manner, airbreathing propulsion can be used for a large 
portion of the space launch from Mach 2 to Mach 10-15 using a combination of ramjet, scramjet and even shcramjet propulsion to reduce the total amount of onboard oxygen required.

\subsection{Types of Hypersonic Airbreathing Propulsion}

The main types of hypersonic airbreathing propulsion systems are ramjets and scramjets. The ramjet works by compressing the air required for combustion by shocks produced from flying at high speeds, also known as the ram effect. This design cannot provide thrust at take off or at low speeds due to the lack of the ram effect. In a ramjet, the airflow is decelerated to subsonic flow by the time it reaches the combustor through a final normal shock. The deceleration of the airflow incurs high losses at higher speeds and more importantly, heats the flow to very high temperatures and thus ionizing the air. Ionization of molecules requires energy and will only be released if they recombine. Even with the reduced temperatures in the nozzle, the high speed flow in the engine will not allow enough time for most of the ions to recombine before being ejected from the nozzle. The supersonic combustion ramjet (scramjet) is the faster variant in which the compressed flow remains supersonic in the combustor and therefore is not subjected to the high losses associated with decelerating the flow to subsonic speeds. Its flight regime is higher than the ramjet, typically between Mach 5-10. For even higher speeds, there is another variant called the shock-induced combustion ramjet. The difference between a scramjet and shock-induced combustion ramjet is explained next.

\subsubsection{Scramjet}

The design of a scramjet engine is very simple and can be broken down into three sections: the inlet, the combustor and the nozzle. The inlet serves to compress the oncoming air entering the engine. The combustor is the main design challenge and serves to mix and burn fuel simultaneously through diffusive combustion. Finally the nozzle serves to expand the combusted mixture for thrust. The scramjet design can be expressed as:

\section{Scramjet: Compression $\Rightarrow$ (Mixing+Burning) $\Rightarrow$ Expansion}

The issue with using a scramjet at high Mach numbers $(>10)$ is the combustor required for diffusive burning may become excessively long, incurring large frictional losses and increasing the vehicle size and weight. 


\subsubsection{Shcramjet}

The design of a shock-induced combustion ramjet (shcramjet) is quite different from the scramjet but can still be broken down into the same three sections: the inlet, the combustor and the nozzle. However, the shcramjet inlet serves to compress the oncoming air and to inject/mix the fuel. The compression is significantly less in the shcramjet's inlet. The shcramjet's combustor uses a shock to compress and burn the fuel/air mixture simultaneously through shock-induced combustion or a detonation wave. Finally the nozzle expands the combusted mixture for thrust, just as in the scramjet. The shcramjet design can be expressed as:

\section{Shcramjet: (Compression+Mixing) $\Rightarrow($ Compression+Burning $) \Rightarrow$ Expansion}

In this design, the mixing process can be done in the long inlet required for compression with fuel injection at the tip of the inlet. Additionally, the combustor required is significantly shorter and thus causes less frictional drag while decreasing the vehicle size and weight. Furthermore the required cooling is reduced due to the smaller high temperature regions. However, the main drawback of the shcramjet is properly mixing the fuel and air before the combustor without premature ignition.

\subsection{Background}

\subsubsection{Fuel / Air Premixing}

For hypersonic airbreathing propulsion, the most challenging task is mixing fuel and air effectively. At the flight speed these vehicles are travelling at, the residence time of air through the engine is very short, on the order of milliseconds. Many mixing strategies have been proposed for the scramjet engine including cavity, pylon, wall, ramp and solid droplet fuel injection. ${ }^{34}$ Most of the research has been applied to scramjet engines at Mach numbers lower than this study. The direction of fuel injection is of particular importance. Fuel injection perpendicular to the flow will yield high mixing efficiency, however it will create large losses and will not generate any thrust. For fuel injection parallel to the flow, there will be less losses and provide thrust, however it will take longer to mix. At high Mach numbers, parallel fuel injection is often used as it is a significant portion of the thrust generation. 
One parallel or near parallel fuel injection system is the ramp fuel injector as described by Waitz et al. ${ }^{39}$ By having the fuel injector protrude from the wall, the difference in pressure over and in between the injectors create streamwise vortices that stretch the fuel/air interface. Additionally, the shock structure created from its geometry aid in mixing through the generation of baroclinic torque.

For the shcramjet engine, alternative mixing strategies need to be explored due to its different set of constraints. In the shcramjet engine, the combustion mechanism requires a well mixed flow before it reaches the combustor in order for it to perform well. Additionally, the fuel air mixture must not burn before it reaches the combustor, otherwise it will burn at a low pressure and would result in poor performance. This yields two conditions: fuel may be injected early in the inlet prior to the combustor or internal duct for longer mixing time, and fuel must not enter the hot boundary layers or go through strong shocks that will cause it to burn prematurely.

This has led to the design and research of cantilevered fuel injectors positioned at the tip of the inlet, examined in various studies. 3,36,27,24,37 Cantilevered ramp fuel injectors act similarly to regular ramp injectors in that they create streamwise vortices and baroclinique torque that serve to enhance the mixing process. The difference is that they are lifted and seperated from the wall such that the fuel is injected away from the wall and the hot boundary layer.

Difficulty arises when injecting fuel from the inlet tip as fuel is only injected from one side and keeping the fuel away from the boundary layers while going through shocks is a difficult task. As this technique has only yielded marginal mixing efficiencies under $47 \%$ for hydrogen fuel, an alternative design has been studied where fuel is injected via two arrays of injectors on both the body and cowl walls in the internal duct. In this manner the mixing efficiency should be improved with two array of injectors and the mixture does not go through inlet shocks. However this design requires a mixing duct prior to the combustor. Alexander et al. ${ }^{3}$ showed that this configuration can achieve mixing efficiencies of 54\% in $1 \mathrm{~m}$ for hydrogen fuel through specific injector geometry while avoiding premature ignition by injecting the fuel at the center of the duct.

\subsubsection{Shock-Induced Combustion}

The use of shock-induced combustion or a detonation wave for heat addition has been proposed long ago by Roy ${ }^{32}$ in 1946 . The idea is to replace the long diffusive burning process with a short detonation wave or shock-induced combustion. Since then, research into its stability in engines 
has been evaluated. Early research had been on normal detonation waves but quickly turned to oblique. ${ }^{17}$ Oblique detonation waves can be created by wedges turning the flow.

With a low wedge angle, a shock-induced combustion wave occurs where the shock increases the temperature and pressure such that the mixture burns further downstream of the shock. At high wedge angles, a detonation wave is produced where the shock and flame front are coupled and the original shock position is changed. The normal component of the flow behind the shock is subsonic. At a specific wedge angle in between, a detonation wave is created where the normal flow component is exactly sonic and is refered as the Chapman-Jouguet (CJ) condition which results in minimum entropy. At very high wedge angles, the flow behind the detonation wave becomes subsonic (absolute velocity not the normal component) and the detonation wave detachs from the wedge and can cause engine unstart.

For the shock-induced combustion or detonation wave engine to function practically, it must be able to stabilize in the presence of inhomogeneities and unsteady mixtures. First studies by Nicholls et al..$^{22}$ as well as Gross and Chinitz ${ }^{15}$ in the 1950 's confirmed the possibility of stabilizing an oblique shock wave at high Mach numbers. Additionally, studies ${ }^{14}$ have shown numerically the stability of detonations in unsteady flows. Time accurate simulations were performed of the combustor with time dependent inhomogeneities and showed that the near CJ detonation wave was resilient to the inhomogeneities.

\subsection{Scope of Present Study}

In the present study, the numerical simulation of a shcramjet vehicle flowfield from tip to tail is determined and its performance quantified. This simulation includes the inlet compression system, fuel injection, combustion modelling, flow expansion through the nozzle and flow around the outer body of the vehicle. Earlier simulations were mostly two dimensional, assumed homogeneous stoichiometric fuel/air mixture and/or inviscid flow. One study ${ }^{1}$ simulated the shcramjet vehicle using the WARP code 28,26 in three dimensions, solving the Favre Averaged Navier Stokes equations, using the Wilcox $k-\omega$ turbulence model ${ }^{40}$ and the Jachimowski chemical kinetics model. 16 The shcramjet design used a 2-shock inlet with internal upper and lower duct wall fuel injectors as opposed to preinjection in the inlet tip. This study used a high equivalence ratio of 2.7 and therefore its $I_{s p}$ was only $683 s$. In the present study, the WARP will be continued to be used and the shcramjet will be simulated in the same manner, shown in Fig.1.1(a), but injecting fuel at stoichio- 
metric proportions in hopes of attaining a higher specific impulse. Also, the compression system will use a different design, a compression ramp inlet, to yield better performance. Therefore in this study, many design parameters will be varied in hopes of attaining a much higher performing shcramjet vehicle.

The simulation of this shcramjet vehicle will be at a flight Mach number of 11, which has been shown in previous studies ${ }^{12}$ to be the trade-off point where the shcramjet engine becomes more efficient than the scramjet engine. As such, a previously completed scramjet engine, shown in Fig.1.1(b) has been simulated specifically for this comparison using many of the same components. In the present study, a quantitative comparison of the scramjet and shcramjet at Mach 11 will be performed in realistic simulations.

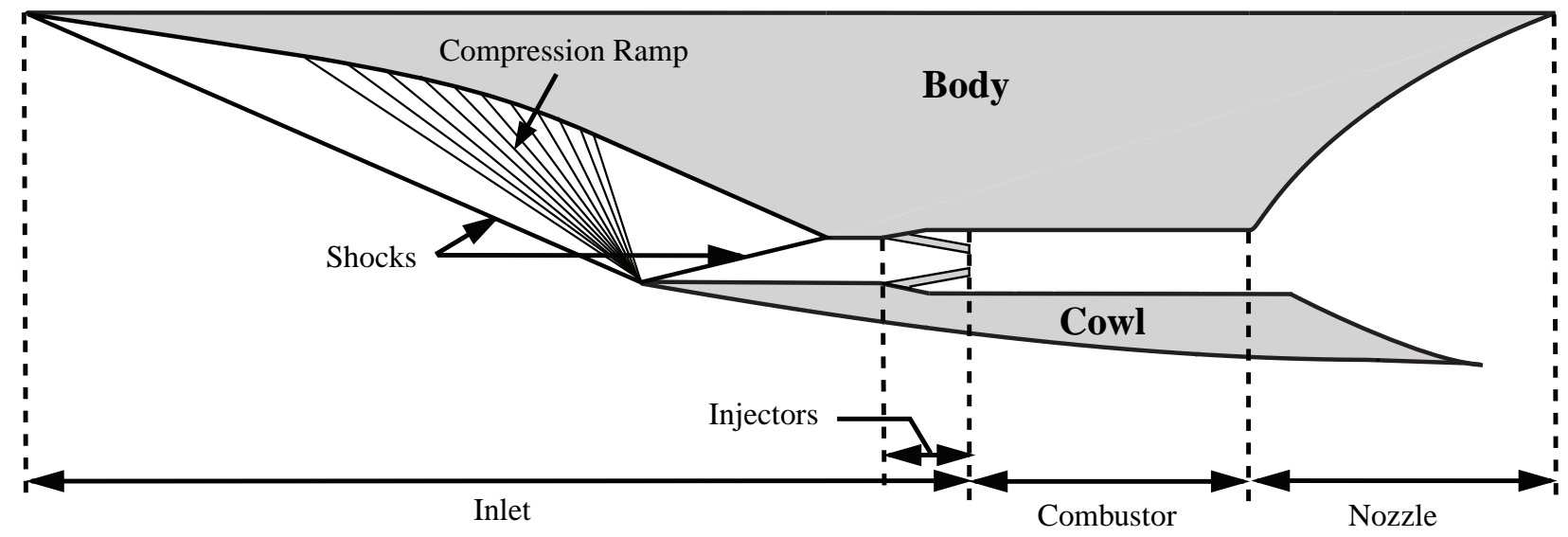

(a) Compression Ramp Scramjet

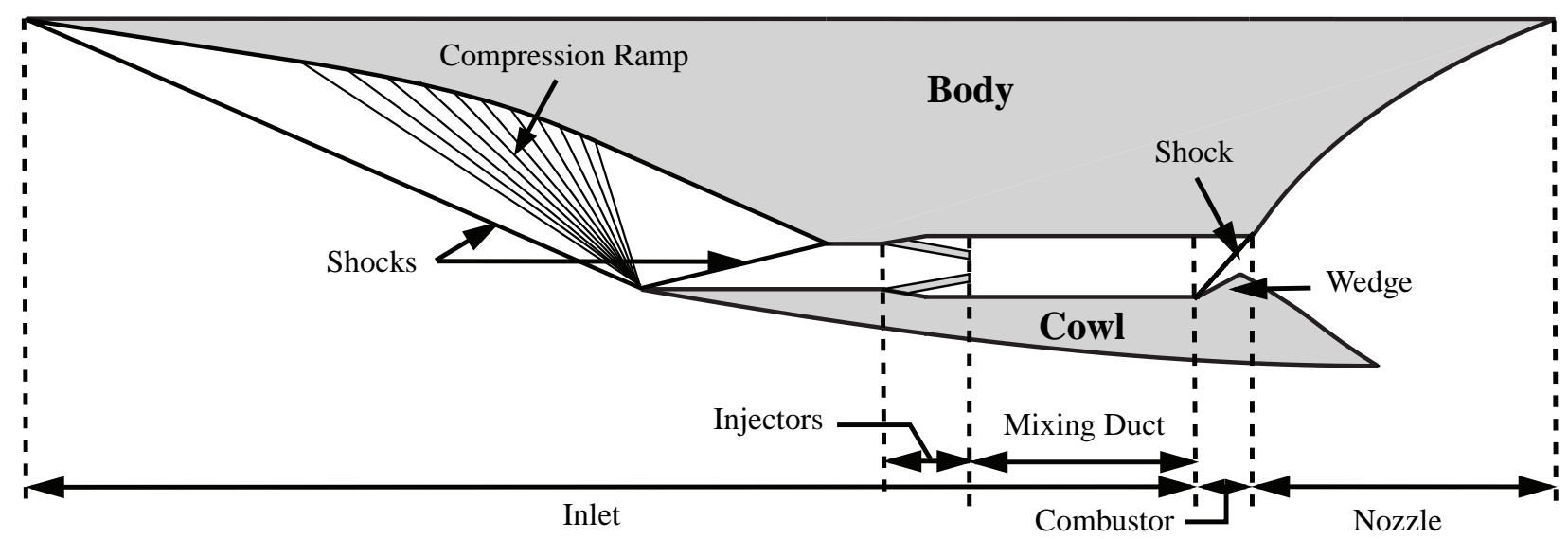

(b) Compression Ramp Shcramjet with Internal Injection

FIGURE 1.1: Hypersonic air-breathing engine schematics 


\subsubsection{Thesis Objectives and Outline}

The objective of this study is to numerically simulate a shock-induced combustion ramjet at Mach 11 and determine its relative aeropropulsive performance to that of a scramjet

- Simulate a flowfield of a shock-induced combustion ramjet including fuel injection, mixing and combustion.

- Generate realistic flowfields including three-dimensional, viscous, turbulent and finite rate chemistry effects.

- Generate high propulsive performance through parametric studies of design variables including fuel injection properties, mixing duct length, combustion wedge angle and nozzle design.

- Compare the flowfields and aeropropulsive performance of the shock-induced combustion ramjet to a similarly designed scramjet under the same flight conditions.

Chapter 2 briefly describes the derivation and validation of the numerical code used herein. Chapter 3 explains the method of comparison to be used between the shock-induced combustion ramjet and the scramjet. The tools used to compare the aeropropulsive performance of the two vehicles will also be defined. Chapter 4 describes the design method used to generate the compression ramp inlet used in the study. The corresponding flowfields are assessed. In Chapter 5, the geometry of the cantilevered ramp fuel injectors is described and the fuel injection properties given. Two sets of fuel injection properties are used and their corresponding flowfields are assessed. In Chapter 6, the shock-inducing combustion wedge is described and various geometries altering the wedge angle and length are tested. Their corresponding flowfields are assessed and compared to determine the optimal combustor geometry. In Chapter 7, the design methodology of the nozzle is described including the dual-wall method which utilizes the Method of Characteristics. Various cases are presented and assessed for determining the optimal performance. Finally in Chapter 8 , the scramjet is presented with its design methodology including the false-wall method used for its nozzle design. The scramjet's flowfield is presented and compared with that of the shcramjet to determine the relative aeropropulsive performance. 


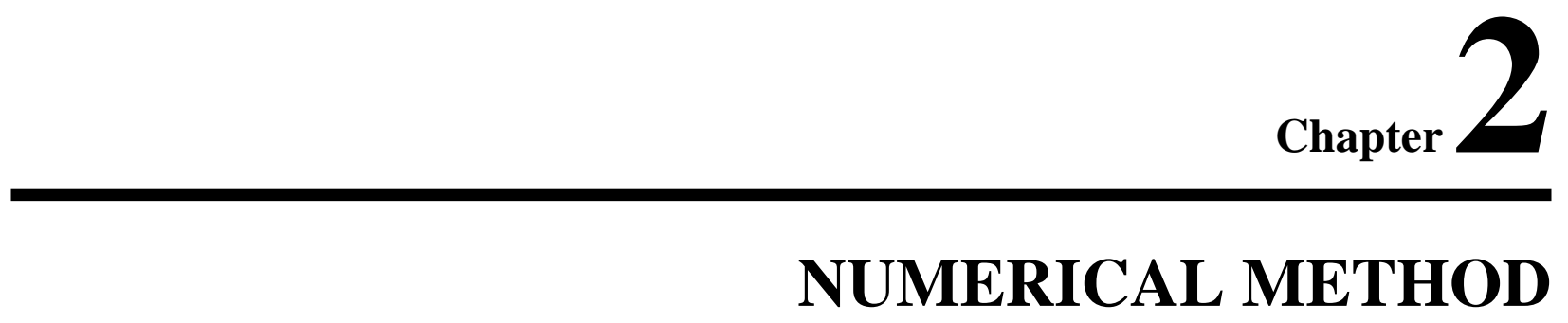

For the flows studied herein the two and three-dimensional, multispecies, Favre-averaged NavierStokes equations are solved in generalized curvilinear coordinates to a steady state solution with the Window Allocatable Resolver for Propulsion (WARP) code, originally developed by Parent. ${ }^{25}$ Turbulence is accounted for with the two-equation $k$ - $\omega$ turbulence model and the Wilcox dilatational dissipation correction. ${ }^{40,41}$ The numerical method used in the WARP code is included for completeness and to allow for recreation of the present study.

\subsection{Governing Equations}

Investigated flowfields are described by the Favre-averaged Navier-Stokes equations, closed by the $k$ - $\omega$ turbulence model of Wilcox ${ }^{40}$ and the 9 species, 20 reaction Jachimowski ${ }^{16} H_{2}$-air chemical kinetics model (nitrogen is assumed to be an inert gas). The equations are expressed in generalized coordinates as $\partial \mathbf{Q} / \partial \tau=-\mathbf{R}$, where minimization of the residual is sought.

$$
\mathbf{R}=\sum_{i=1}^{n d}\left[\frac{\partial \mathbf{F}_{i}}{\partial X_{i}}-\sum_{j=1}^{n d} \frac{\partial}{\partial X_{i}}\left(\mathbf{K}_{i, j} \frac{\partial \mathbf{G}}{\partial X_{j}}\right)\right]-\mathbf{S}
$$


For the conservative variable, convective flux, and diffusion term, we have:

$$
\mathbf{Q}=\frac{1}{J}\left[\begin{array}{c}
\rho c_{1} \\
\vdots \\
\rho c_{n s} \\
\rho v_{1} \\
\vdots \\
\rho v_{n d} \\
\rho E \\
\rho k \\
\rho \omega
\end{array}\right], \mathbf{F}_{i}=\frac{1}{J}\left[\begin{array}{c}
\rho V_{i} c_{1} \\
\vdots \\
\rho V_{i} c_{n s} \\
\rho V_{i} v_{1}+X_{i, 1} p^{\star} \\
\vdots \\
\rho V_{i} v_{n d}+X_{i, n d} p^{\star} \\
\rho V_{i} E+V_{i} p^{\star} \\
\rho V_{i} k \\
\rho V_{i} \omega
\end{array}\right], \mathbf{G}=\left[\begin{array}{c}
c_{1} \\
\vdots \\
c_{n s} \\
v_{1} \\
\vdots \\
v_{n d} \\
T \\
k \\
\omega
\end{array}\right]
$$

where

$$
V_{i}=\sum_{m=1}^{n d} X_{i, m} v_{m}
$$

is the contravariant velocity. The total energy and effective pressure include molecular and turbulent components, $E=e+k+1 / 2 q^{2}$ and $p^{\star}=p+2 / 3 \rho k$. The internal energy, enthalpy, and specific heat at constant pressure are determined from temperature dependent polynomials from McBride and Reno, ${ }^{20}$ whereas $p$ is found through the ideal gas law from the temperature and density. With

$$
\alpha_{i, j}=J^{-1} \sum_{m=1}^{n d} X_{i, m} X_{j, m}
$$

the diffusion matrix can be shown to be:

$$
\mathbf{K}_{i, j}=\left[\begin{array}{ccccc}
\alpha_{i, j} D_{1}^{\star} & \cdots & 0 & 0 & \cdots \\
\vdots & \ddots & \vdots & \vdots & \ddots \\
0 & \cdots & \alpha_{i, j} D_{n s}^{\star} & 0 & \cdots \\
0 & \cdots & 0 & \mu^{\star} \beta_{i, j}^{1,1} & \cdots \\
0 & \cdots & 0 & \vdots & \ddots \\
0 & \cdots & 0 & \mu^{\star} \beta_{i, j}^{n d, 1} & \cdots \\
\alpha_{i, j} h_{1} D_{1}^{\star} & \cdots & \alpha_{i, j} h_{n s} D_{n s}^{\star} & \mu^{\star} \sum_{k=1}^{n s} v_{k} \beta_{i, j}^{k, 1} & \cdots \\
0 & \cdots & 0 & 0 & \cdots \\
0 & \cdots & 0 & 0 & \cdots
\end{array}\right.
$$




$\left.\begin{array}{cccc}0 & 0 & 0 & 0 \\ \vdots & \vdots & \vdots & \vdots \\ 0 & 0 & 0 & 0 \\ \mu^{\star} \beta_{i, j}^{1, n d} & 0 & 0 & 0 \\ \vdots & 0 & 0 & 0 \\ \mu^{\star} \beta_{i, j}^{n d, n d} & 0 & 0 & 0 \\ \mu^{\star} \sum_{k=1}^{n s} v_{k} \beta_{i, j}^{k, n d} & \alpha_{i, j} \kappa^{\star} & \alpha_{i, j} \mu_{k}^{\star} & 0 \\ 0 & 0 & \alpha_{i, j} \mu_{k}^{\star} & 0 \\ 0 & 0 & 0 & \alpha_{i, j} \mu_{\omega}^{\star}\end{array}\right]$

For the effective viscosity, thermal conductivity, mass diffusion, and diffusion coefficients of the turbulent kinetic energy and length scale determining equations, we have $\mu^{\star}=\mu+\mu_{T}, \kappa^{\star}=$ $\kappa+c_{p} \mu_{T} / \operatorname{Pr}_{T}, D_{k}^{\star}=D_{k}+\mu_{T} / S c_{T}, \mu_{k}^{\star}=\mu+\mu_{T} / \sigma_{k}$, and $\mu_{\omega}^{\star}=\mu+\mu_{T} / \sigma_{\omega}$. Based on dimensional analysis arguments, the turbulent viscosity can be written as $\mu_{T}=0.09 \rho k / \omega$. The turbulent Prandtl number, $\sigma_{k}$, and $\sigma_{\omega}$ are set to $0.9,2.0$, and 2.0 respectively, while the turbulent Schmidt number is set to 1.0 and not altered in space. The source term includes the chemical species production terms and the baseline terms of the $k-\omega$ model as well as additional terms needed to account for compressibility effects.

$$
\mathbf{S}=\frac{1}{J}\left[\begin{array}{c}
\dot{W}_{1} \\
\vdots \\
\dot{W}_{n s} \\
0 \\
\vdots \\
0 \\
0 \\
P_{k}-\rho k \omega-\rho k \omega f\left(M_{T}\right) \\
\frac{\omega}{\widetilde{k}}\left(\frac{5}{9} P_{k}+\frac{5}{6} \rho k \omega\right)+\rho \omega^{2} f\left(M_{T}\right)
\end{array}\right]
$$

The dilatational dissipation correction terms [that is the ones involving $f\left(M_{T}\right)$ ] are necessary to account for the reduced growth of shear layers when the convective Mach number is high. 10,23 The Wilcox ${ }^{41}$ dilatational dissipation model specifies $f\left(M_{T}\right)=3 / 2 \max \left(0, M_{T}^{2}-1 / 16\right)$. This improves 
the baseline $k-\omega$ equations in solving high convective Mach number shear layers without underpredicting the skin friction in high Mach number boundary layers, at least up to a freestream Mach number of 6 . More compressible corrections exist, ${ }^{8}$ but due to very little or no empirical data to justify their presence, their effect is neglected in the present study. From the exact form of the transport equation for $k$, the turbulent kinetic energy production term can be written in generalized coordinates as:

$$
P_{k}=\sum_{i=1}^{n d} \sum_{j=1}^{n d}\left(-\frac{2}{3} \rho k X_{i, j} \frac{\partial v_{j}}{\partial X_{i}}+\mu^{\star} \sum_{m=1}^{n d} \sum_{n=1}^{n d} J \beta_{i, j}^{m, n} \frac{\partial v_{n}}{\partial X_{j}} \frac{\partial v_{m}}{\partial X_{i}}\right)
$$

\subsection{Numerical Method}

The discretized governing equations together with the boundary conditions are solved on a generalized structured mesh using the Window Allocatable Resolver for Propulsion (WARP) code. A detailed description of the computational technique employed in the WARP code can be found in [26]. All partial derivatives are discretized using second-order accurate, centered finite difference stencils except for the convection derivative, which is discretized using the approximate Riemann solver of Roe ${ }^{31}$ and made second-order accurate through a symmetric minmod limiter by Yee et al. ${ }^{42}$ The discretized residual is solved to steady state using a block-implicit factorization algorithm ${ }^{5}$ including the analytical Jacobian derived from the chemical model and a linearization strategy of the viscous terms by Chang and Merkle: ${ }^{7}$

$$
\prod_{i=1}^{n d}\left[I+\Delta \tau \delta_{X_{i}} \frac{\partial \mathbf{F}_{i}}{\partial \mathbf{Q}}-\Delta \tau \delta_{X_{i}}\left(\mathbf{K}_{i, i} \delta_{X_{i}} \mathbf{B}\right)-\delta_{1, i} \Delta \tau \mathbf{C}^{-}\right] \Delta \mathbf{Q}=-\Delta \tau \mathbf{R}_{\Delta}
$$

with $\mathbf{B} \equiv \partial \mathbf{G} / \partial \mathbf{Q}$ the linearization Jacobian of the viscous terms and $\mathbf{C}^{-} \equiv \partial \mathbf{S}^{-} / \partial \mathbf{Q}$ the linearization Jacobian of the chemical and negative turbulent source terms. Only the negative turbulent source terms are linearized to ensure the stability of the implicit algorithm. The term $\delta_{X_{i}} \partial \mathbf{F}_{i} / \partial \mathbf{Q}$ is determined by the linearization of the first-order Roe scheme with the Roe Jacobian locally frozen. 9,4 Although more costly per iteration compared with a lower-upper symmetric GaussSeidel inversion strategy, approximate factorization is chosen here for its ability to solve the Roe scheme without the need for introducing an explicit artificial dissipation term in the residual (the entropy correction) to stabilize the iterative process. The introduction of the entropy correction adds additional artifical dissipation to the numerical scheme, which affects the accuracy of the 
solution considerably. ${ }^{24}$

The quantity $\xi$ is defined as the maximum between the sum of the discretized continuity residuals and the energy conservation residual divided by $\mathbf{Q}$ :

$$
\xi \equiv \max \left(\frac{\sum_{k=1}^{n s}\left|\mathbf{R}_{\Delta, k}\right|}{J^{-1} \rho}, \frac{\left|\mathbf{R}_{\Delta, n s+n d+1}\right|}{J^{-1} \rho E}\right)
$$

For all cases considered, $\xi$ decreases through at least five orders of magnitude and convergence is reached when $\xi$ for all nodes falls below $\xi_{\text {converge }}=400 s^{-1}$. The pseudotime step, $\Delta \tau$, is fixed to the geometric average between the minimum and maximum Courant-Friedrichs-Lewy (CFL) conditions, which is found to give faster convergence than the minimum CFL condition for cases involving high mesh aspect ratios.

The WARP code has been validated against the following experimental data obtained for a number of hypervelocity flows similar to those simulated herein: Settles et al. ${ }^{35}$ shock wave / turbulent boundary layer interaction at $\mathrm{M}=2.84$, Burrows and Kurkov's ${ }^{6}$ wall fuel injection mixing and combusting flowfield, Waitz et al. ${ }^{39}$ Mach 6 fuel/air mixing by a ramp injector, Donohue et al. ${ }^{11}$ Mach 2 swept ramp injector mixing problem, Mao et al. ${ }^{19}$ Mach 3 wall fuel injection at a 15 degree angle, and Lehr's ${ }^{18}$ blunt-body detonation and shock-induced combustion in a Mach 5 stoichiometric $\mathrm{H}_{2}$ /air flow. In all cases considered agreement of the numerical predictions were well within limits acceptable in the hypersonic propulsion research community. For more details on the validation effort and the various levels of agreement see [28,3].

\subsection{Freestream Conditions}

In the Wilcox $k-\omega$ model, ${ }^{40}$ the turbulent kinetic energy is set to a small value in the freestream to prevent division by zero in the dissipation rate source term, Eq. 2.4. However, in the present study, in the freestream $k=0$ and $\widetilde{k}$ is defined as:

$$
\widetilde{k}=\max \left[k, \min \left(k_{\mathrm{div}}, \frac{\omega \mu}{\rho}\right)\right]
$$

with $k_{\text {div }}$ a user-specified constant that is generally set lower than one-tenth of the maximum value of $k$ throughout the boundary layer. ${ }^{26}$ This is verified numerically not to affect the laminar sublayer, but to improve the robustness and efficiency of the integration significantly. The minimum between 
$k_{\mathrm{div}}$ and $\omega \mu / \rho$ is taken so that a clipping occurs only in nonturbulent flow regions in which an accurate representation of $\omega$ does not affect the accuracy of the flowfield. A value of $k_{\text {div }}$ of 1000 $\mathrm{m}^{2} / \mathrm{s}^{2}$ is used for all cases and is verified to be below the maximum value of $k$ in the boundary layer, which for the present case is between 40, 000 and 70, $000 \mathrm{~m}^{2} / \mathrm{s}^{2}$. The freestream $\omega$ is set to $10 \mathrm{~m}^{-1}$ times the freestream velocity as suggested by Wilcox, which is 100-1000 times smaller then the maximum $\omega$ value present at all $x_{1}$ planes. 


\section{METHOD OF ANALYSIS}

\subsection{Analysis Tools}

\subsubsection{Thrust Potential}

The concept of thrust potential $30,27,1$ is used in the present study to evaluate the propulsive effectiveness of the hypersonic engine components when significant total temperature variations are present. The thrust potential determines how much thrust a section of the engine would develop by taking the difference in momentum of stations at the end of the section (outlet) and the tip of the inlet (reference). The outlet momentum is found from a reversible expansion of the flow at the outlet station (subscript b) to an iteratively determined back pressure at the nozzle exit area of the vehicle (subscript c). ${ }^{27}$ All irreversible losses occurring ahead of station $b$ in the propulsive flow path, due to shocks, mixing processes, and friction, are reflected in the numerically determined magnitude of the flow momentum at that station. Thrust potential, $\mathscr{F}_{\text {pot }}$, is thus defined as:

$$
\mathscr{F}_{\text {pot }}=-\mathscr{F}_{\text {pot }, \text { ref }}+\int_{b} \frac{\rho_{c} q_{c}^{2}+p_{c}^{*}}{\rho_{c} q_{c}} d \dot{m} / \dot{m}_{\text {air,engine }}
$$

The reference thrust potential is the negative of the oncoming airflow momentum at the initial cross-section of the engine per unit mass of the airflow entering the engine, i.e. $\mathscr{F}_{\text {pot }, r e f}=\left(\rho_{0} v_{0}^{2}+\right.$ $\left.p_{0}\right) A_{0} / \dot{m}_{\text {air,engine }}=3411 \mathrm{~N} \cdot \mathrm{s} / \mathrm{kg}$. The thrust potential at the initial engine cross-section is thus zero. 


\subsubsection{Mixing Efficiency}

The concept of mixing efficiency quantifies the fuel/air mixing process. The fuel-based mixing efficiency, $\eta_{m}$, at a streamwise plane of interest (denoted by subscript $b$ ), is defined as the ratio of the fuel that would burn in the plane to the mass flux of fuel entering the engine.

$$
\eta_{m}=\int_{b} c_{H_{2}}^{R} d \dot{m} /\left(\dot{m}_{\text {fuel }}\right)
$$

The mass fraction of reacting fuel, $c_{\mathrm{H}_{2}}^{R}$, is given as:

$$
c_{H_{2}}^{R}=\min \left(c_{H_{2}}, c_{H_{2}}^{S} \cdot c_{O_{2}} / c_{O_{2}}^{S}\right)
$$

with the stoichiometric mass fraction of oxygen, $c_{\mathrm{O}_{2}}^{S}$, equal to 0.2284 and the stoichiometric mass fraction of hydrogen, $c_{\mathrm{H}_{2}}^{S}$, equal to 0.02876 . Note that this formulation does not take into account the flammability limits of hydrogen in air, which are $0.1<\phi<7.0$ at standard pressure and have been shown to lie above $\phi=0.8$ for cases similar to the ones studied here. ${ }^{33}$

\subsubsection{Thrust Forces}

The propulsive characteristics such as overall thrust and specific impulse, as well as the magnitudes of the total frictional and pressure forces acting on the entire, finite span, engine from tip to tail, were quantified as follows. The thrust of the vehicles is here determined by the forces acting on their surfaces. The force on the engine walls due to the pressure is taken as the negative of the inviscid momentum terms on the wall surfaces:

$$
\mathscr{F}_{\text {pressure }, i}=\sum_{\text {surface nodes }} \Delta X_{i}\left[-\mathbf{F}_{i}\right]
$$

where the sum is taken over all surfaces with wall boundary conditions. The term $\Delta X_{i}$ is a directional variable that corresponds to +1 or -1 depending whether the normal to the surface is in the positive or negative $X_{i}$ direction. The skin friction is found as the negative of the viscous momentum on the wall surfaces:

$$
\mathscr{F}_{\text {friction }, i}=\sum_{\text {surface nodes }} \Delta X_{i}\left[\sum_{j=1}^{n d} \mathbf{K}_{i, j} \frac{\partial \mathbf{G}}{\partial X_{j}}\right]
$$


where in both Eqs. 3.4 and 3.5 only the momentum components of the vectors on the right side are used. The thrust generated by the fuel entering the engine is determined from its momentum:

$$
\mathscr{F}_{\text {fuel }, i}=-\Delta X_{i}\left(\rho v_{i}^{2}+p\right)_{\text {fuel }} A_{\text {fuel }}
$$

where $A_{f u e l}$ is the fuel injection cross-sectional area. The total thrust and lift, which are positive in the $-x_{1}$ and $x_{2}$ directions, respectively, are the sum of the pressure, friction, and fuel thrust forces:

$$
\begin{aligned}
& \mathscr{F}_{\text {thrust }}=-\mathscr{F}_{\text {pressure }, 1}-\mathscr{F}_{\text {friction }, 1}-\mathscr{F}_{\text {fuel }, 1} \\
& \mathscr{F}_{\text {lift }}=\mathscr{F}_{\text {pressure }, 2}+\mathscr{F}_{\text {friction }, 2}+\mathscr{F}_{\text {fuel }, 2}
\end{aligned}
$$

\subsubsection{Specific Impulse}

The specific impulse, $I_{s p}$, can be used for comparison of the performance of different engines with a variation in size and mass flow rates. The specific impulse of the engine can be found as:

$$
I_{s p}=\frac{\mathscr{F}_{\text {thrust }}}{g \dot{m}_{\text {fuel }}}
$$

where $g$ is gravitational acceleration. The thrust potential can likewise be converted to an impulse value by multiplying by the mass flow rate of air entering the engine as follows:

$$
I_{s p, p o t}=\frac{\mathscr{F}_{\text {pot }} \dot{m}_{\text {air }, \text { engine }}}{g \dot{m}_{\text {fuel }}}
$$

\subsection{Method of Comparative Analysis}

Comparison of the aeropropulsive performance characteristics of the two vehicles is performed herein at a flight Mach number of 11, considered to be the lower limit at which the expected advantages of the shock-induced combustion ramjet over the scramjet could be realized. At an altitude of $34.5 \mathrm{~km}$, corresponding to a flight dynamic pressure of $67.03 \mathrm{kPa}$ (1400 psf), the oncoming airflow conditions are: a pressure of $601 \mathrm{~Pa}$, temperature of $235 \mathrm{~K}$ and a velocity of $3391 \mathrm{~m} / \mathrm{s}$. The comparative analysis is performed by assuming that both ramjets share the same: inlet type, fuel properties and injection systems, mixing and/or combustor geometry and nozzle 
design methodology. The WARP code is used for both cases with identical gridding technique. For each engine, no attempt has been made to apply specific optimization techniques to improve their respective component efficiencies.

The scramjet vehicle has been previously completed by Derrick Alexander during his post-doc research, specifically for this study. Therefore this report will focus on the design methodology of the shcramjet vehicle. Finally in Chapter 8 , the design of, and comparison with, the scramjet vehicle will be assessed.

One important aspect of the comparison that needs to be discussed is the relative sizing of the vehicles. Due to their different design criteria, the vehicles will have different relative sizes of their components. For example, the inlet might be $15 \%$ of the total length in one case and $30 \%$ of the total length in the other. Therefore there are two seemingly logical options: keep the overall length of both vehicles equal or keep specific components of the vehicles the same size. With the design criteria of both vehicles, the scramjet vehicle will have a much larger inlet compared to its main duct due to all the compression taking place in the inlet. In the shcramjet, since a portion of the compression is produced by the shock-inducing wedge in the combustor, the inlet will be much smaller relative to its main duct. Therefore if the vehicles' lengths were kept equal, the internal duct of the scramjet would be much smaller than the shcramjet. This would result in the fuel injection system, mixing process and combustion process to occur at a much smaller scale. It is known that shear layer mixing relies on absolute length as does induction distances for combustion. Additionally, from past studies, it is known that the mixing performance is heavily dependent on the fuel injection geometry. The compression and expansion system on the other hand, do not depend much on size. Therefore keeping the overall length equal results in having the compression and expansion system relatively equal and having the mixing and combustion processes at different scales. Instead it was chosen to keep the main duct height equal such that the mixing and combustion process are at the same scale and have the compression and expansion systems at different scales. The duct height used in this comparison was $8 \mathrm{~cm}$, based on previous injector studies ${ }^{3}$ comparing various injector and array spacing geometries for optimal mixing performance. Additionally, performance of the vehicles will be measured mainly by specific impulse, which should factor out most of the effects of vehicle sizing. 


\subsection{Domain}

The simulations herein will consist of three dimensional domains of the vehicle from tip to tail including flow around the exterior body. However, the entire span of a vehicle is not simulated. The wings, vertical stabilizers and the sidewalls are neglected and only the center section of the vehicle is simulated where the effects of the wall are negligible, as shown in Figs.3.1 and 3.2. Due to the symmetry of this center section, which will be explained in more detail in Section 5.1, a slice of the span will be simulated to represent the entire center section of our vehicles. This approximation also requires that the design of the vehicle is planar, with the exception of the injectors.

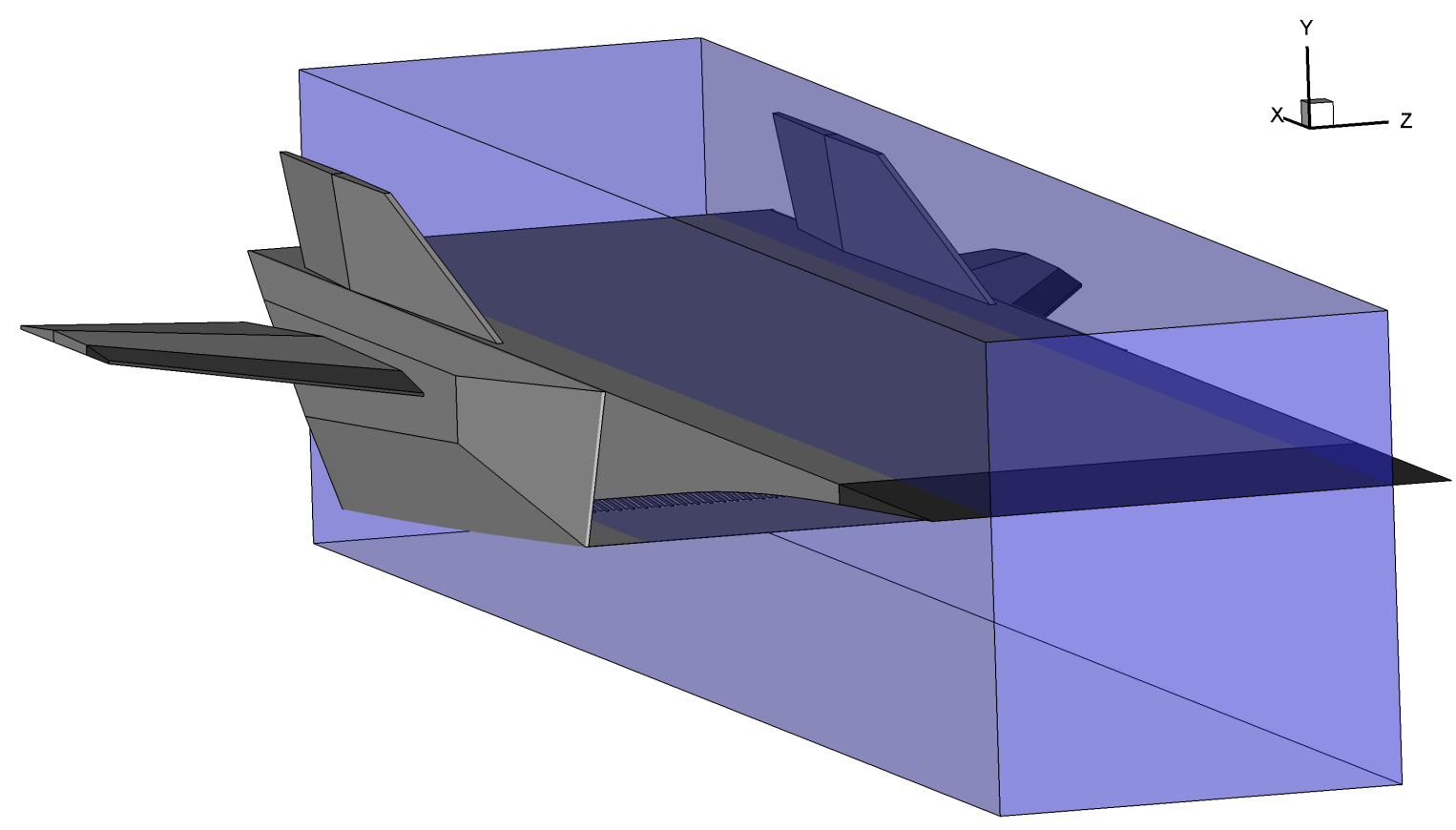

FIGURE 3.1: Isometric view of simulation domain

\subsection{Boundary Conditions}

As mentionned above, a slice of the vehicle is representing the center section of the vehicle due to symmetry. As such, second order symmetric boundary conditions have been imposed on either side of the domain in the spanwise direction. Additionally, the domain boundary in the front of the vehicle has been set to supersonic inflow while the upper, lower and exit boundaries are set to zeroth order supersonic outflow. All vehicle wall surfaces are no-slip, non-catalytic, and 


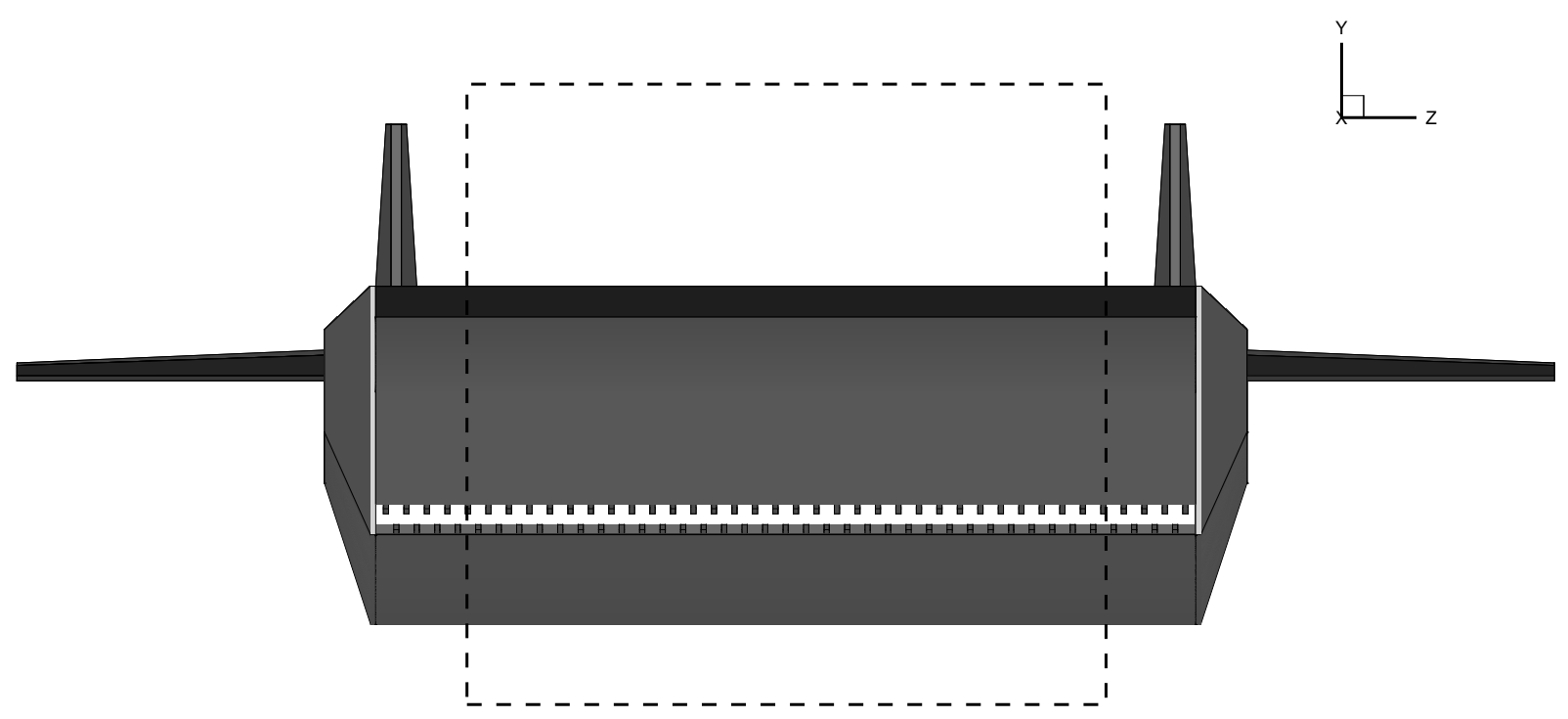

FIGURE 3.2: Front view of simulation domain

cooled to an arbitrarily chosen constant temperature with quantities at the walls determined by a second-order extrapolation from the interior flow. The scramjet walls are set to $800 \mathrm{~K}$ while the scramjet was set to $500 \mathrm{~K}$. The scramjet wall temperatures were limited to material properties. The shcramjet wall temperatures were set lower to keep the boundary layers cooler in the mixing duct to prevent premature ignition. At the wall $k=0$, while the specific dissipation rate $\omega=36 \mu / 5 \rho d_{\mathrm{w}}^{2}$ as given by Wilcox. ${ }^{40}$ In order to maintain practical grid sizes, node spacing at the wall surfaces is $d_{\mathrm{w}}=25 \mu \mathrm{m}$ up until the end of the fuel injector arrays and $d_{\mathrm{w}}=10 \mu \mathrm{m}$ thereafter. The value of $y^{+}$varies through the domain between 0.406 and 6.604, with the highest values being found in regions with high pressure and temperature. 


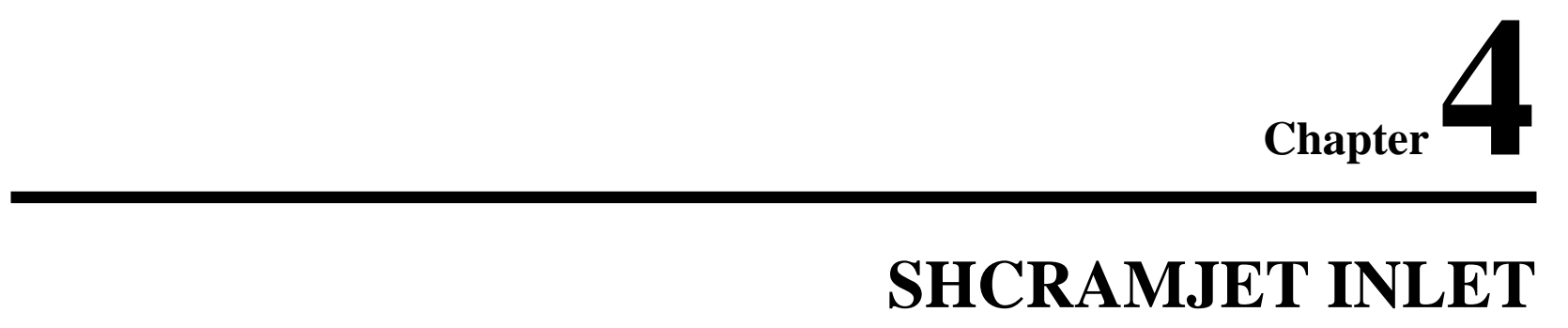

This chapter examines the inlet used in the shcramjet vehicle studied herein. For this compression system, a compression ramp inlet will be used which consists of an initial shock, followed by a Prandtl Meyer compression ramp and then finally a shock redirecting the flow parallel to the direction of the vehicle. This type of inlet has been chosen over more conventional inlets like two-shock inlets for its performance.

\subsection{Inlet Configuration}

To design a compression ramp inlet, the first step is to use a three shock mixed compression inlet with two equal strength external shocks and one internal shock as seen in Fig.4.1. The strength of the shock system can be found using the inlet exit temperature constraint. In this hydrogen powered shcramjet, the temperature of the flow exiting the inlet must be kept sufficiently below the autoignition temperature of hydrogen in order to avoid premature ignition of the mixture in the mixing duct before it reaches the combustor. At the high pressures found in the mixing duct, the autoignition temperature of hydrogen is around $1000 \mathrm{~K}$ and therefore the inlet exit temperature was set to $800 \mathrm{~K}$ for a safety margin. Using this constraint, the angles for the three shock mixed compression inlet is 4.4, 9.8 and $-9.8 \mathrm{deg}$ from inviscid calculations. From here, the second external shock can be replaced by a Prandtl Meyer compression fan centered at the cowl tip as seen in Fig.4.2. This is theoretically an isentropic process that yields the same temperature ratio but with a higher compression ratio.

With all the angles determined, there is still an additional constraint needed to fix the size 
of the inlet. This constraint has been chosen to be the height of the inlet exit which stems from the constraint of having the mixing duct/combustor duct height of $8 \mathrm{~cm}$ for both the scramjet and shcramjet.

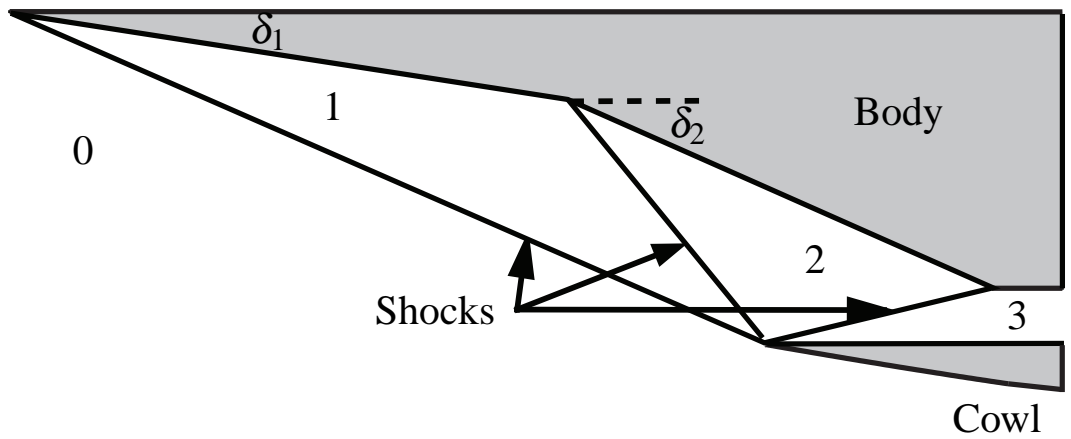

FIGURE 4.1: 3 shock mixed-compression inlet configuration

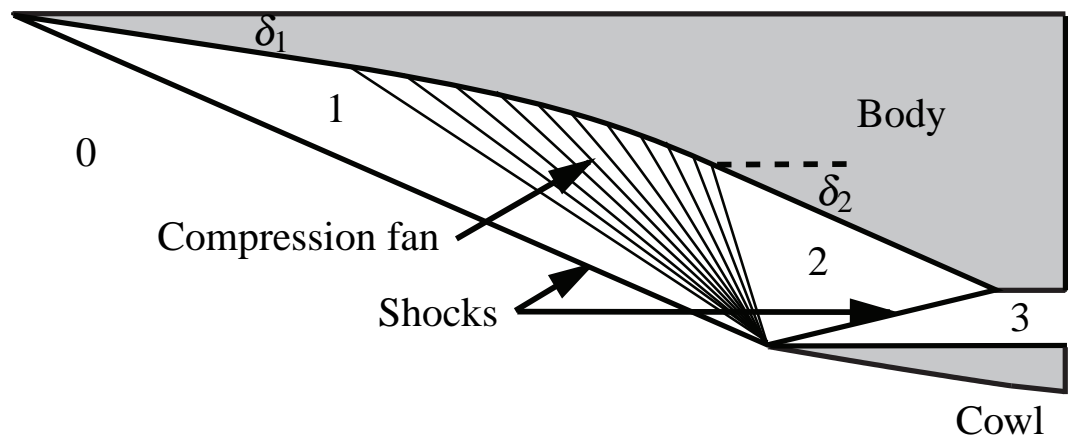

FIGURE 4.2: Compression ramp inlet configuration

This type of inlet has been used instead of 2 and 3 shock inlets for the improved performance. It is tempting to go further and replace the first shock by a Prandtl Meyer compression fan as well however this would yield the inlet tip angle being 0 deg and infinitely thin (unless a flat top body is not used). With the current inlet configuration, the initial angle is large enough for practical cooling methods.

After the inviscid inlet configuration has been completed, a viscous simulation will yield in an off-design flow where the initial shock and Prandtl Meyer compression fan are not centered on the cowl tip nor is the final shock hitting the body duct entrance. This is caused by the boundary layer affecting the shocks/mach waves emanating from the walls. Therefore the inlet angles were adjusted until all the shocks were hitting the right locations. The Prandtl Meyer compression fan was coalescing much below the design point and was therefore scaled down by $16.8 \%$ in order for it to coalesce at the correct height. The final inlet angles ended up being 4.0, 8.7 and $-8.7 \mathrm{deg}$. 
Simulation of the inlet was performed in $2 \mathrm{D}$ due to the spanwise symmetry of the inlet. The final grid size of the inlet was $2556 \times 248$ nodes. The number of nodes in the $\mathrm{x}$-direction was quite large and was increased due to the solution not converging in the duct region when using less nodes. Although unnecessary, additional nodes were added across the entire inlet instead of just the duct region. $d_{w}$ was kept to $25 \mu \mathrm{m}$ in the inlet.

\subsection{Inlet Flowfield}

With the geometry given in the previous section, the flowfield in the inlet can be obtained given the oncoming flow conditions. At our chosen Mach 11 flight at an altitude of $34.5 \mathrm{~km}$, the oncoming air properties are a pressure of $601 \mathrm{~Pa}$, a temperature of $235 \mathrm{~K}$ and a velocity of $3391 \mathrm{~m} / \mathrm{s}$. The simulation of the inlet consists of the air flow between the tip of the body and the tip of the cowl. The inlet has been simulated for on-design conditions and therefore there is no flow spillage from the inlet. In this manner, the internal flow in the inlet can be simulated independently from the flow above the body top and below the cowl. The flow of the inlet can be seen in Figs.4.3 and 4.4.

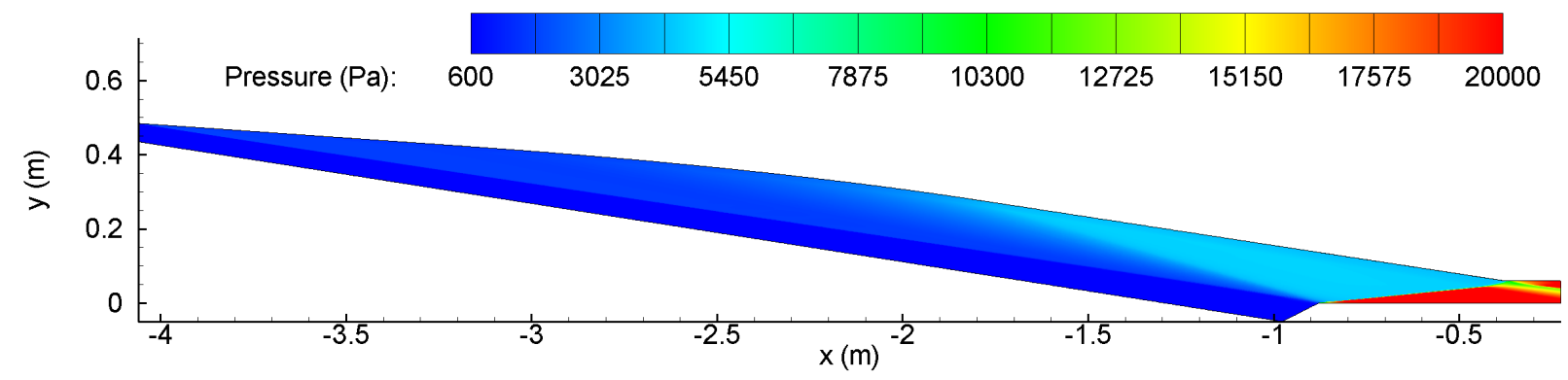

FIGURE 4.3: Shcramjet inlet pressure flowfield

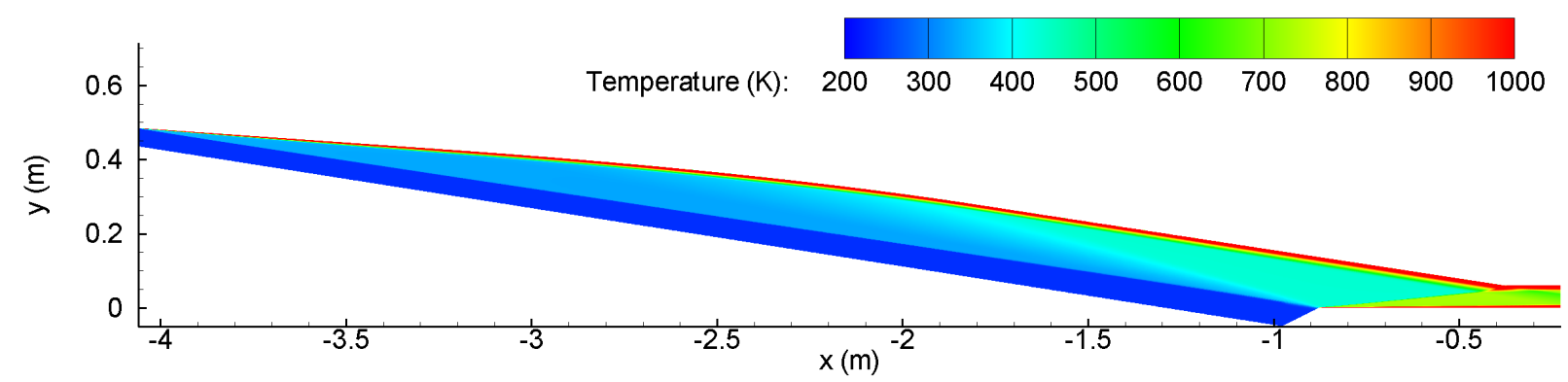

FIGURE 4.4: Shcramjet inlet temperature flowfield

From Figs 4.3 and 4.4 , it can be seen that inlet is operating at on design conditions. Although 
TABLE 4.1: Inlet flow properties

\begin{tabular}{|l|c|}
\hline Length $(\mathrm{m})$ & 3.834 \\
\hline Height $(\mathrm{m})$ & 0.484 \\
\hline Exit Height $(\mathrm{m})$ & 0.0595 \\
\hline Contraction Ratio & 8.14 \\
\hline Exit Pressure, $P_{3}(\mathrm{~Pa})$ & 18616 \\
\hline Compression Ratio & 30.98 \\
\hline Exit Temperature $(\mathrm{K})$ & 798 \\
\hline Exit Velocity $(\mathrm{m} / \mathrm{s})$ & 3156 \\
\hline Exit Mach number & 5.58 \\
\hline Exit Thrust Potential $(\mathrm{Ns} / \mathrm{kg})$ & -70.07 \\
\hline Air Mass Flow Rate $(\mathrm{kg} / \mathrm{s})$ & 0.292 \\
\hline Pressure at 1 & 1740 \\
\hline Temperature at 1 & 330 \\
\hline Pressure at 2 & 4590 \\
\hline Temperature at 2 & 435 \\
\hline$P_{1} / P_{0}$ & 2.896 \\
\hline$P_{2} / P_{1}$ & 2.638 \\
\hline$P_{3} / P_{2}$ & 4.056 \\
\hline
\end{tabular}

simulations of the flow result in finite thickness shocks, they do end at the appropriate locations. The flow properties of the inlet are summarized in Table 4.1.

The profile of the axial velocity is given for the inlet exit in Fig.4.5. The boundary layer thickness was determined using the distance from the wall to a point that has $95 \%$ of the freestream velocity. The boundary layer thicknesses were determined to be $6.7 \mathrm{~mm}$ and $10.0 \mathrm{~mm}$ for the lower and upper duct walls, respectively. Looking at the flow before the final shock on the upper body wall, it can be seen that the boundary layer thickness is quite large (approx 2-3 cm) before being compressed. This is due to the length of the inlet, approximately $4 \mathrm{~m}$.

Of particular interest is the final shock emanating from the cowl tip and hitting the upper wall boundary layer as seen in Fig.4.6. Much care is needed to avoid/minimize the recirculation region caused by the shock/boundary layer interaction. If the shock reaches the upper wall before the final turn, then there will certainly be a larger recirculation region due to the large boundary layer formed on this wall. However, if the shock reaches the wall after the final turn, then the flow near the wall goes through an expansion and its velocity is increased and is less susceptible to flow seperation and creating a recirculation region. In this case, the shock hits the wall slightly after the turn and a small recirculation is created with a length of approximately $8 \mathrm{~mm}$. With enough design iterations, it is possible to completly eliminate the recirculation region but for real flow conditions, 


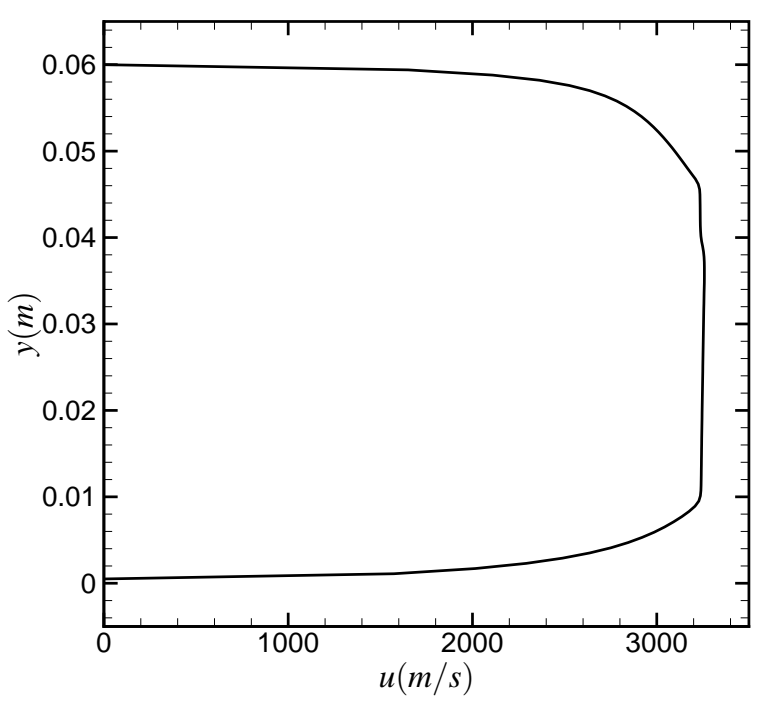

FIGURE 4.5: Shcramjet inlet exit velocity profile

this would not be possible and therefore research into the effect of off-design conditions with larger recirculation regions should be studied to evaluate the performance loss.

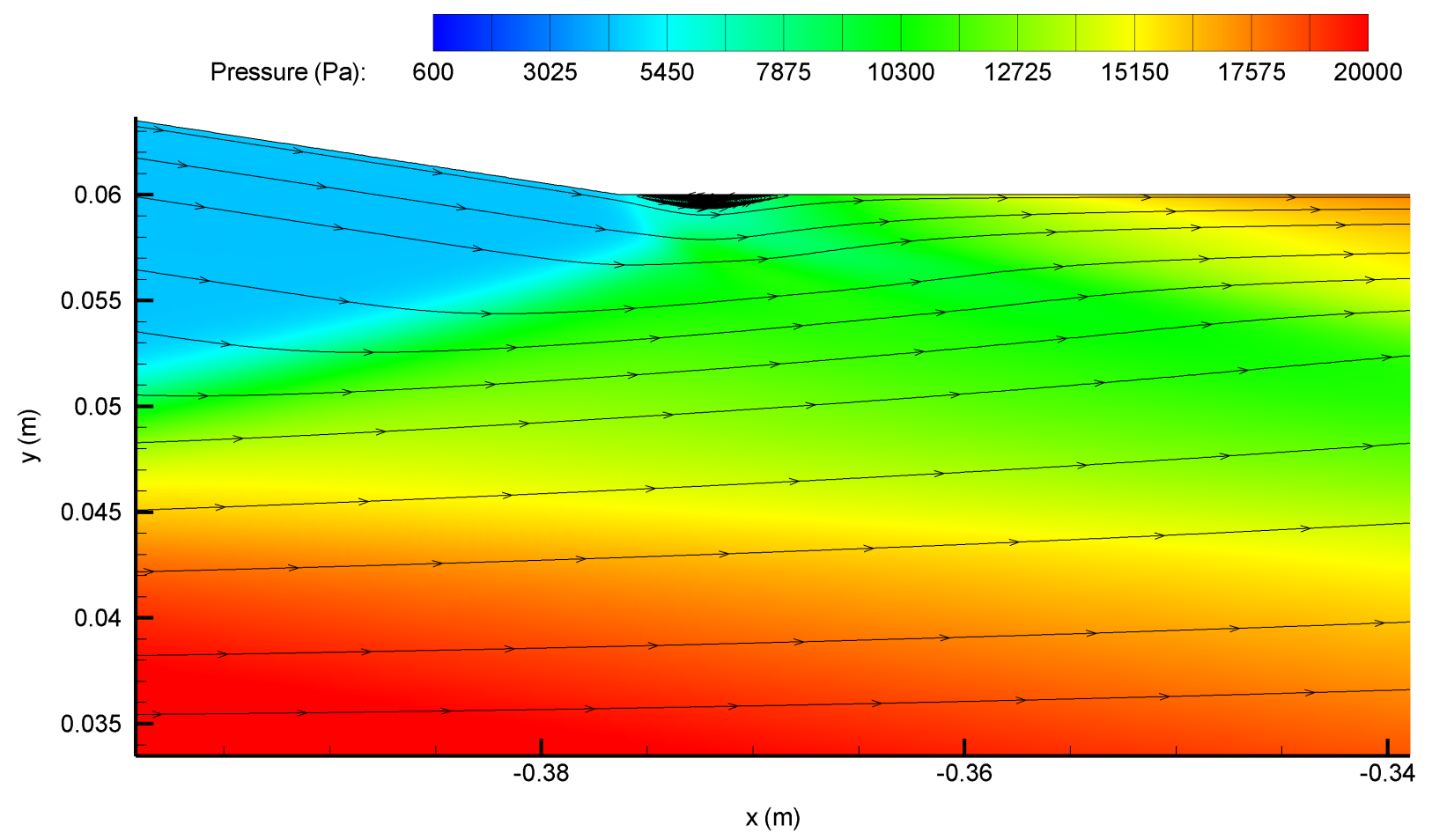

FIGURE 4.6: Shcramjet inlet recirculation 


\subsubsection{Pressure Wave Study}

One interesting flow feature was the pressure wave emanating from the point where the final shock hits the upper body wall, seen in Figs 4.3 and 4.6. Initially this was thought to have been caused by the shock reflecting from the wall however it is a low pressure wave. It was then thought to be a result of the shock boundary layer interaction and the recirculation region. Looking closely at the flow in this region, it can be seen that the flow must go around the recirculation region, causing it to expand and then contract. This would result in a low pressure region followed by pressure recovery.

A simpler two shock inlet was simulated with a similar recirculation region and low pressure wave. The inlet flow was then resimulated using slip walls and therefore had no boundary layers. Many iterations were performed attempting to minimize/avoid the pressure wave by shifting the location where the shock hits the wall. All locations resulted in a pressure wave and the iteration with the minimal pressure wave is shown in Fig.4.7. Looking closer, it can be seen that the final shock does not always hit the corner on the upper wall exactly and/or the thickness of the shock is quite large in the simulation. Therefore the compression of the shock and expansion around the corner does not occur simulaneously. This results in some of the flow near the wall to compress and create a reflected shock before being expanded and some to expand around the corner before being compressed by the final shock.

\subsubsection{Comparison with 2-Shock Inlet}

Figure 4.8 shows the stagnation pressures and thrust potentials of both the compression ramp inlet used and a 2 shock inlet with the same design conditions (exit temperature and exit height). It can be seen that there is a significant reduction in stagnation pressure loss in the compression ramp inlet over the 2 shock inlet as well as the thrust potential. However, these only consider the internal flowpath of the inlets and do not consider the exterior flow around the body. The compression ramp inlet is much longer and will incur more frictional loss on the upper and lower exterior body. 


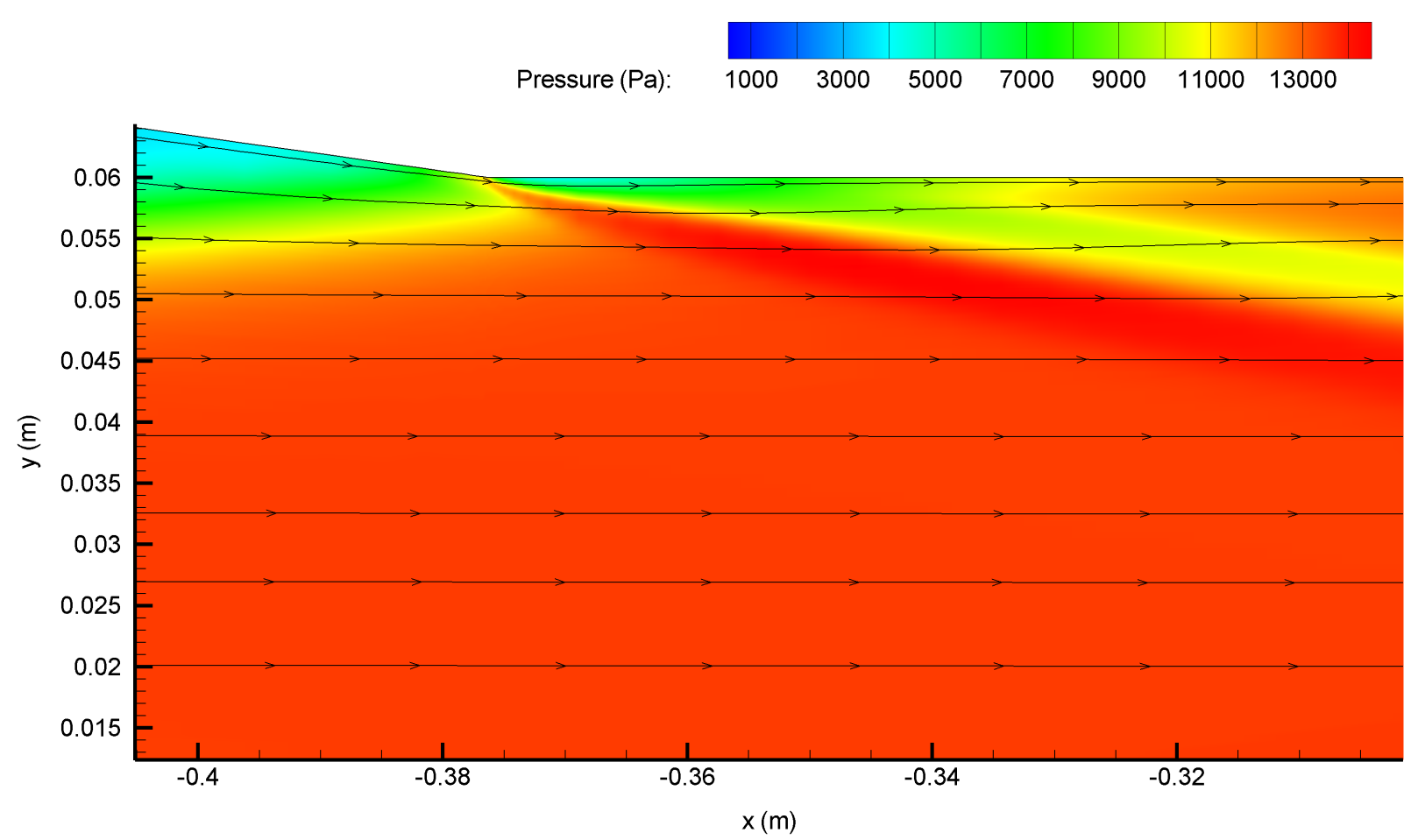

FIGURE 4.7: Inviscid pressure wave

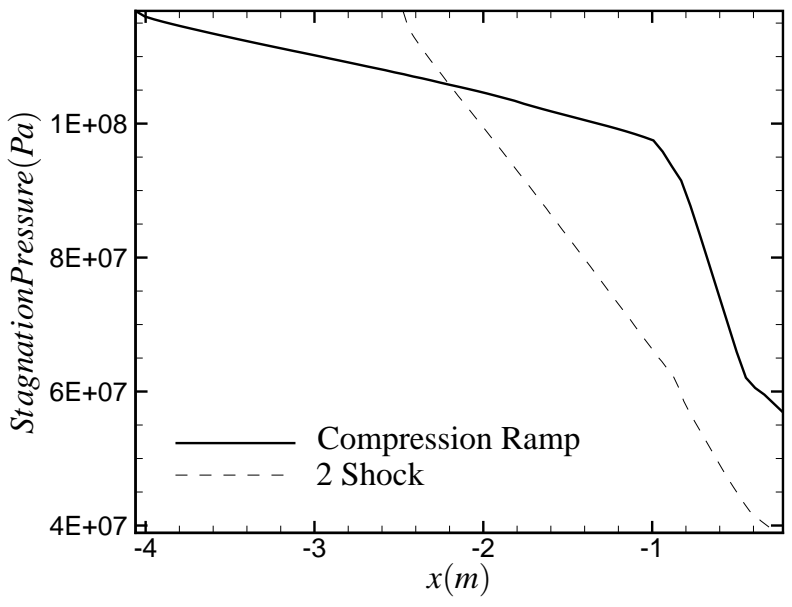

(a) $P_{\text {stag }}$ Comparison

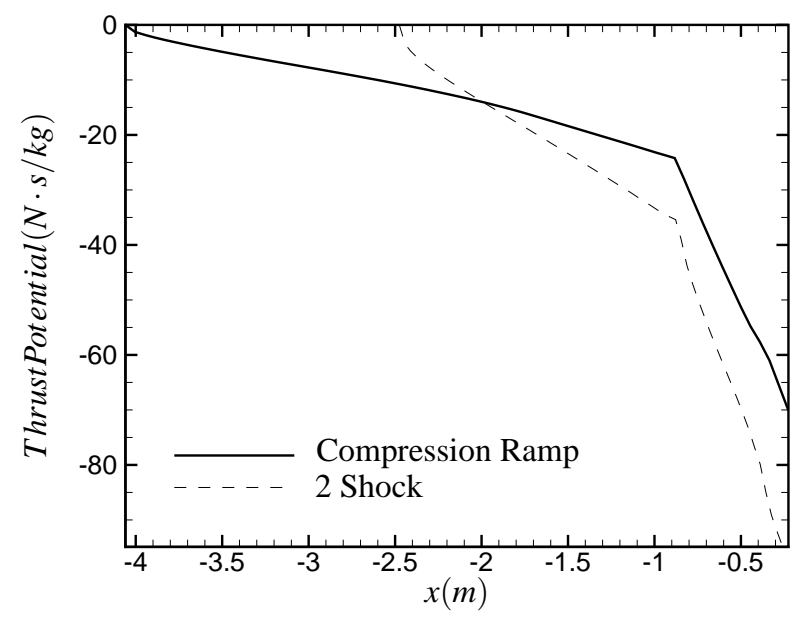

(b) $F_{p o t}$ Comparison

FIGURE 4.8: Inlet type comparison 


\section{SHCRAMJET INJECTORS}

This chapter examines the fuel injection system and the mixing duct where the fuel and air mix. Gaseous hydrogen is injected into the mixing duct via a system of cantilevered ramp fuel injectors. The arrays are placed on the upper and lower walls at the entrance of the internal duct of the engine in a staggered manner. This design has proven to be particularly suited to keep the combustible mixture away from the boundary layers of the duct walls in shcramjet engines. In this chapter, the geometry of the injectors will not be varied as previous parametric studies have shown it to be the optimal configuration. However, two different fuel injection cases are studied to predict which would ultimately yield a higher vehicle performance. The performance parameters that will be evaluated are mixing efficiency, thrust potential, absolute thrust provided by the fuel injection and length of the mixing duct.

\subsection{Injector Configuration}

The system of cantilevered ramp fuel injectors consist of arrays placed on the upper and lower walls at the entrance of the internal duct of the engine in a staggered manner, as seen in Fig.5.1. There are many variables for this design including vertical and horizontal spacing between the injectors, injector exit size, sweep angle, injector cantilever angle, duct expansion angle, injector length, expansion length and injector protrusion height. The geometry of the injectors used in the shcramjet has been studied extensively and therefore the optimal geometry found in a previous study ${ }^{3}$ will be used, given in Fig.5.1(a). With the current geometry, the mixing efficiency should be high while keeping the injected fuel near the center of the duct and away from the hot boundary 
layers near the walls.

The simulation of the injectors and mixing duct must be completed in three dimensions. Although the inlet was simulated in two dimensions due to its planar symmetry, an overlap region between them was made that connected the two and three dimensional domains. Due to the symmetry of the injectors, the domain consists of the area between the middle of the lower injector to the middle of the upper injector, as seen in Fig.5.1(b).

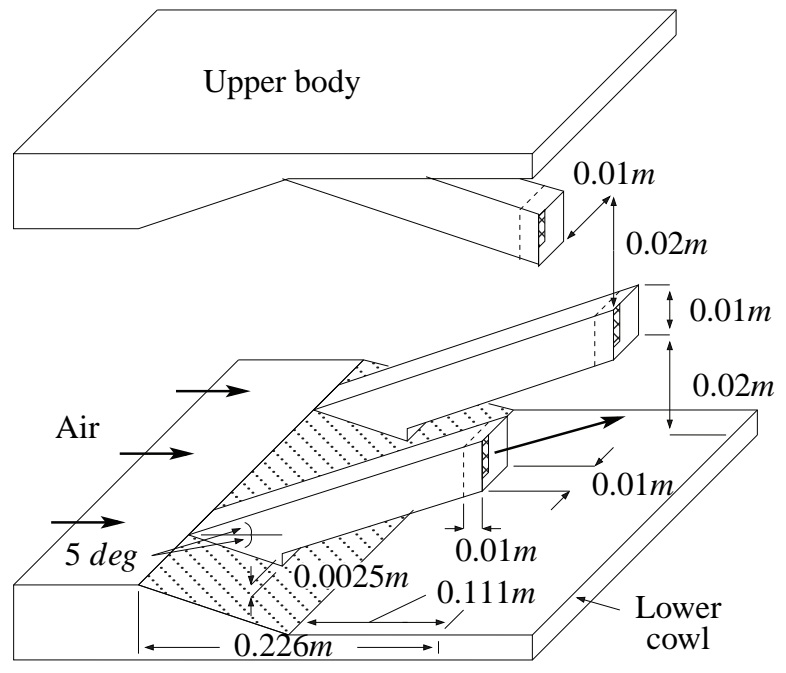

(a) Isometric view

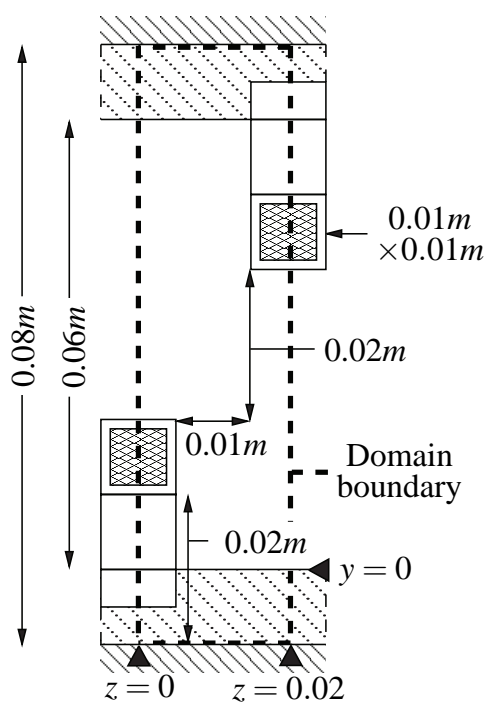

(b) $y-z$ domain

FIGURE 5.1: Cantilevered ramp injector array geometry

For the injectors region, a grid consisting of $199 \times 280 \times 105$ nodes was used with $d_{w}$ kept at $25 \mu \mathrm{m}$, shown in Fig.5.2. The mixing duct region's grid depended on the length but its cross sectional gridding was kept at $280 \times 105$ nodes. $d_{w}$ was kept to $10 \mu \mathrm{m}$ after the point of injection due to the possible higher temperatures and pressures which may or may not occur in the mixing duct. A $10 \mathrm{~mm}$ long runway is used inside the fuel injectors prior to the plane of injection to reduce the solutions sensitivity to the freestream value of $\omega$, which is known to cause difficulties in $k$ - $\omega$ schemes.

\subsection{Injector Cases}

The conditions imposed on the fuel being injected are subject to many constraints. The first constraint is to inject fuel in stoichiometric proportions. Therefore a fuel mass flow rate of 0.008797 $\mathrm{kg} / \mathrm{m}^{3}$ has been used. One critical constraint is injecting fuel at a pressure equal to the surrounding 


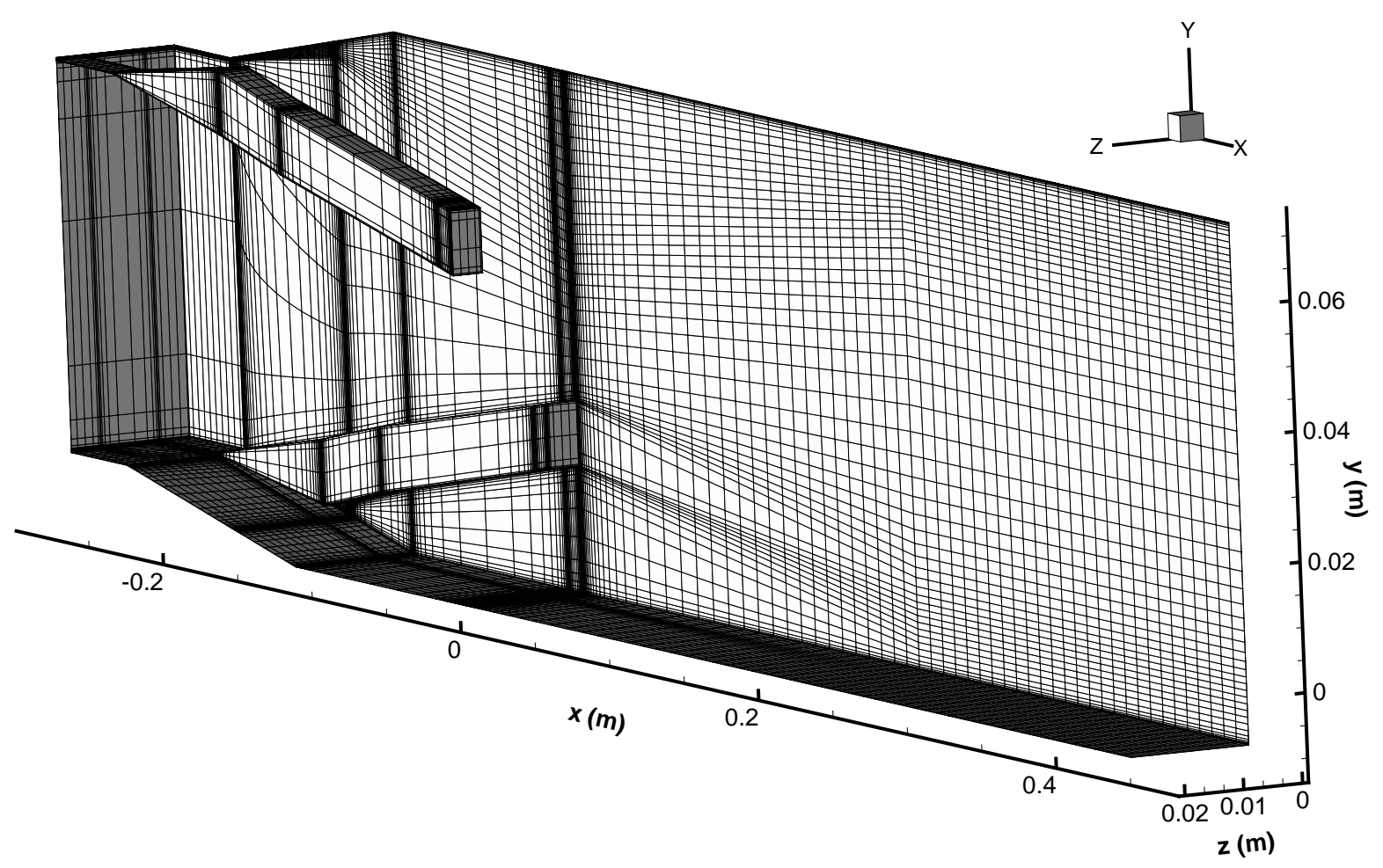

FIGURE 5.2: Injector region grid (reduced density)

air at the point of injection. If a large pressure differential exists then shocks will be created which can cause the fuel/air mixture to combust prematurely before it reaches the combustor. Therefore a fuel exit pressure of $18000 \mathrm{~Pa}$ is used. At this point there is still one degree of freedom remaining for the fuel injection properties. In Table 5.1, the fuel exit temperature is varied from $120 \mathrm{~K}$ to 309 $K$ and the remaining fuel properties are summarized including the convective Mach number $\left(M_{C}\right)$, thrust/specific impulse generated from fuel injection and the fuel injector nozzle throat area $\left(A^{*}\right)$. Limits are imposed on the fuel stagnation pressure and/or temperature to keep them in practical limitations. The constraints used were $1700 \mathrm{~K}$ for stagnation temperature and $150 \mathrm{~atm}$ for stagnation pressure. In this case, the stagnation temperature maximum is reached first. The first case studied herein is the maximum stagnation temperature case $(1660 \mathrm{~K})$ where the exit temperature is $309 \mathrm{~K}$. The scramjet used in the comparison will also have a similar fuel stagnation temperature. For reasons explained in the next section, a second case with lower temperature is simulated as well with an exit temperature of $250 \mathrm{~K}$ and a stagnation temperature of $1152.7 \mathrm{~K}$. This will yield a convective Mach number similar to that of the scramjet vehicle to be compared with. 
TABLE 5.1: Fuel injection properties

\begin{tabular}{|c|c|c|c|c|c|c|c|c|c|}
\hline $\begin{array}{c}\text { Temp } \\
(K)\end{array}$ & Mach & $\begin{array}{c}\text { Fuel Speed } \\
(\mathrm{m} / \mathrm{s})\end{array}$ & $M_{c}$ & $\begin{array}{c}\rho \\
\left(\mathrm{kg} / \mathrm{m}^{3}\right)\end{array}$ & $\begin{array}{c}T_{\text {total }}(\mathrm{K}) \\
(P a)\end{array}$ & $\begin{array}{c}P_{\text {total }} \\
(P a)\end{array}$ & $\begin{array}{c}\text { Thrust } \\
(\mathrm{N})\end{array}$ & $\begin{array}{c}\text { Isp } \\
(s)\end{array}$ & $\begin{array}{c}A^{*} \\
\left(\mathrm{~mm}^{2}\right)\end{array}$ \\
\hline 120.0 & 2.83 & 2419.0 & -0.52 & 0.036 & 350.2 & 4.88 & 21.3 & 246.6 & 31.0 \\
\hline 129.5 & 2.94 & 2609.4 & -0.38 & 0.034 & 396.9 & 5.72 & 23.0 & 266.0 & 28.2 \\
\hline 138.9 & 3.05 & 2799.9 & -0.24 & 0.031 & 444.9 & 6.69 & 24.6 & 285.4 & 25.5 \\
\hline 148.4 & 3.15 & 2990.4 & -0.11 & 0.029 & 494.3 & 7.82 & 26.3 & 304.8 & 23.1 \\
\hline 157.8 & 3.26 & 3180.9 & 0.01 & 0.028 & 545.4 & 9.12 & 28.0 & 324.3 & 20.8 \\
\hline 167.3 & 3.37 & 3371.4 & 0.13 & 0.026 & 598.2 & 10.59 & 29.7 & 343.7 & 18.8 \\
\hline 176.7 & 3.47 & 3561.9 & 0.25 & 0.025 & 653.0 & 12.26 & 31.3 & 363.1 & 17.0 \\
\hline 186.2 & 3.57 & 3752.4 & 0.36 & 0.023 & 709.8 & 14.13 & 33.0 & 382.5 & 15.4 \\
\hline 195.6 & 3.66 & 3942.9 & 0.47 & 0.022 & 768.8 & 16.21 & 34.7 & 401.9 & 14.0 \\
\hline 205.1 & 3.76 & 4133.4 & 0.57 & 0.021 & 829.9 & 18.53 & 36.4 & 421.3 & 12.7 \\
\hline 214.5 & 3.85 & 4323.9 & 0.68 & 0.020 & 893.3 & 21.09 & 38.0 & 440.8 & 11.6 \\
\hline 224.0 & 3.94 & 4514.4 & 0.78 & 0.019 & 959.1 & 23.90 & 39.7 & 460.2 & 10.6 \\
\hline 233.4 & 4.02 & 4704.9 & 0.88 & 0.019 & 1027.2 & 26.97 & 41.4 & 479.6 & 9.8 \\
\hline 242.9 & 4.11 & 4895.4 & 0.97 & 0.018 & 1097.7 & 30.32 & 43.1 & 499.0 & 9.0 \\
\hline 250.0 & 4.17 & 5039.5 & 1.04 & 0.017 & 1152.7 & 33.05 & 44.3 & 513.7 & 8.4 \\
\hline 259.5 & 4.25 & 5230.0 & 1.14 & 0.017 & 1227.6 & 36.91 & 46.0 & 533.1 & 7.8 \\
\hline 268.9 & 4.33 & 5420.5 & 1.23 & 0.016 & 1305.0 & 41.08 & 47.7 & 552.5 & 7.2 \\
\hline 278.4 & 4.41 & 5611.0 & 1.32 & 0.016 & 1385.0 & 45.57 & 49.4 & 572.0 & 6.7 \\
\hline 287.8 & 4.49 & 5801.5 & 1.40 & 0.015 & 1467.5 & 50.38 & 51.0 & 591.4 & 6.3 \\
\hline 297.3 & 4.57 & 5992.0 & 1.49 & 0.015 & 1552.5 & 55.54 & 52.7 & 610.8 & 5.8 \\
\hline 309.0 & 4.66 & 6228.8 & 1.59 & 0.014 & 1661.9 & 62.44 & 54.8 & 634.9 & 5.4 \\
\hline
\end{tabular}

\subsection{Injector Flowfields}

\subsubsection{Case A: $T=309 K$}

Using the fuel injection properties shown in Table 5.1 for $T=309 K$, the hydrogen mass fraction flowfield is shown in Fig.5.4. With the maximum temperature used, the fuel air mixture is very close to the ignition point and it can be seen in Fig.5.3 that the onset of diffusive combustion occurs near $x=0.45 \mathrm{~m}$. This is undesired as it either means the mixing duct must be ended here with a low mixing efficiency, or the mixing duct continues further and a portion of the fuel is combusted at a low pressure, producing less energy.

In Fig.5.7(b), the thrust potential in the mixing duct is near constant with a slight increase. In the mixing duct, this is expected to decrease due to losses caused by friction on the walls and mixing losses. However looking at Fig.5.3, there is minimal diffusive burning which is offsetting the losses. 


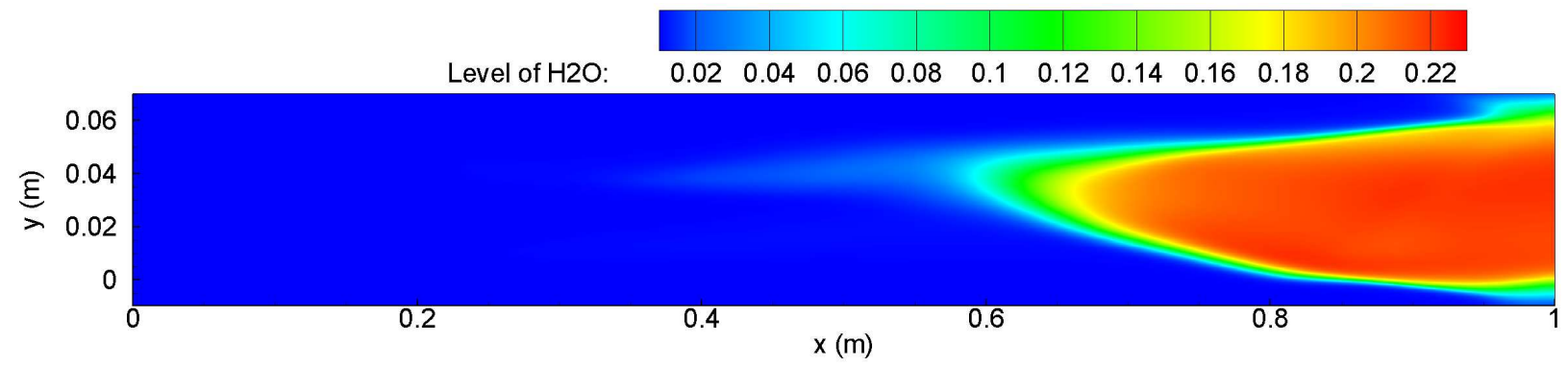

FIGURE 5.3: Case A mixing duct water mass fraction

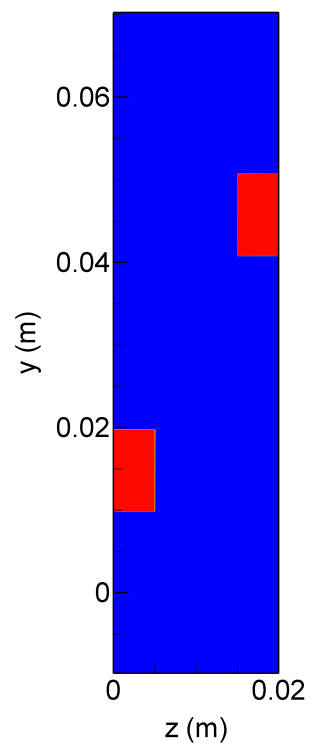

(a) $x=0 \mathrm{~m}$

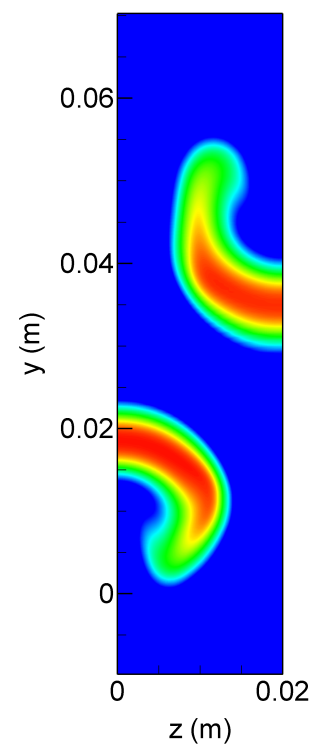

(b) $x=0.15 \mathrm{~m}$

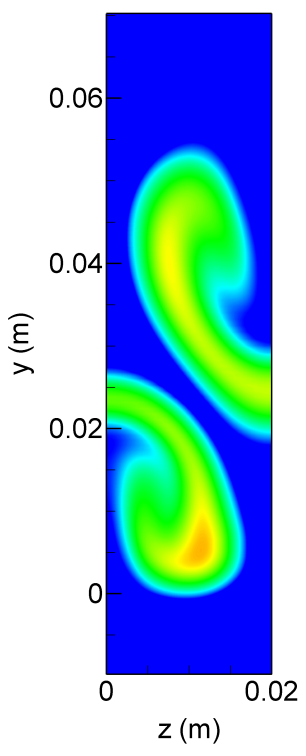

(c) $x=0.3 m$

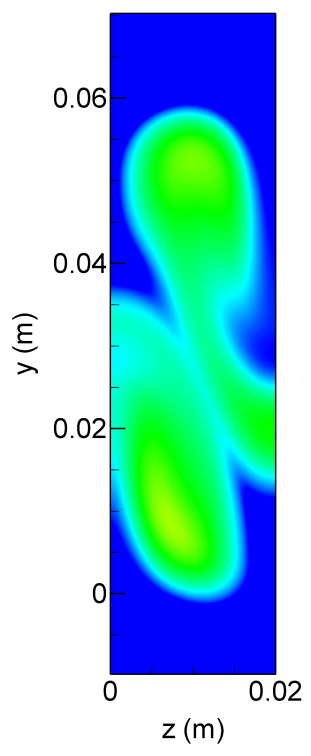

(d) $x=0.45 \mathrm{~m}$
Level of $\mathrm{H}_{2}$

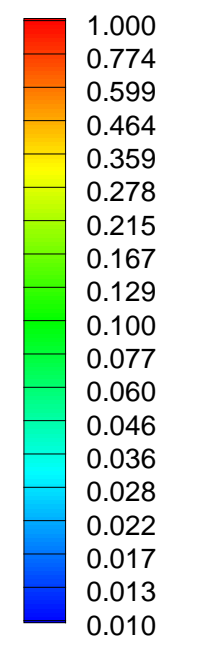

(e)

FIGURE 5.4: Hydrogen mass fraction contours in Case A's mixing duct

\subsubsection{Case B: $T=250 \mathrm{~K}$}

Using the fuel injection properties shown in Table 5.1 for $T=250 \mathrm{~K}$, the hydrogen mass fraction flowfield is shown in Fig.5.6. In this case, the stagnation temperature is no longer near the limit and the exit temperature has been reduced significantly as well. This was done in hopes to avoid premature ignition in the mixing duct. As seen in Fig.5.5, the onset of combustion does not occur until $x=1.2 \mathrm{~m}$. By this length, the mixing efficiency has reached $71 \%$, which is much higher than the previous case.

In Fig.5.7(b), the thrust potential in the mixing duct for this case decreases as expected. Due to the length of this mixing duct, there is considerable amount of thrust potential loss. 


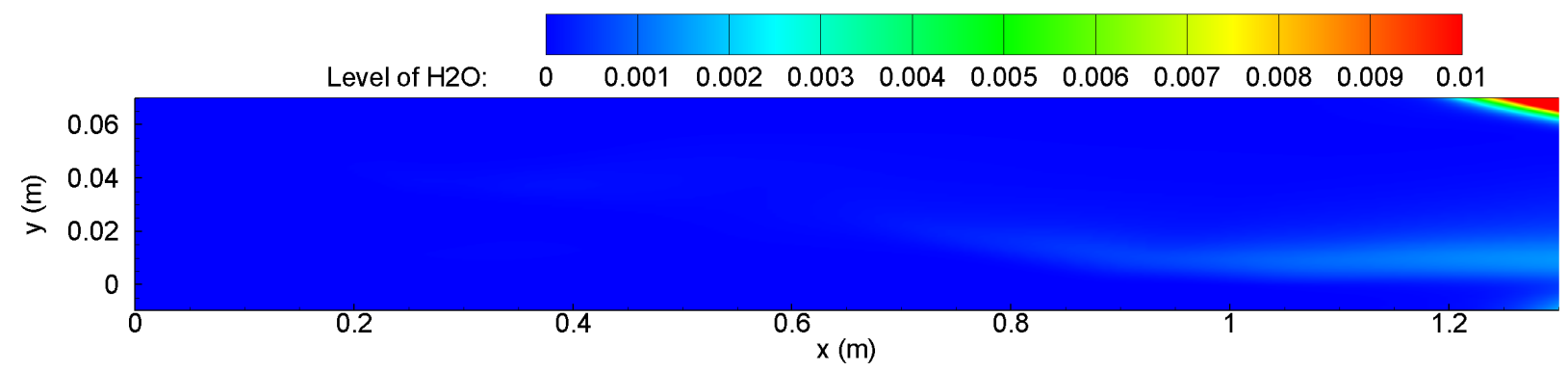

FIGURE 5.5: Case B mixing duct water mass fraction

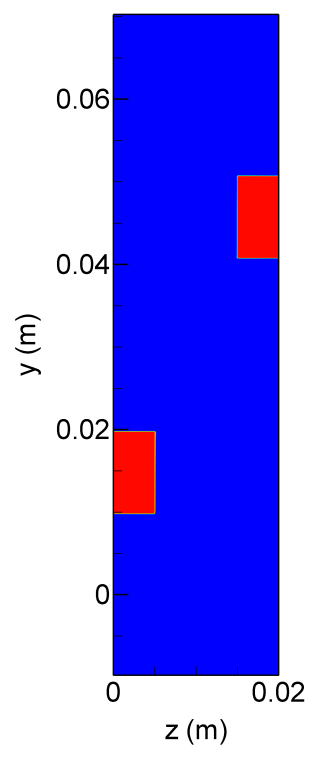

(a) $x=0 \mathrm{~m}$

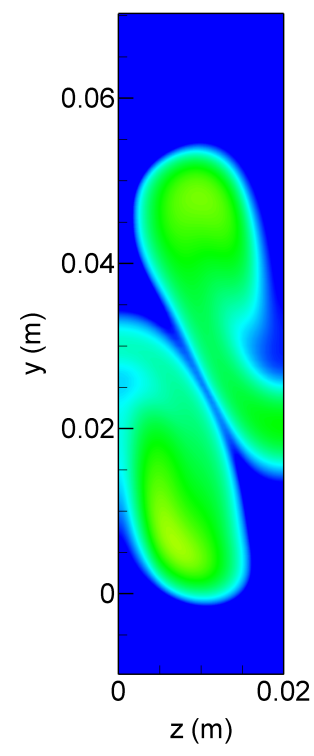

(b) $x=0.15 \mathrm{~m}$

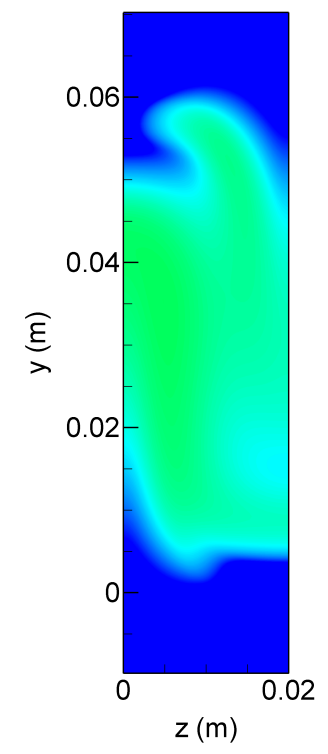

(c) $x=0.3 m$

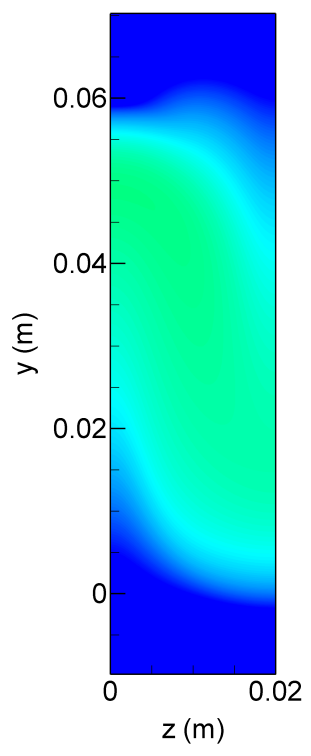

(d) $x=0.45 \mathrm{~m}$
Level of $\mathrm{H}_{2}$

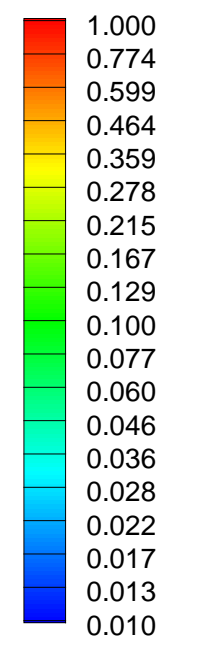

(e)

FIGURE 5.6: Hydrogen mass fraction contours in Case B's mixing duct

\subsubsection{Comparison}

With the two different fuel injection cases, there are a few things to mention. Looking at Fig.5.7(a), both cases mix at the same rate however for Case A, it begins to decrease due to combustion occuring (mixing efficiency loses meaning as the fuel burns) whereas Case B continues to rise. Although Case B has a much higher mixing efficiency and does not combust prematurely, it does suffer from having large friction losses. Additionally, with the lower temperature fuel injection, the amount of thrust provided by the fuel injection is decreased as well. At this point, it is unknown which case would perform better and both cases will be continued into the combustor and nozzle flowfields. Table 5.2 summarizes the two different cases. 


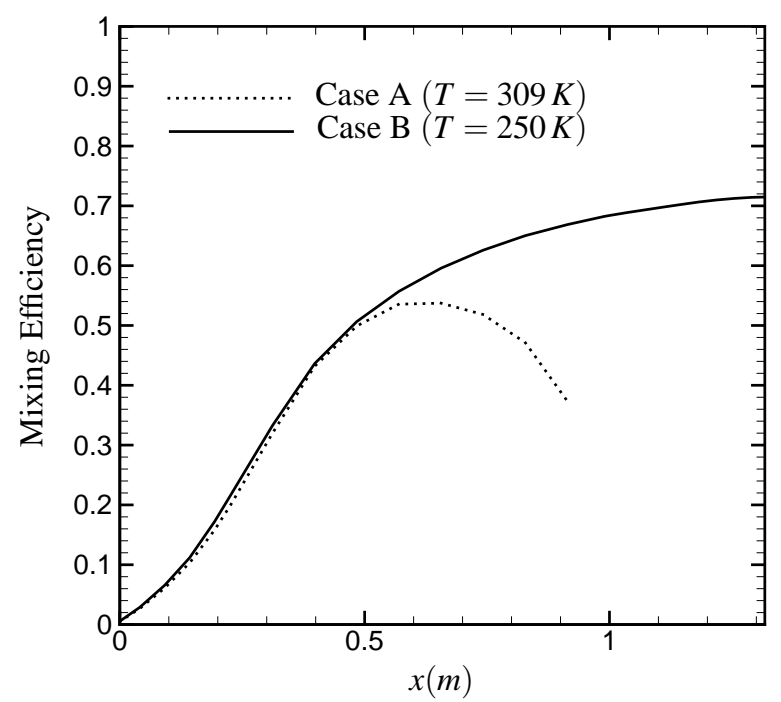

(a) Mixing Efficiency Comparison

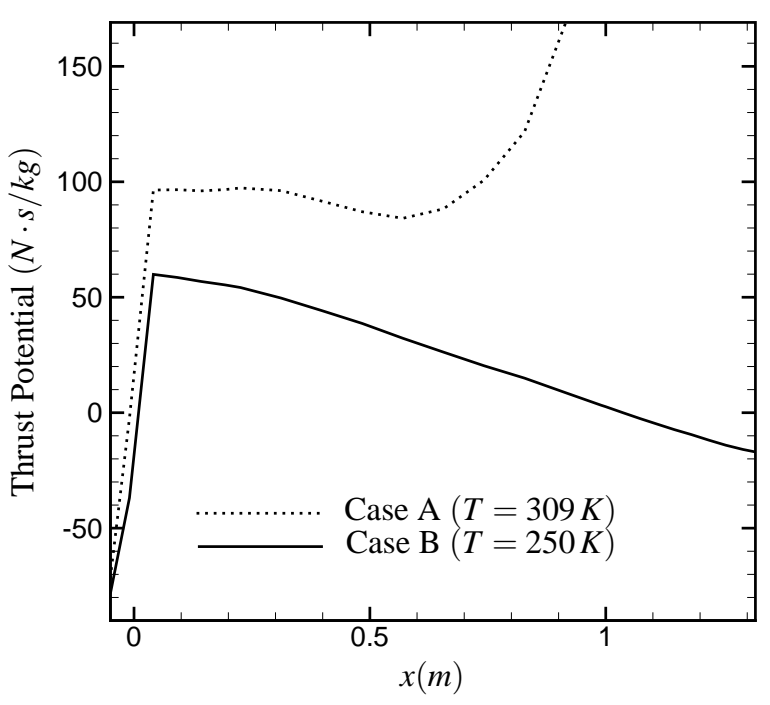

(b) Thrust Potential Comparison

FIGURE 5.7: Mixing duct comparisons

TABLE 5.2: Mixing duct cases comparison

\begin{tabular}{|c|c|c|}
\hline & Case A & Case B \\
\hline Length $(\mathrm{m})$ & 0.45 & 1.2 \\
\hline Mixing Efficiency & 0.48 & 0.71 \\
\hline Final Thrust Potential $(N \cdot \mathrm{s} / \mathrm{kg})$ & 88 & -10 \\
\hline Fuel Injection Thrust $(N)$ & 54.8 & 44.3 \\
\hline
\end{tabular}




\section{chamer 6}

SHCRAMJET COMBUSTOR

This chapter examines the combustion process in the shcramjet engine. The geometry of the combustor is very simple and consists of a bend in the lower duct wall. This design has been chosen over other geometries, such as dual wedges on both walls or floating wedges, due to the simplicity of the flow in it. For inviscid flows without boundary layers, dual wedges can reduce the length of the combustor in half, although the pressure drag loss will be the same as there will be two surfaces with half the length. Factoring in the induction distance caused by boundary layers in viscous flows, the wedges will need to be extended and the pressure drag losses will actually be increased. Additionally the flow may become more complicated as the two shocks collide and will have additional losses from the reflecting shocks. Previous studies ${ }^{2}$ have shown that the current configuration is most suited to the needs of the shcramjet engine and will be used in this study. In this chapter, the wedge combustor will be studied based on wedge angle and length. Both of the previous mixing cases will be continued in the combustor studies.

\subsection{Combustor Configuration}

The shock-inducing wedge geometry will be a very simple bend in the lower duct wall at various angles and lengths. By varying the wedge angle, the shock will be of varying strength as will the resulting shock-induced combustion or detonation wave. Previous studies have shown shock-induced combustion or detonation waves near the Chapman-Jouguet point incur less losses however have longer induction distances, resulting in additional pressure drag and friction losses on the wedge surface. It was shown that having a slightly overdriven detonation would signifi- 
cantly reduce the induction distance, improve practical stability while only sligtly increasing the entropy compared to the CJ point. Therefore it will be attempted to find the slightly overdriven case.

The next variable to be varied will be the length of the combustion wedge. The start of the wedge is simply the bend in the duct wall and the end of the wedge will be the bend leading to expansion in the nozzle. The length of the wedge must be longer than the induction distance in order for the detonation wave to form. After it has formed, the wedge may be immediately expanded into the nozzle, however the expansion waves must not quench the combustion process. Therefore it may be necessary to extend the combustion wedge to a certain point past the induction distance for proper combustion.

For the following simulations, an initial length of the wedge was chosen to be about $11 \mathrm{~cm}$ based on previous studies and have an expansion angle equal to the wedge angle. From here, only a few cases were chosen to be carried forward and simulated with a different wedge length. The bend at the end of the combustor where the wedge expands into the nozzle were smoothed using $4^{\text {th }}$ order polynomials.

The combustor region was also simulated in three dimensions. Although the geometry of the combustor is planar symmetric, the flow entering it is highly three dimensional due to the three dimensional injectors. The grid used was $128 \times 280 \times 105$ nodes. The last portion of the upper wall has been set to an outflow condition to allow the flow to escape after being turned by the shock and to avoid having a shock reflection off the wall.

\subsection{Combustor Flowfield}

The analysis of the following combustor flowfields has proven to be particularly difficult due to the boundary conditions and the geometry of the flow structures. In the mixing duct region and in scramjet combustors, the flow in the engine is mostly constant in the axial cross section of the engine. This allows for integration of the cross sectional area for flow properties along the engine as the gridding is orthogonal to the flow. However, in the shcramjet combustor, the wedge combustor causes the flow to turn and the oblique shock creates non constant cross sectional flow properties, ie the flow near the wedge can be combusted and the flow above non-combusted. Additionally, the expansion process at the end of the combustor typically occurs before the oblique shock reaches the top of the body wall. This means some parts of the combusted flow will be expanded before 
others have been combusted. Furthermore, the boundary condition for the last portion of the upper wall has been set to an outflow condition so that the shock does not reflect, which would not occur in the final design as the nozzle expansion starts when the shock hits the wall. This means the mass flow rate in the domain decreases near the end as the flow escapes. This makes it difficult for quantitative analysis of post-combustion flow properties.

\subsubsection{Case A: $T=309 K$}

Using the mixing duct flowfield from Case A, the combustion wedge flowfield was simulated. Case A's mixing duct resulted in a short duct $(0.45 \mathrm{~m})$ with a highly non-mixed flow $(48 \%$ mixing efficiency). The combustion wedge in this case starts at $x=0.45 \mathrm{~m}$ and a small amount of diffusive burning has been initiated by this point. This diffusive burning can be seen to help with the formation of the shock-induced combustion or detonation wave.

\subsubsection{1 $15^{\circ}$}

The first simulation used a wedge angle of $15^{\circ}$ and a length of about $11 \mathrm{~cm}$, shown in Figs.6.1 and 6.2. It can be seen that the combustion process is not complete and does not span over the entire cross sectional area. This is mainly due to the highly unmixed incoming flow with regions being either very fuel rich or very fuel lean, seen in Fig.5.4. Additionally, the induction distance in this case is quite long, close to the length of the wedge.

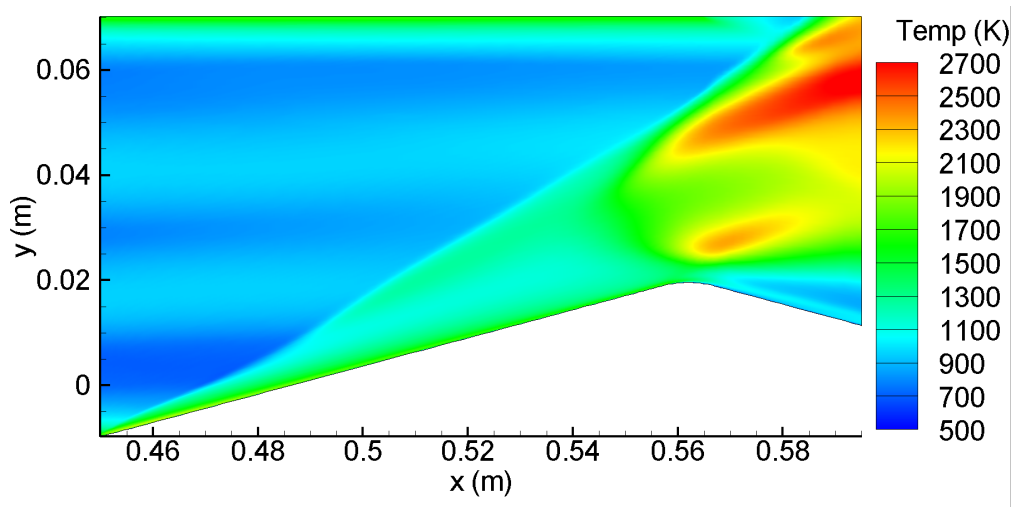

(a) $z=0.01 \mathrm{~m}$

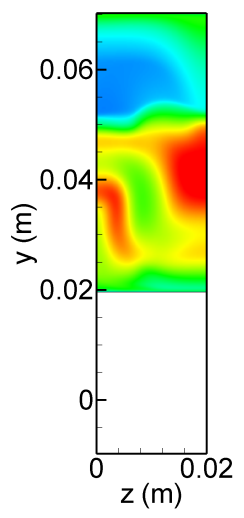

(b) $x=0.562 \mathrm{~m}$

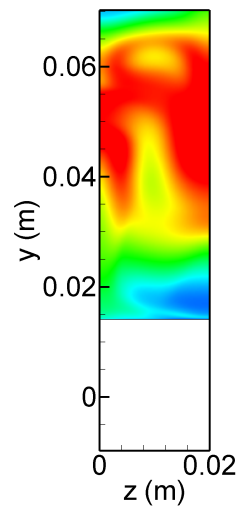

(c) $x=0.585 \mathrm{~m}$

FIgURE 6.1: Combustor temperature flowfield for Case A: $15^{\circ}$ 


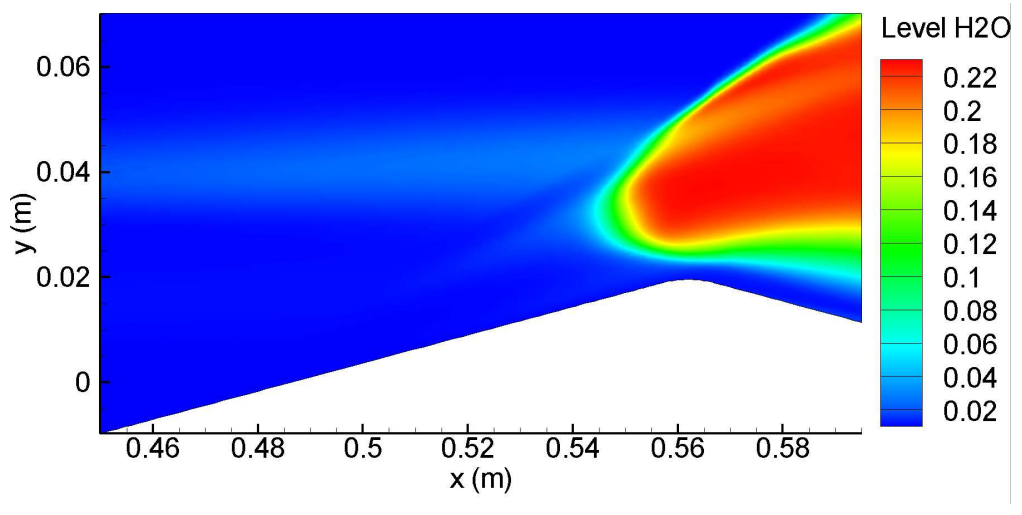

(a) $z=0.01 \mathrm{~m}$

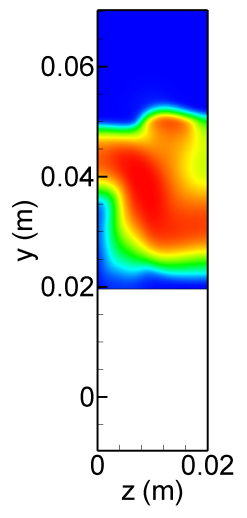

(b) $x=0.562 m$

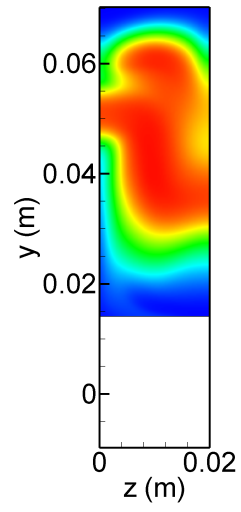

(c) $x=0.585 \mathrm{~m}$

Figure 6.2: Combustor $\mathrm{H}_{2} \mathrm{O}$ level flowfield for Case A: $15^{\circ}$

\subsubsection{2 $15^{\circ}$ Short}

The next simulation used the same wedge angle of $15^{\circ}$ but with a reduced length of $8 \mathrm{~cm}$ instead of 11. It was shown that this case's length was not sufficient as some areas did not combust. This is due to some regions of the flow requiring longer induction distances while some only requiring short distances.

\subsubsection{3 $18^{\circ}$}

This simulation used a higher wedge angle, $18^{\circ}$, with a shorter length of $9 \mathrm{~cm}$. The short length was chosen as increasing the wedge angle should decrease the induction distance, which can be seen in Fig.6.4. Again, due to the highly unmixed flow entering the combustor, the combustion is not fully complete and does not span the entire cross sectional area. The added pressure and temperature rise from a stronger shock does not help when the flow is unmixed. 


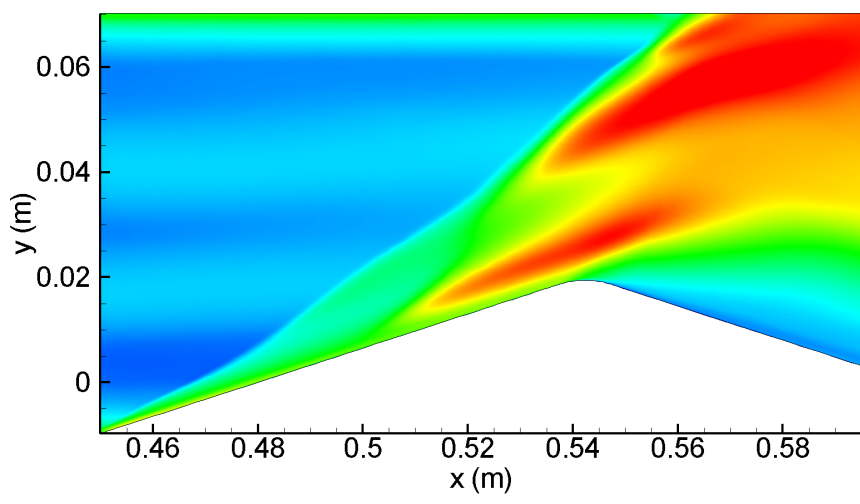

(a) $z=0.01 \mathrm{~m}$

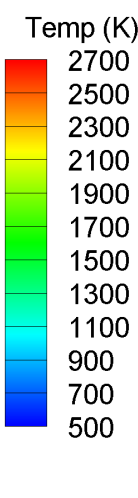

(b) $x=0.542 m$

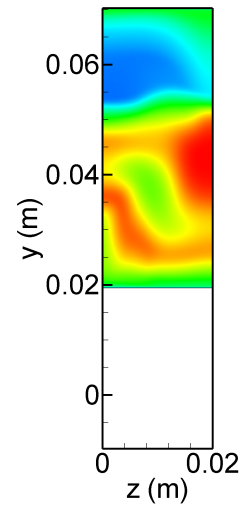

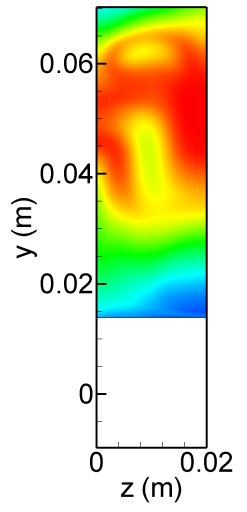

(c) $x=0.562 \mathrm{~m}$

FIgURE 6.3: Combustor temperature flowfield for Case A: $18^{\circ}$

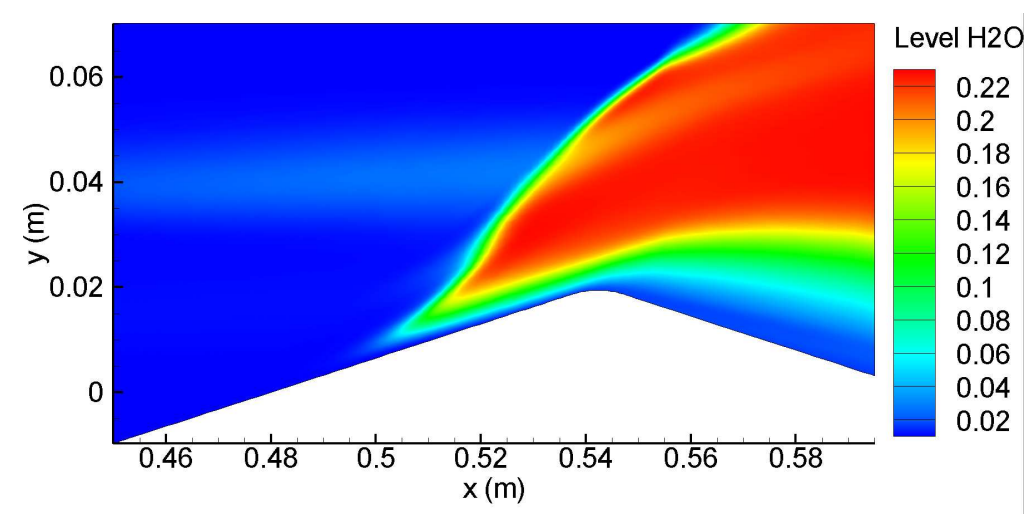

(a) $z=0.01 \mathrm{~m}$

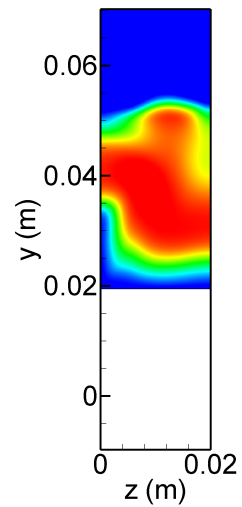

(b) $x=0.542 m$

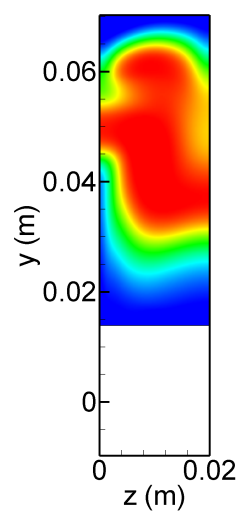

(c) $x=0.562 \mathrm{~m}$

FIGURE 6.4: Combustor $\mathrm{H}_{2} \mathrm{O}$ level flowfield for Case A: $18^{\circ}$

\subsubsection{Case Comparison}

For Case A, the combustor flow properties are shown in Fig.6.5. The plots are cut off when the shock reaches the upper boundary of the domain for the $15^{\circ}$ and $18^{\circ}$ wedge. For the $15^{\circ}$ short wedge, the domain ended before the shock reached the upper boundary but there was sufficient data for analysis. All wedges provided moderate burning due to the low mixing efficiency. Levels of water mass fraction and remaining hydrogen are quite similar in all cases, being offset due to the difference in induction lengths. In the full length cases, about $29.5 \%$ of the hydrogen remains by the time the shock impinges the body wall. The plot for the short wedge is not complete however it can be seen that it burns less fuel than its longer version. The higher angle wedge does not burn more hydrogen but reaches a higher pressure due to the stronger shock. The short wedge's pressure 
is reduced from expanding the flow earlier on. The most interesting plot is the thrust potential comparison. It appears as though both full length wedges can provide approximately the same amount of thrust. However the absolute drag calculated from pressure drag and friction drag for the two full length wedges are $-61.1 N$ and $-81.6 N$ for the $15^{\circ}$ and $18^{\circ}$ wedge respectively. Clearly the higher wedge angle has more drag, but its higher pressure flow has the ability to provide more thrust, which is taken into account by the thrust potential. However the thrust potential calculates the thrust by a reversible expansion to a chosen exit area. In reality, the extra expansion required will have additional losses. Both of the full length wedges will be continued into the nozzle. The shorter wedge will not be continued as it does not perform as well as its full length version. The $18^{\circ}$ wedge will be simulated to see the overall effect of increasing the pressure rise while creating more pressure drag even though there was no additional combustion. 


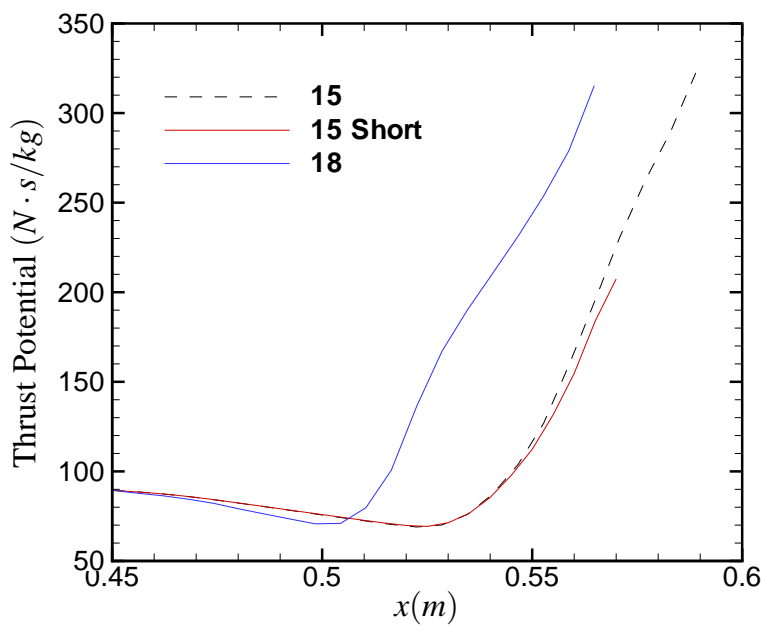

(a) Thrust Potential Comparison

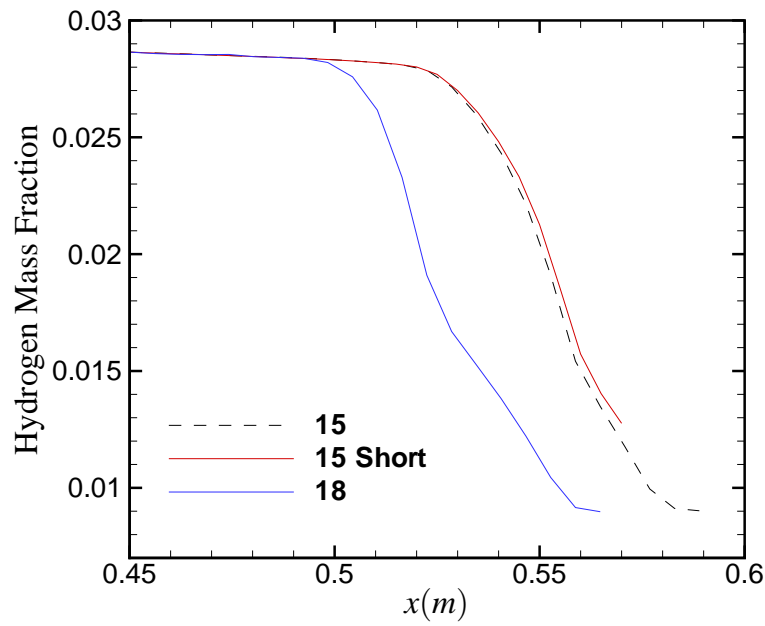

(c) Hydrogen Mass Fraction Comparison

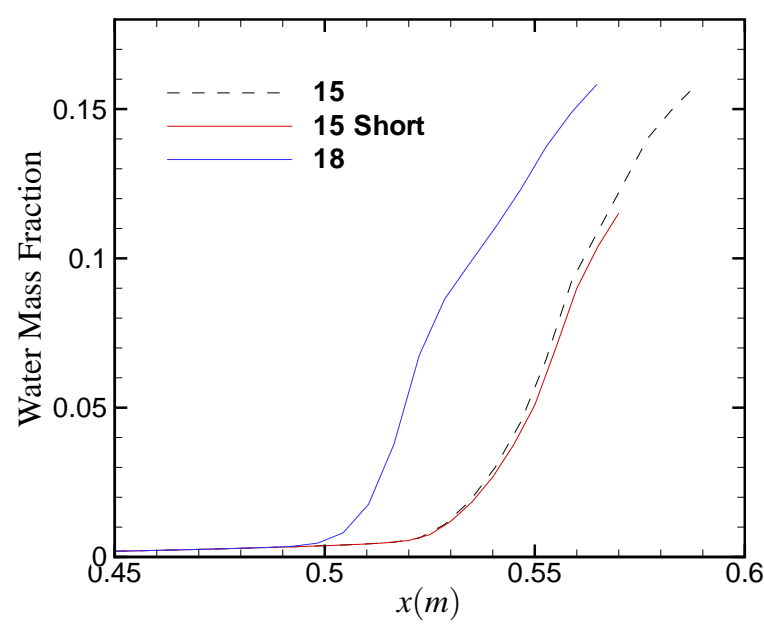

(b) Water Mass Fraction Comparison

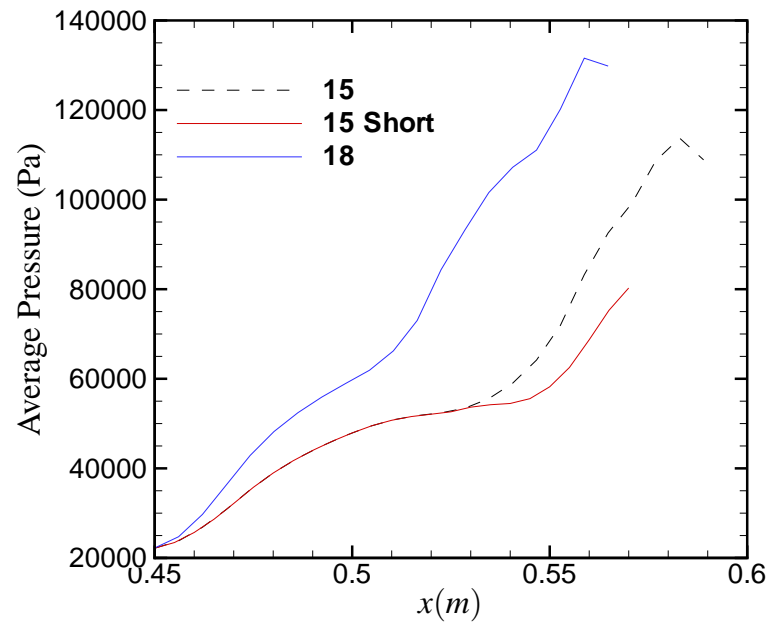

(d) Average Pressure Comparison

FIGURE 6.5: Case A combustor flowfield properties comparison

\subsubsection{Case B: $T=250 \mathrm{~K}$}

For the mixing Case $\mathrm{B}$, where the length of the mixing duct was long $(1.2 \mathrm{~m})$ and the mixing efficiency was high $(71 \%)$, wedge angles were simulated in $1^{\circ}$ increments from $12^{\circ}$ to $17^{\circ}$. For all angles, the length of the wedge was set to $11.2 \mathrm{~cm}$. Additional cases were added to observe the impact of the length of the combustor. A shorter $(8.6 \mathrm{~cm}) 15^{\circ}$ wedge was simulated as well as a longer $(14 \mathrm{~cm}) 13^{\circ}$ wedge. 


\subsubsection{1 $13^{\circ}$}

The combustor shown here represents a low wedge angle used for Case B. It can be seen that even with a low wedge angle, the mixture burns quite well. In Fig.6.7, the water mass fraction level is very high and covers most of the cross sectional area. The only regions where there is low levels is near the walls where the fuel was not injected. Looking at the fuel distribution, Fig.5.6, it can be seen that the combustion follows the exact same pattern. Additionally, the induction length is quite short considering the lower wegde angle.

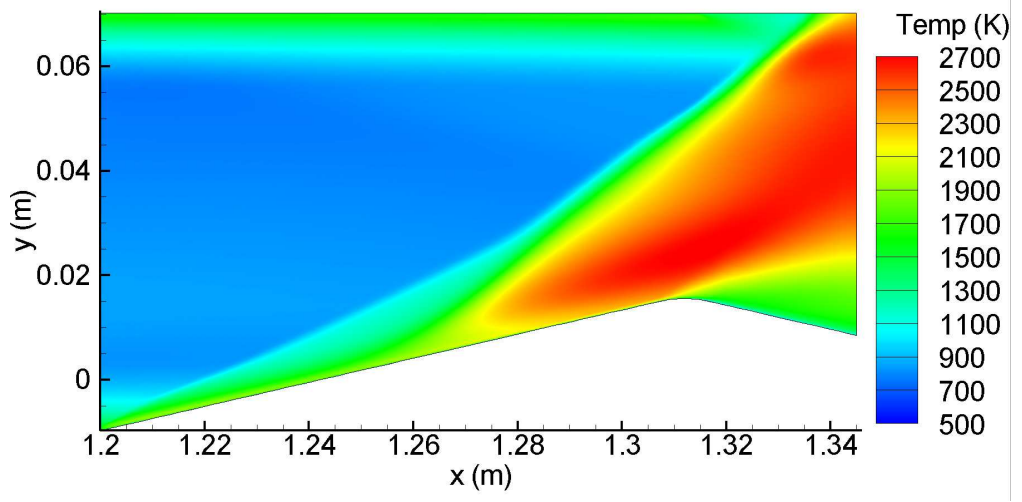

(a) $z=0.01 \mathrm{~m}$

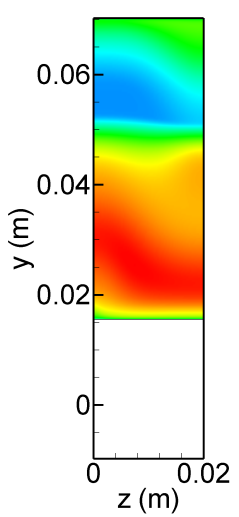

(b) $x=1.312 \mathrm{~m}$

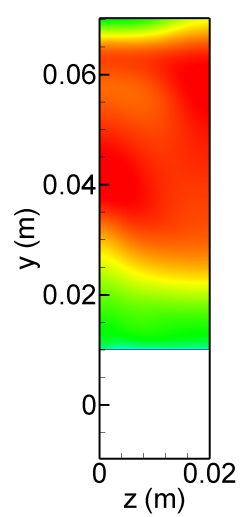

(c) $x=1.338 \mathrm{~m}$

FIgURE 6.6: Combustor temperature flowfield for Case B: $13^{\circ}$

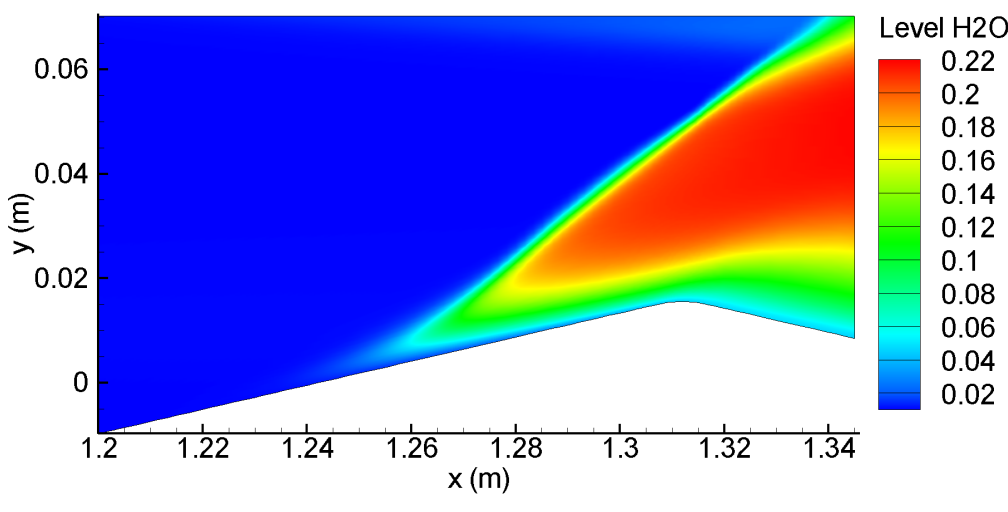

(a) $z=0.01 \mathrm{~m}$

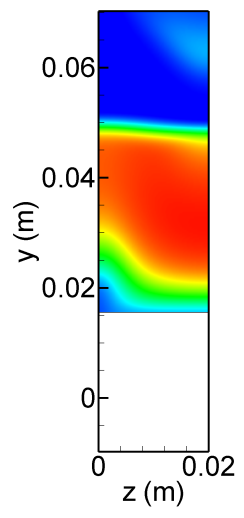

(b) $x=1.312 \mathrm{~m}$

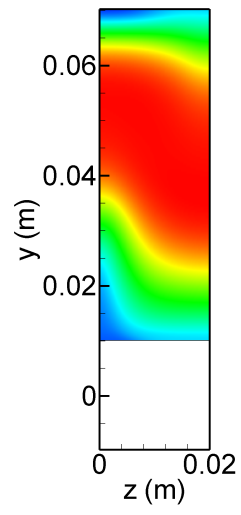

(c) $x=1.338 \mathrm{~m}$

FIGURE 6.7: Combustor $\mathrm{H}_{2} \mathrm{O}$ level flowfield for Case B: $13^{\circ}$

\subsubsection{2 $17^{\circ}$}

The combustor shown here represents a high wedge angle used for Case B. It can be seen that the mixture burns quite well however without any significant improvement over the lower wedge 
angles. The higher wedge angle does shorten the induction distance and provides a higher temperature and pressure. Again this will come at a cost with the pressure drag loss on the front face of the combustor. It can also be noted that the shock reaches the body wall at nearly the same point as where the expansion begins.

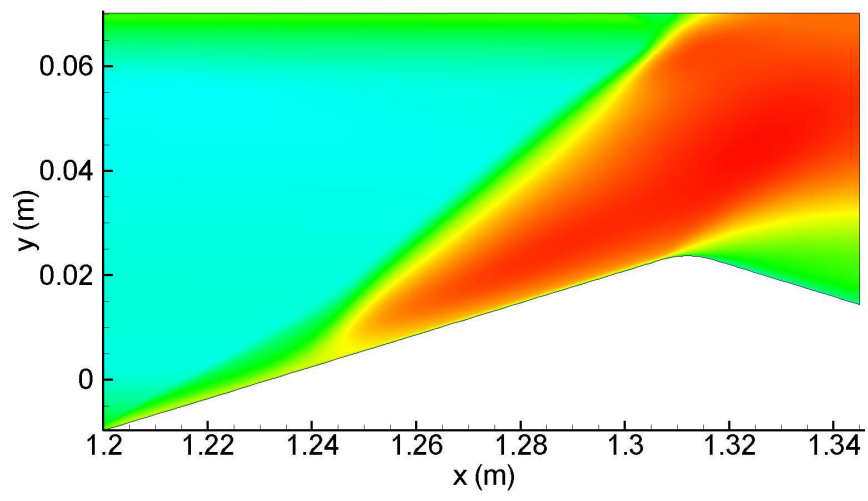

(a) $z=0.01 \mathrm{~m}$

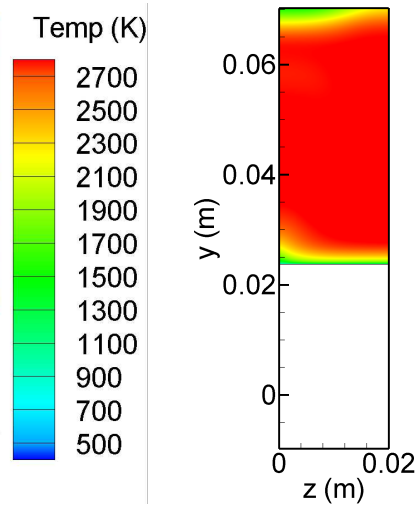

(b) $x=1.312 \mathrm{~m}$

FIGURE 6.8: Combustor temperature flowfield for Case B: $17^{\circ}$

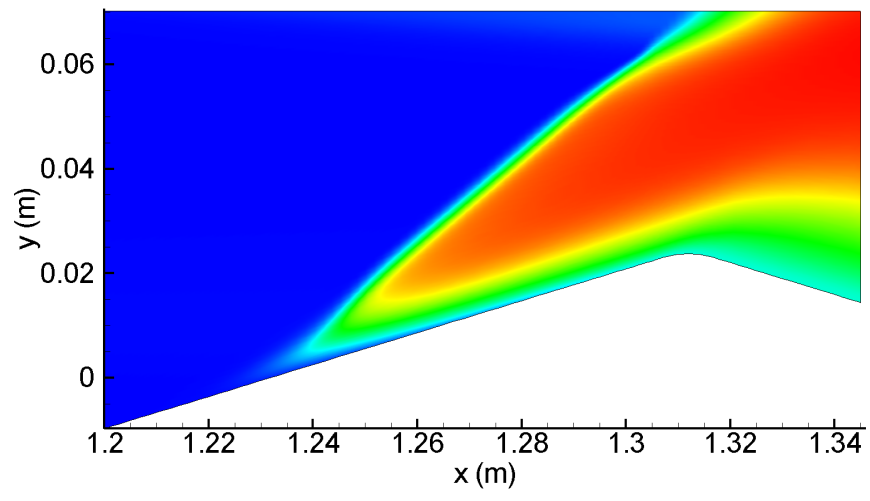

(a) $z=0.01 \mathrm{~m}$

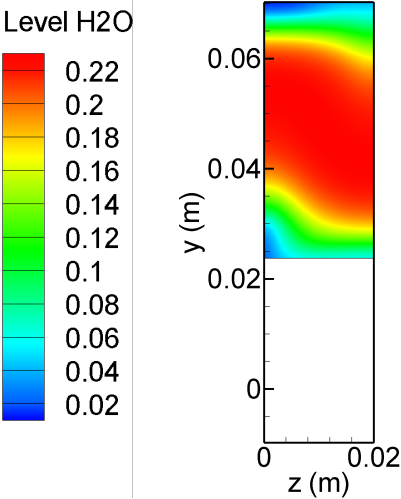

(b) $x=1.312 m$

FIgURE 6.9: Combustor $\mathrm{H}_{2} \mathrm{O}$ level flowfield for Case B: $17^{\circ}$

\subsubsection{Case Comparison}

For Case B, the combustor flow properties are shown in Fig.6.10. The plots are cut off when the shock reaches the upper boundary of the domain for each case and will vary from case to case. Due to the highly mixed flow entering the combustor, all wedge angles combusted the mixture well. In all cases, about $23.9 \%$ of the hydrogen is remaining by the time the shock impinges the body wall. This is signicantly lower than the combustors for Case A. Again, a higher wedge angle serves to 
shorten the induction distance and bring the mixture to a higher temperature and pressure. It does not increase the amount of combustion nor does it have much effect on the thrust potential. Another point of interest is the short and long combustor cases. Reducing and extending the length of the combustor does not seem to have much effect. However, if reduced near the induction distance, the combustion will be affected. It can be seen that the long combustor case does not burn additional fuel. Without any additional mixing, the fuel near the center of the duct cannot burn without the oxygen near the walls. For Case B, a lower angle was chosen $\left(13^{\circ}\right)$ to be continued into the nozzle as it creates less pressure drag losses while still combusting the mixture well.

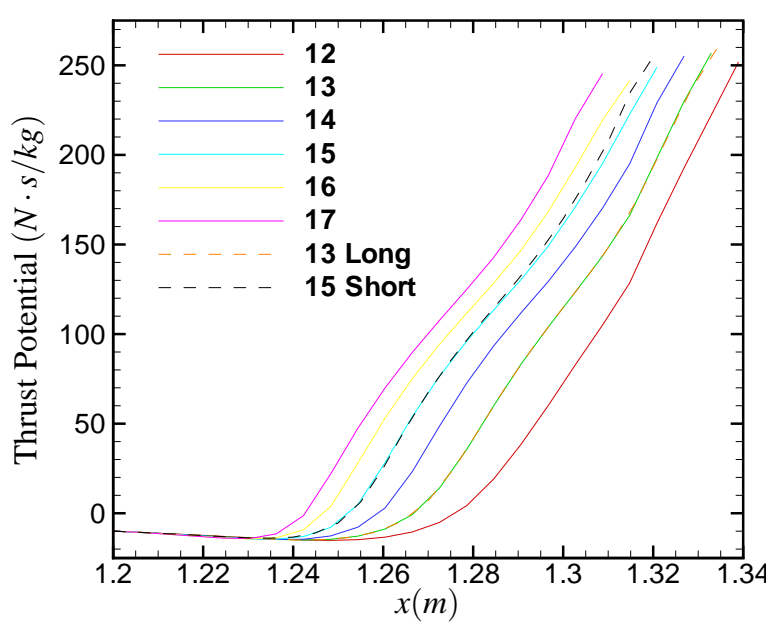

(a) Thrust Potential Comparison

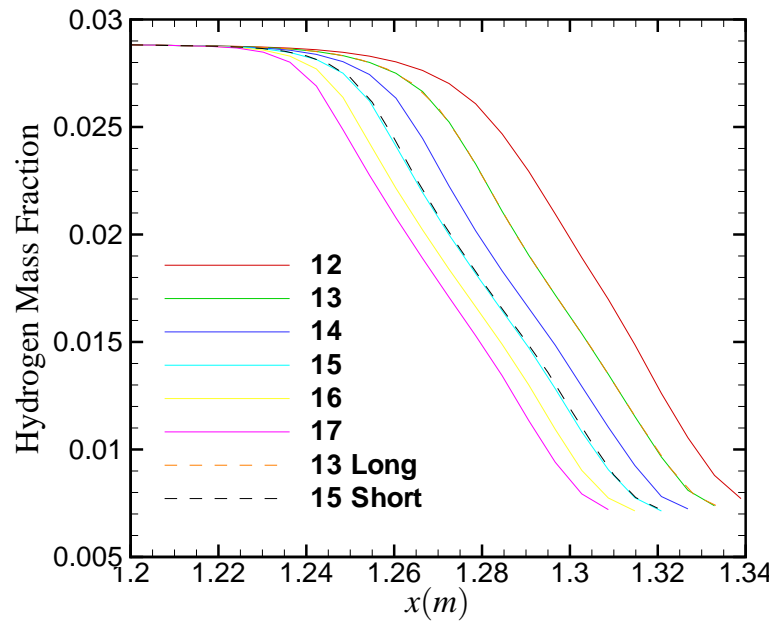

(c) Hydrogen Mass Fraction Comparison

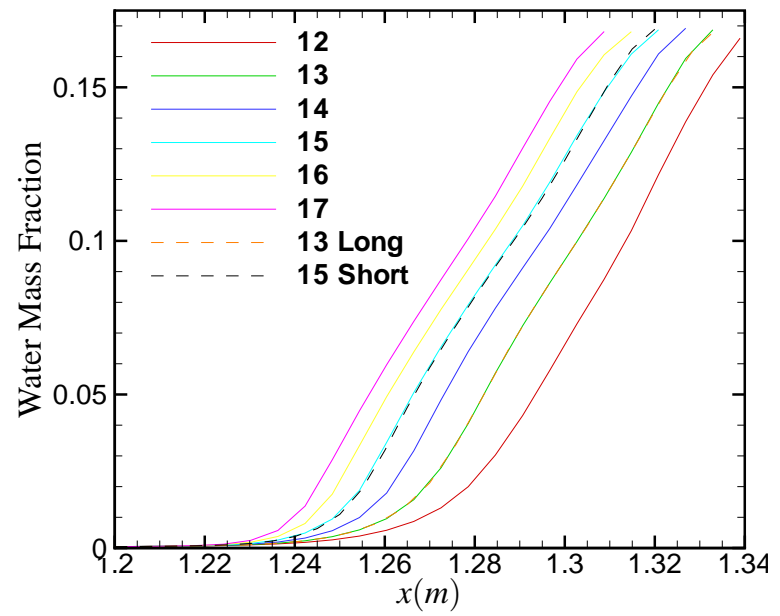

(b) Water Mass Fraction Comparison

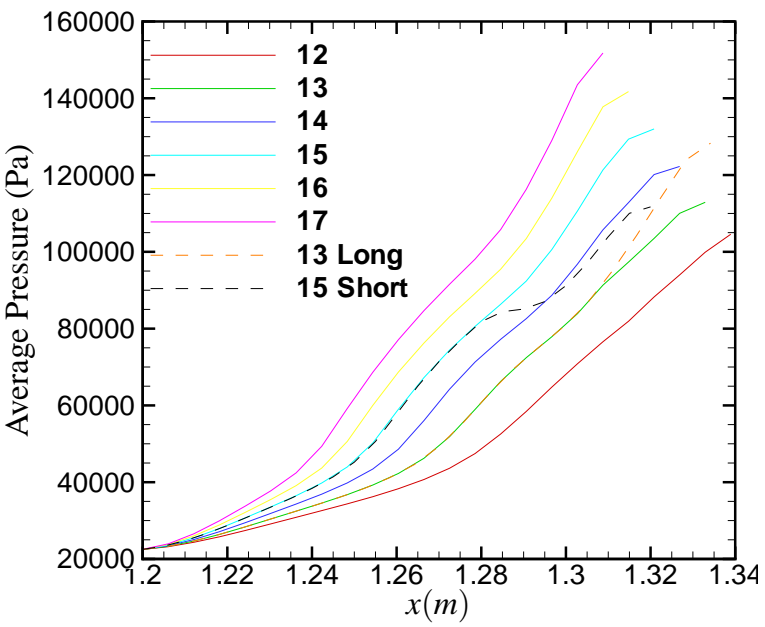

(d) Average Pressure Comparison

FIgURE 6.10: Case B combustor flowfield properties comparison 


\section{SHCRAMJET NOZZLE}

This chapter investigates the expansion system of the shcramjet vehicle. The geometry of the nozzle walls is more complex and requires more advanced methods to design them. The current nozzle wall contour generation method is the dual wall method which utilizes the two dimensional Method of Characteristics (M.O.C.) for rotational flows. An iterative procedure is used to size the nozzle accordingly. This design procedure attempts to maximize thrust but is by no means a maximum thrust nozzle and much improvement can be made. Once the nozzle wall contours are generated, the geometry is used in the WARP code to simulate the three-dimensional reactive flow like the rest of the vehicle.

\subsection{Nozzle Configuration}

For the shcramjet, an iterative procedure using the dual wall technique ${ }^{21,38}$ is used to determine the nozzle wall contours due to the combustor exit's flow being directed upwards. Although the false-wall method has been shown to reduce the cowl height and improve performance in scramjet vehicles, the upward flow from the combustor in a shcramjet results in a similar nozzle contour using the dual wall method.

The dual wall method utilizes the two dimensional Method of Characteristics for rotational flows and is inviscid and chemically frozen. The two dimensional method will be used to represent the entire three dimensional domain. It requires an initial data line which will be taken from a chosen plane from the span of the combustor. The nozzle wall contours generated from the two dimensional method will be used across the span of the actual nozzle. 
The nozzle region will then be simulated in WARP in three dimensions. Although the geometry of the nozzle is planar symmetric, the flow entering it is also three dimensional due to the three dimensional injectors. The grid used was 340-406 $\times 280 \times 105$ nodes, depending on the length of the nozzle.

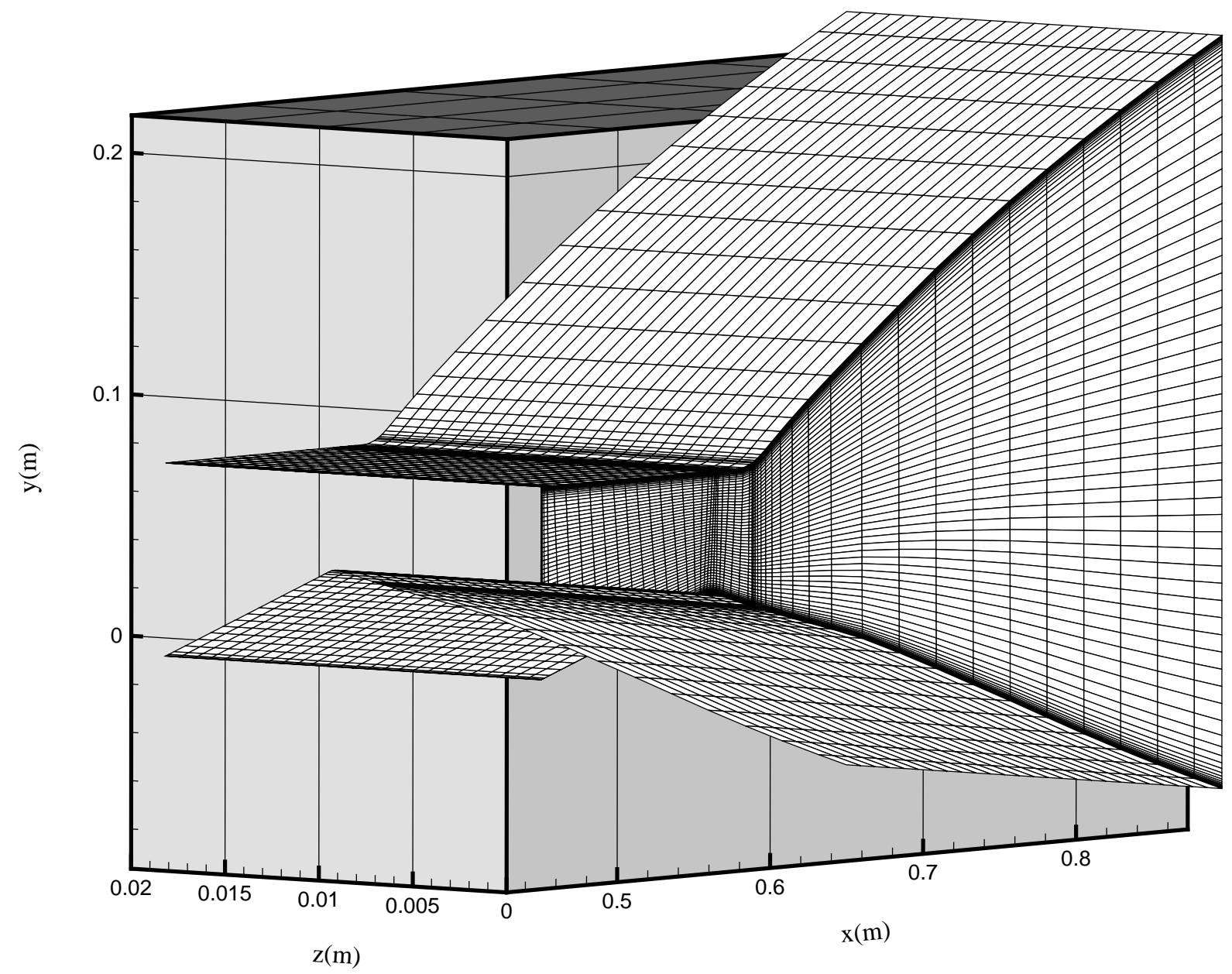

FIGURE 7.1: Nozzle gridding with every $4^{\text {th }}$ line shown

\subsubsection{Method of Characteristics}

The current Method of Characteristics used is the two dimensional method for rotational flows which uses three characteristics. This has been used due to the non-uniform combustion process which causes a rotational flow entering the nozzle. In order to use the method of characteristics the flow is assumed to be supersonic, vibrationally and chemically frozen. The governing equations used assume steady, inviscid flow and are as follows: 


$$
\begin{array}{rcc}
\text { Continuity : } & \sum_{i=1}^{2} \rho \frac{\partial v_{i}}{\partial x_{i}}+\sum_{i=1}^{2} v_{i} \frac{\partial \rho}{\partial x_{i}} & =0 \\
\text { SpeciesContinuity : } & \sum_{i=1}^{2} \rho v_{i} \frac{\partial c_{k}}{\partial x_{i}} & =0 \\
\text { Momentum : } & \sum_{i=1}^{2} \rho v_{i} \frac{\partial v_{j}}{\partial x_{i}}+\frac{\partial p}{\partial x_{j}} & =0 \\
\text { Energy : } & \sum_{i=1}^{2} v_{i} \frac{\partial p}{\partial x_{i}}-a_{\text {frozen }}^{2} \sum_{i=1}^{2} v_{i} \frac{\partial \rho}{\partial x_{i}} & =0
\end{array}
$$

The conservation of energy was reduced to the sound speed equation where a thermally perfect gas has been assumed in the derivation and the frozen sound speed is defined as $a_{\text {frozen }}^{2} \equiv \gamma_{\text {frozen }} R T$.

These equations are hyperbolic, quasi-linear (linear in the derivatives but may be nonlinear in the dependent and independent variables ${ }^{43}$ ) non-homogeneous partial differential equations. Therefore the Method of Characteristics may be used to reduce them to a set of ordinary differential equations. These ordinary differential equations are valid along characteristics and are called compatibility equations. Physically, characteristics are the path of propagation of a disturbance, or mathematically, a curve along which the derivatives of a physical property may be discontinuous, but the property itself is continuous. The characteristic and compatibility equations for the governing equations are as follows:

\section{Streamlines :}

$$
\begin{aligned}
& \text { Characterisitc : } \quad \frac{d x_{2}}{d x_{1}}=\lambda_{0}=\frac{v_{2}}{v_{1}} \\
& \text { Compatibility : } \quad \rho V d V+d p=0 \\
& d p-a_{\text {frozen }}^{2} d \rho=0 \\
& \rho v_{1} d c_{k}=0
\end{aligned}
$$

Mach lines :

$$
\begin{gathered}
\quad \frac{d x_{2}}{d x_{1}}=\lambda_{ \pm}=\tan (\theta \pm \alpha) \\
\text { Characterisitc : } \\
\qquad \begin{aligned}
\text { where } \theta=\tan ^{-1}\left(\frac{v_{2}}{v_{1}}\right) \text { and } \alpha=\sin ^{-1}\left(\frac{1}{M}\right) \\
\text { Compatibility : } \quad d \theta \pm \frac{\sqrt{M^{2}-1}}{\rho V^{2}} d p=0
\end{aligned}
\end{gathered}
$$


where $V=\sqrt{v_{1}^{2}+v_{2}^{2}}$ (not the contravariant velocity), $\lambda_{ \pm}$defines the positive and negative characteristics respectively, and $\theta$ is the angle of the flow.

\subsubsection{Unit Process}

Given a flowfield or initial data line, the flowfield downstream can be found using the following procedure. From Fig.7.2, the location of point 4 downstream in the flow field can be determined from the negative and positive characteristics from points 1 and 2, respectively. The compatibility equations along the negative and positive characteristics as well as the streamline are used to determine properties at point 4 . The streamline can be propagated backwards from point 4 to point 3 , at which the properties are determined from a linear interpolation of points 1 and 2 . Solving the set of non-linear ordinary differential equations is done using an Euler predictor-corrector method.

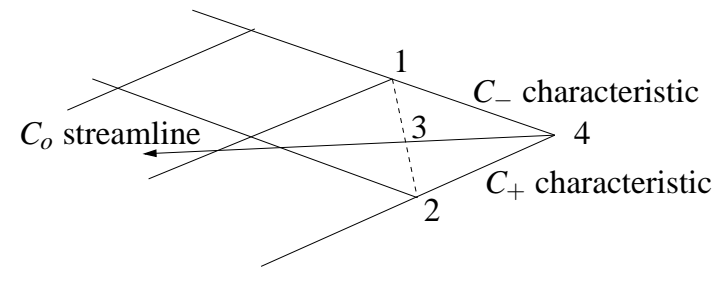

FIGURE 7.2: Method of characteristics solution schematic of point 4 from information at points 1 and 2

\subsubsection{Dual Wall Method}

Using the M.O.C. as described above, the wall contours of a nozzle can be designed with the use of several constraints, mainly directing the flow outwards with a uniform exit pressure. The main purpose of the nozzle is to expand and accelerate the flow. Although straight lines can be used for the nozzle wall contours, nozzle contours found by the M.O.C. will give much shorter lengths and therefore less frictional losses and lower weight. Using curved walls, the nozzle can expand the flow quickly and direct it parallel to the thrust direction. However, with the curve design, after the initial expansion, the flow near the walls are compressed and will lead to shocks. To avoid this, the initial expansion waves are used to cancel out the compression from the walls and can theoretically be isentropic. This nozzle is shown in Fig.7.3 with its corresponding flow regions. The next few sections will describe how each section is calculated. 


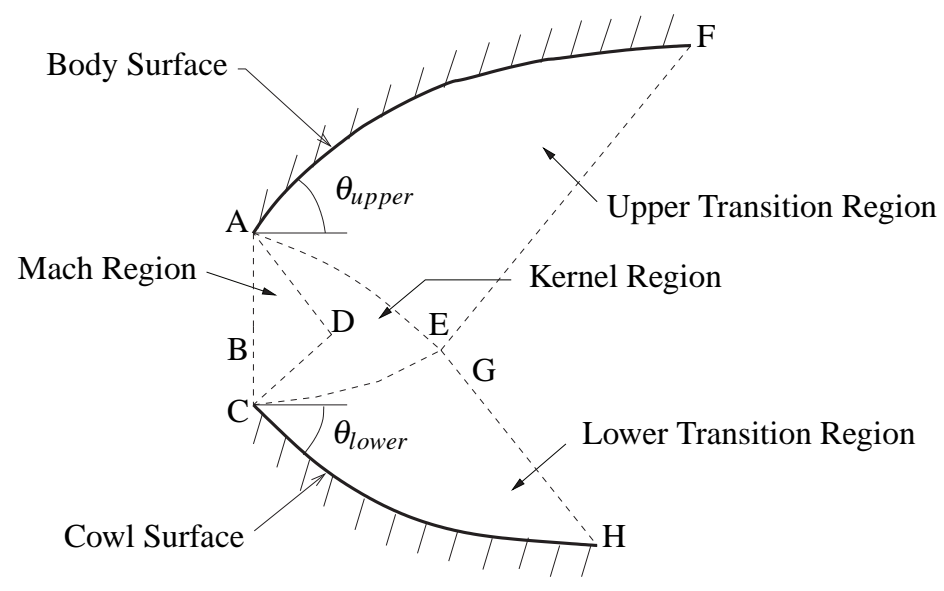

FIGURE 7.3: Schematic of dual wall nozzle design

\subsubsection{Mach Region}

The Mach region is the region directly behind the initial data line and enclosed by the first expansion wave from the start of the nozzle wall expansion on both sides. This region is independent of back pressure and geometry of the nozzle and is calculated using the MOC along with the initial data line.

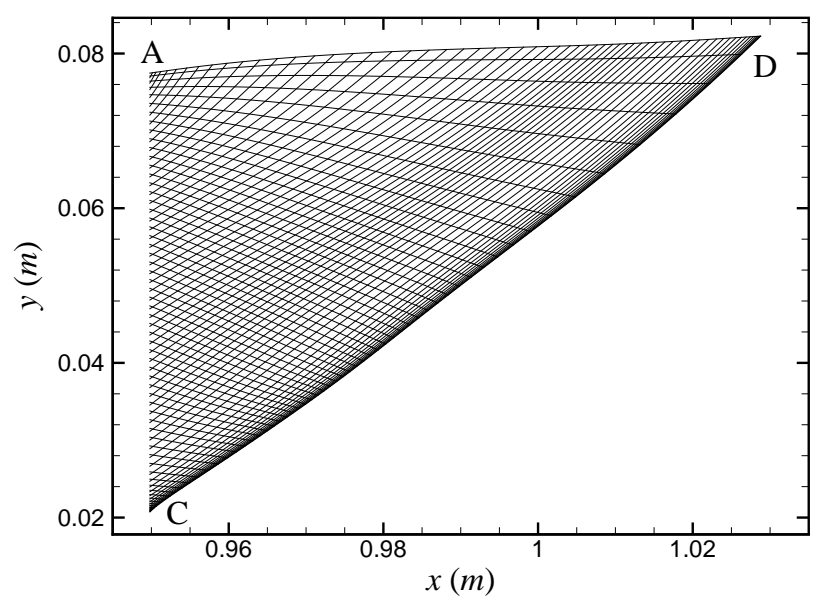

FIGURE 7.4: Mach region

\subsubsection{Kernel Region}

The Kernel region is the region enclosed by the first and last expansion wave of the Prandtl Meyer expansion from the initial nozzle wall expansion on both sides. The Prandtl Meyer expansion is discretized into a chosen number of Mach number lines using the Prandtl Meyer equations. 
Looking at Fig.7.5 and the flow from the lower half of the Kernel region, the Mach number lines from the Prandtl Meyer expansion define the $C^{+}$characteristics. The $C^{-}$and $C^{o}$ (streamlines) characteristics are taken from the initial value lines (CD) from the end of the Mach region. The unit process can be used to solve the flow. Similarly, the upper half of the Kernel region can be solved in the same manner. An iterative procedure (Newton-Raphson, in this case) is used to determine the expansion angles when given the constraints of having a specified back pressure and flow direction at point $\mathrm{E}$, in this case parallel to the flight direction for maximum thrust.

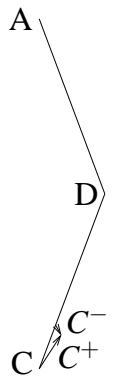

(A)

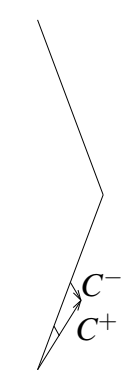

(B)

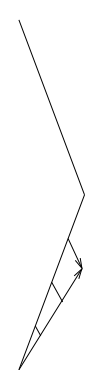

(C)

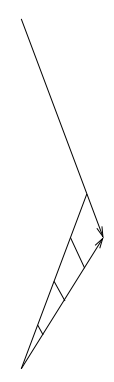

(D)

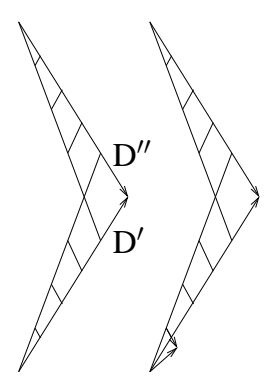

(E)

(F)

FIGURE 7.5: Method of characteristics process in the Kernel region

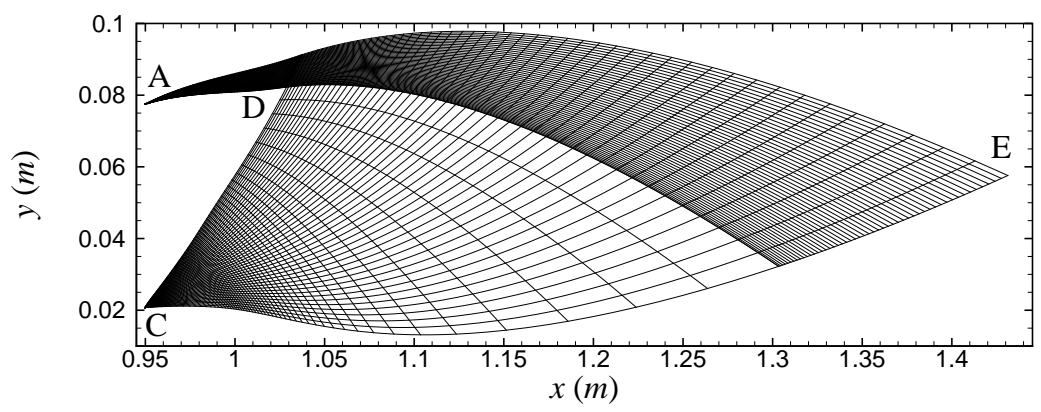

FIGURE 7.6: $C^{+}$and $C^{-}$characteristics in the completed Kernel region

\subsubsection{Transition Region}

The upper and lower Transition regions are the final regions and they define the geometry of the nozzle walls. The Transition region is initiated from the last point (E), shown in Fig.7.7, and proceeds as follows:

- A) Use $C^{+}$from point 2 and $C^{o}$ from point 3 to find the location of point 4 , solve for values using the constraint of parallel flow instead of the last characteristic/compatibility equation 
- B) Use $C^{-}$from point 4 and $C^{+}$from point 3 to find the location of point 1 , then follow the streamline $C^{o}$ back to point 5 and interpolate its data based on its neighboring nodes on the line $\mathrm{AE}$, then solve for values using the four compatibility equations

- C) Continue step B down towards wall

- D) Determine wall location, W, using conservation of mass: Mass flow through AE must equal mass flow through EE'W

Lines are added until the point E' and $\mathrm{W}$ are the same, this marks the end of the nozzle wall. A typical Transition region is shown in Fig.7.8.

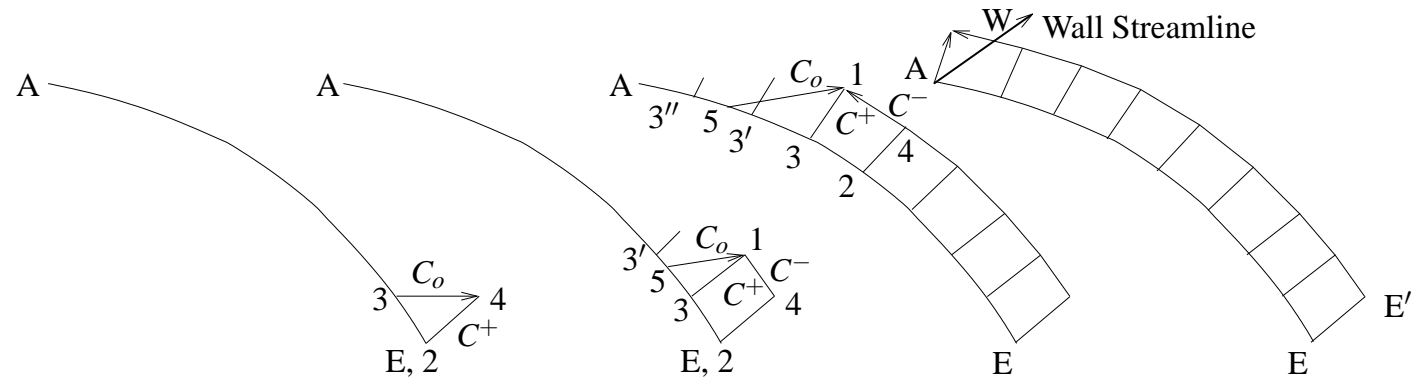

(A)

(B)

(C)

(D)

FIGURE 7.7: Method of characteristics process in the upper Transition region

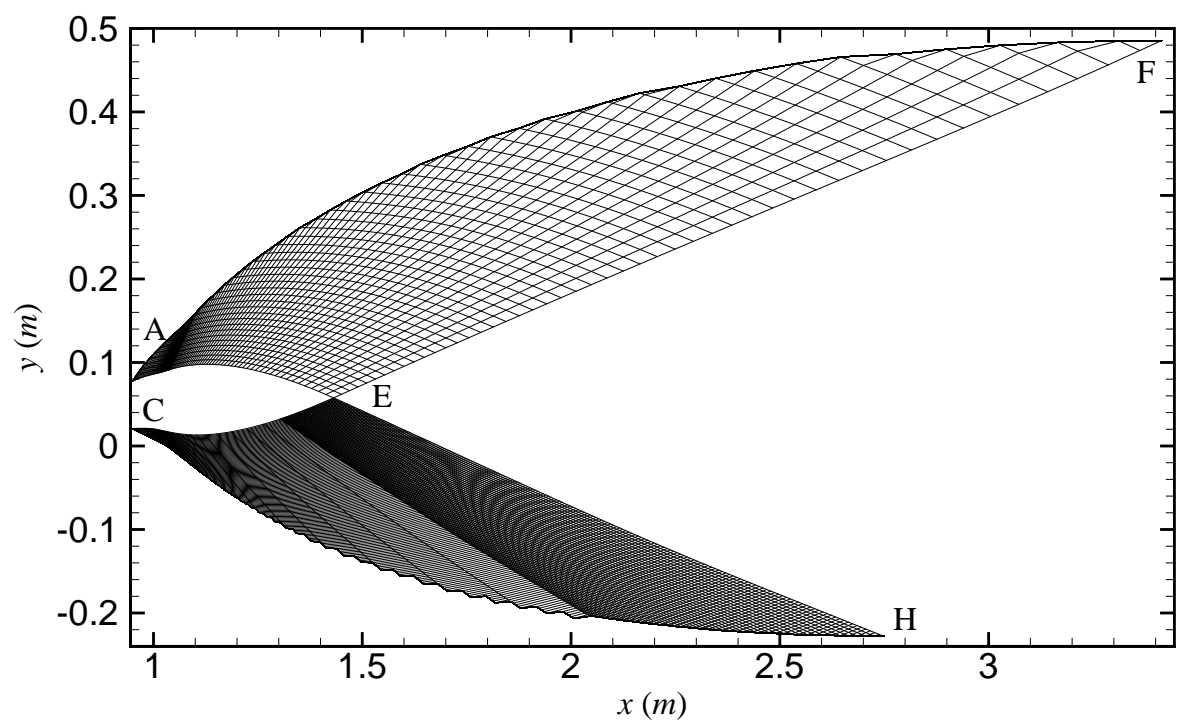

FIGURE 7.8: Typical Transition region 


\subsubsection{Iterative Procedure}

Currently, the nozzle wall contours can be generated using the dual wall method when given an exit pressure. Now, an iterative procedure with several constraints is used to size and optimize the nozzle geometry such that the body nozzle wall terminates at the height of the inlet tip to create a flat body top. The iterative procedure is given below.

1. Guess a nozzle back pressure.

2. Solve for the nozzle wall contours using the dual wall method which constrains the flow parallel to the flight direction to recover maximum thrust.

3. Cut the length of the walls such that a small amount of the thrust (2\% for the body and $5 \%$ for the cowl) is lost in exchange for a significant reduction in length (up to 75\%) and hence weight and friction. The nozzle walls become close to parallel near the end and provide very little thrust. However, cutting the walls short results in non-parallel exit flow and a higher exit pressure.

4. To account for the development of the turbulent boundary layers on the nozzle walls, Edenfield's ${ }^{13}$ experimental correlations are used to determine the displacement thickness, which is then used to adjust the MOC obtained contours by a vertical distance, such that the viscous flow matches the inviscid contour mass flow rate.

5. Check whether the reduced length and boundary layer adjusted nozzle upper wall ends at the same height as the inlet tip (to have a flush top that does not cause pressure drag). If they are equal, then the design procedure is complete

6. If the height is above the inlet tip, then return to step 1 and choose a higher back pressure. If the height is below the inlet tip, then return to step 1 and choose a lower back pressure

\subsubsection{Choosing an Initial Data Line}

The initial data line used to construct the nozzle wall contours has been taken from two different locations. In both cases, the top of the data line starts from the point where the combustioninducing shock impinges the body wall. Expanding the flow at this location mitigates the size of the resulting shock-induced combustion wave/boundary layer interaction generated recirculation zone 


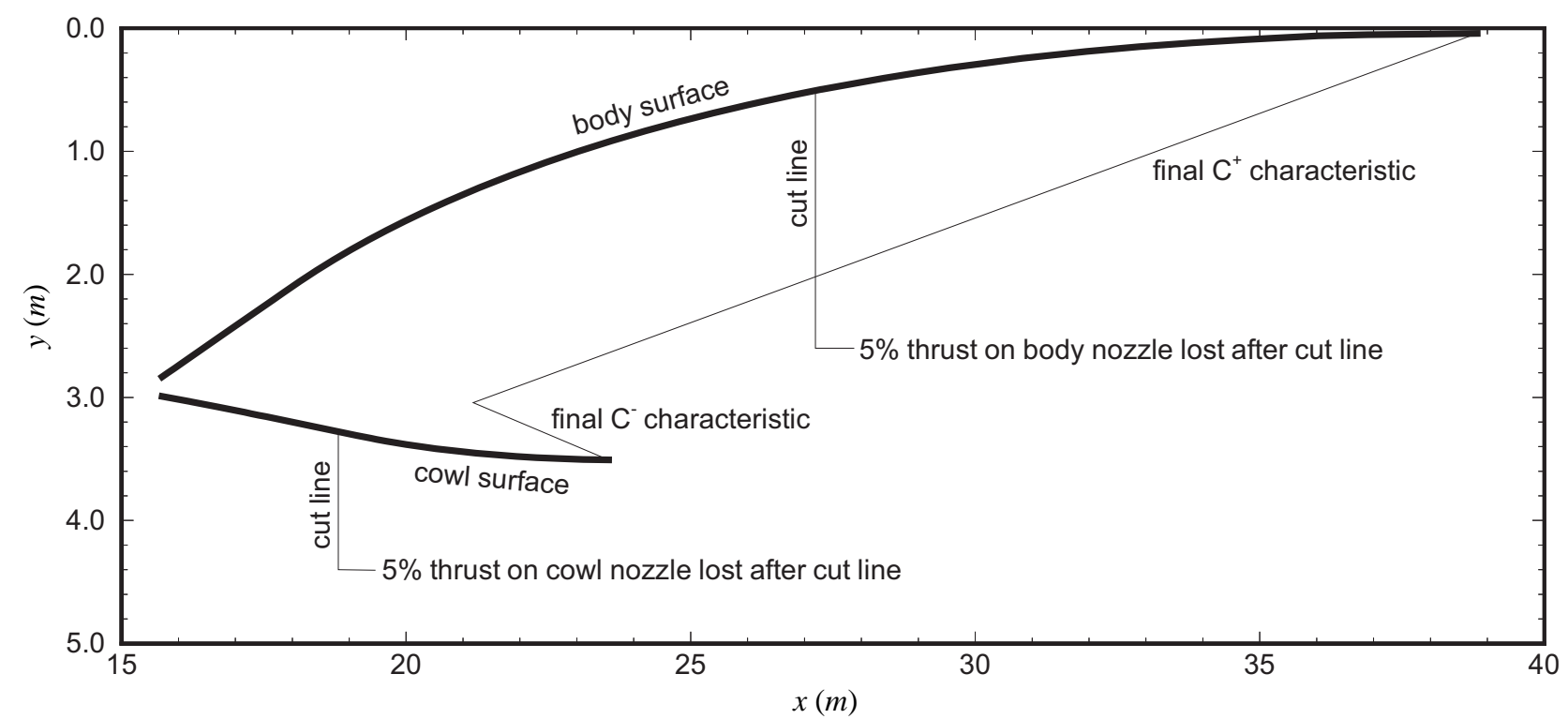

FIGURE 7.9: Step 3: Reduce length of nozzle walls

on the body surface. Prior studies have shown that expansion at this location does not adversely affect the engine performance. ${ }^{2}$ Additionally, no air slot is required to blow or suck away the recirculation region.

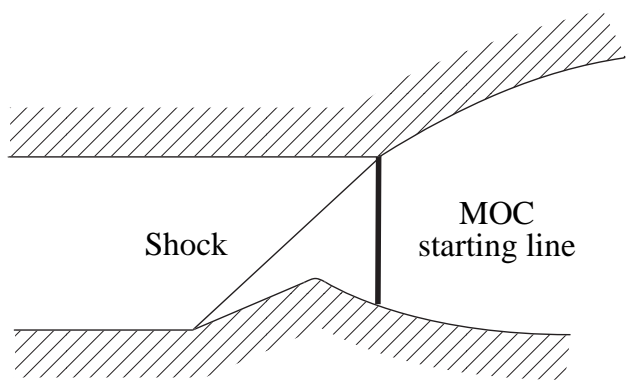

(a) Vertical Starting Line

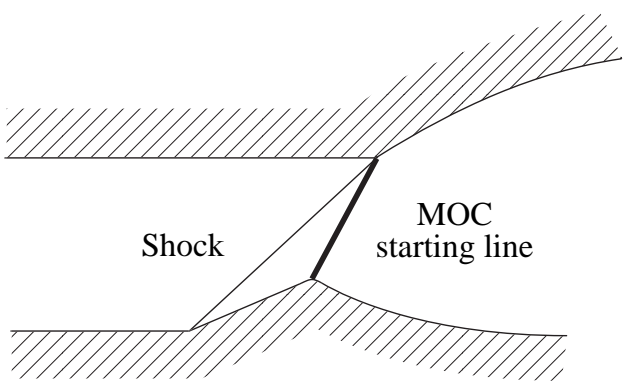

(b) Slanted Starting Line

FIGURE 7.10: Starting lines of the nozzle expansion process

The first simulations $\left(\right.$ Case A $15^{\circ}$ and Case B $13^{\circ}$ ) used a vertical line taken from the $x$ location where the shock reaches the upper body wall, as shown in Fig.7.10(a). Using this approach requires that the expansion on the cowl wall be predetermined. The expansion angle was set to equal the combustor angle. When generating the nozzle wall contours using this starting line, it will specify a second expansion at the bottom of the starting line. Although the second expansion is typically small, this does not create a properly designed nozzle.

All remaining cases used the more proper approach which uses a slanted initial data line that starts at the end of the combustor, as shown in Fig.7.10(b). This position must be chosen carefully 
to ensure the combustion is not quenched by the flow expansion. In this manner, the expansion of the cowl is determined completly from the dual wall method and the cowl nozzle wall is smooth.

Another issue of the current nozzle wall design procedure is selecting the initial data line in the spanwise domain. Currently, the two dimensional MOC uses a starting data line from a plane chosen in the span of the domain to represent the entire span. Although the three dimensional MOC is possible, the current method is sufficient as nozzle wall contours that change along the span of a mostly planar vehicle would create a ribbed surface that would actually cause more problems.

The current issue is to properly choose a plane that best represents the entire span. The chosen plane varied from case to case. Due to the highly non-homogeneous flow from the combustor, the MOC had difficulties solving for the nozzle walls as often the characteristics would cross or were close to crossing each other. This causes unsmooth nozzle wall contours that would not perform well. Therefore the plane in the span must be chosen that will give smooth wall contours or additional smoothing may be required. Also, different planes may be used for generating the body and cowl nozzle walls. For Case B, where the flowfield is much more uniform, there is not much issue. However for Case A, where the flowfield is highly non-uniform, this becomes a more difficult task. In the future, some type of averaging process of the flow properties across the span can be used such that the overall performance across the span is maximized.

\subsubsection{Effects on Nozzle Wall Geometry}

The shape of the nozzle walls generated from the dual wall method and the MOC is very important for hypersonic vehicles as large walls protruding outwards would create a lot of drag on the exterior surface. Currently the inlet system compresses the flow to the lower section of the vehicle. This means that it would be ideal to have an asymmetical expansion system that expands upwards to match the original cross sectional area of the inlet. Looking at Fig.7.11(a), it can be seen that a straight flow from the combuster with a vertical initial data line for the MOC would create a symmetrical nozzle. With this shape, the upper section can be matched to the inlet height to create a flat top, however the lower cowl wall will extend much below the cowl tip and create a large amount of drag. The scramjet vehicle exhibits this type of conditions and there are methods to avoid the large cowl, explained in Section 8.1.4.1. For our current case, a slanted initial data line will be used to initiate the MOC. This will result in a larger cowl wall, shown in Fig.7.11(b), due to the offsetting of the Prandtl-Meyer expansions. However, in our current case the flow has an 
upward velocity component due to the wedge turning the flow. This results in a larger body wall, shown in Fig.7.11(c), that is desired in our current configuration. This upward flow component generally has a greater effect than the slanted initial data line and results in a larger body wall in most cases. If for some reason the cowl wall is larger, the shock-inducing wedge can be placed on the body wall instead of the cowl wall and the nozzle walls will be switched.

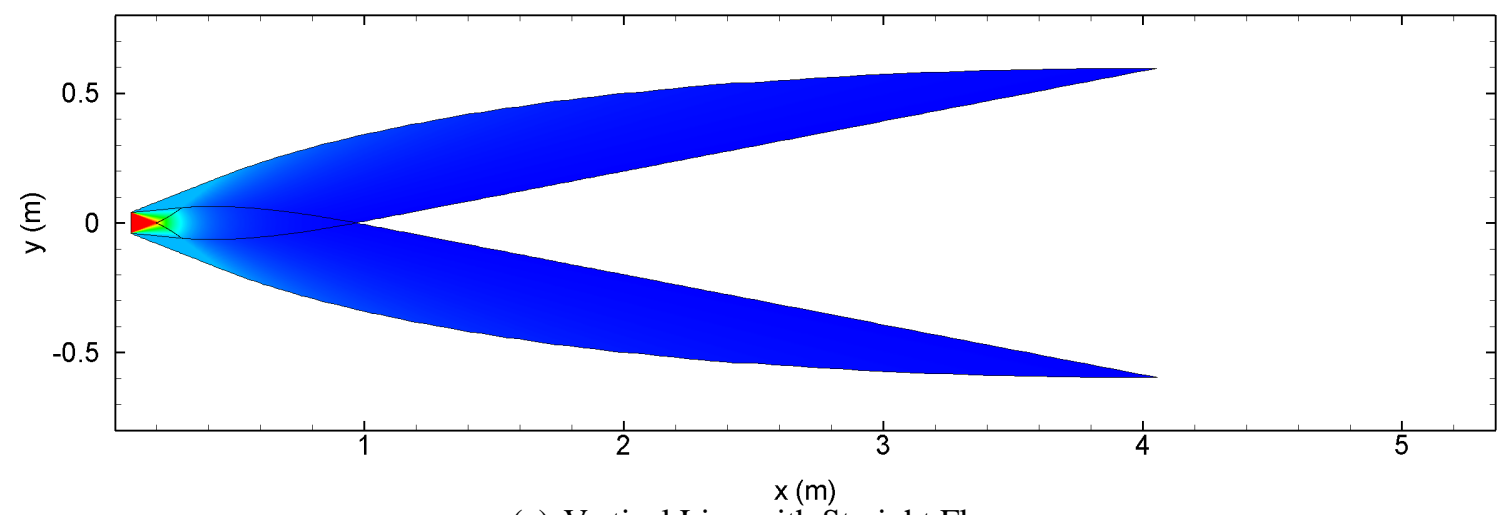

(a) Vertical Line with Straight Flow

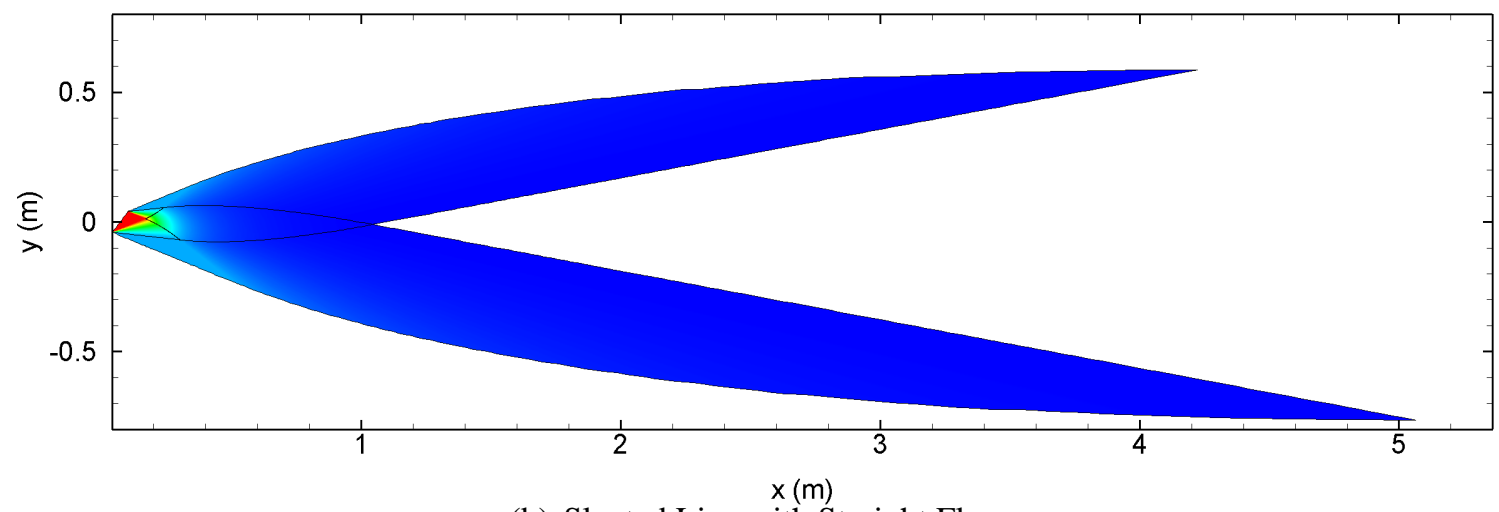

(b) Slanted Line with Straight Flow

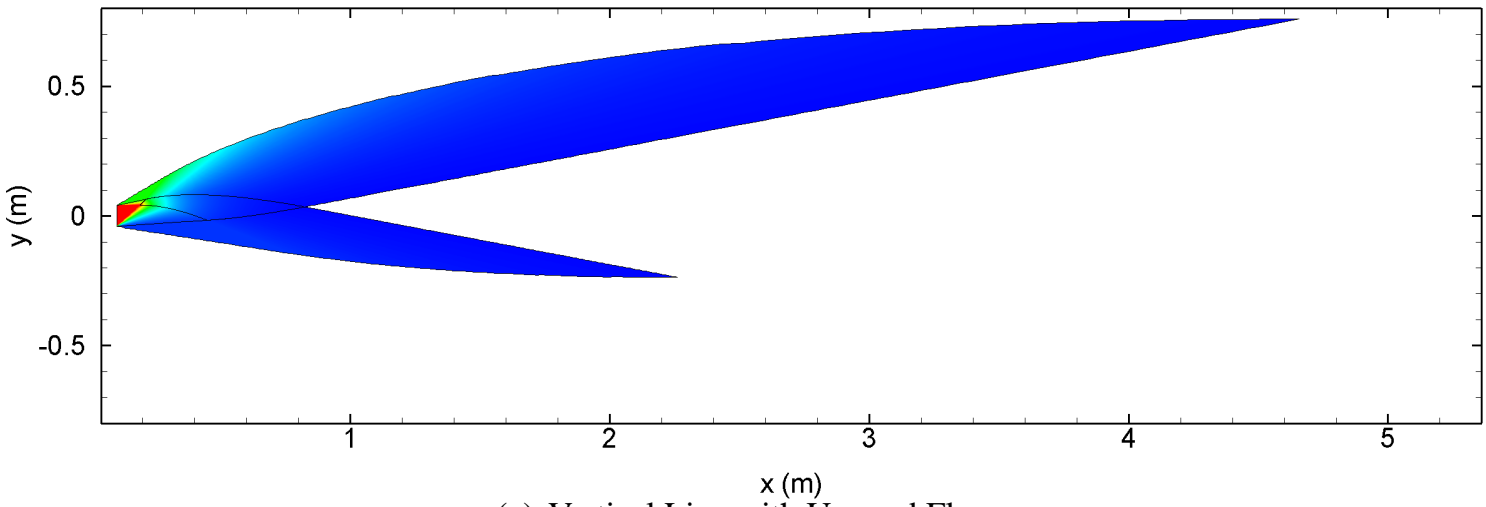

(c) Vertical Line with Upward Flow

FIGURE 7.11: Effect of flow direction and starting line on MOC generated nozzle wall geometry 


\subsubsection{Outer Cowl Design}

The design of the outer cowl is fully dependent on the geometry of the nozzle. With the end of the nozzle cowl wall lower than the inlet cowl tip, Fig.7.12, a surface must be used that will minimize drag. However thermal constraints must be considered as well. The angle on the inlet cowl tip and nozzle cowl end has been set to a minimum of $5 \mathrm{deg}$. With the two points and two angles determined, a third order polynomial can be used to fit a curve as the cowl outer surface. This design has room for improvement and it is shown in the next chapter that every aspect of the vehicle has a very large impact on the overall vehicle performance.

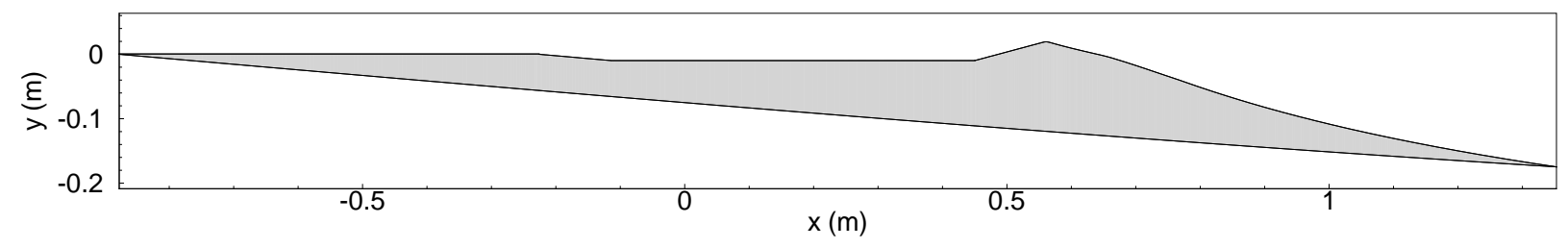

FIGURE 7.12: Cowl geometry

\subsection{Nozzle Flowfield}

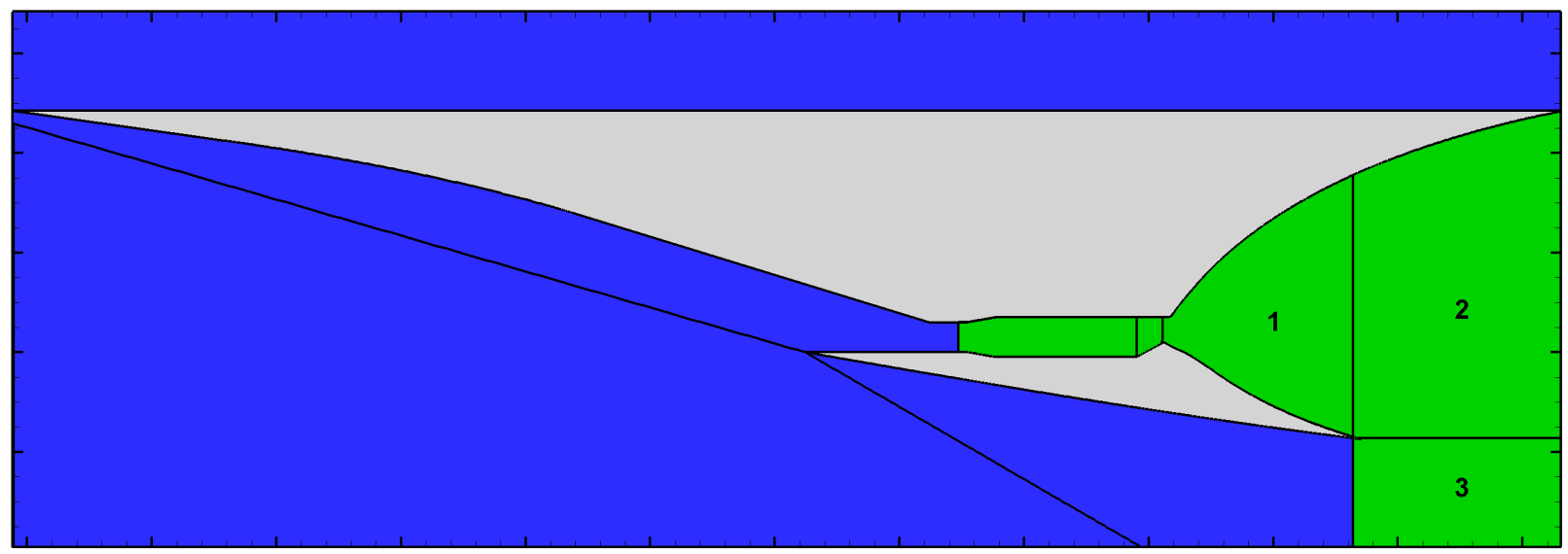

FIGURE 7.13: Regions of the simulation (Blue=2D, Green=3D)

Using the nozzle wall design procedure explained above, the nozzle wall geometry can be used in the three dimensional WARP simulation. For most of the following cases of the shcramjet nozzle, the dual wall method yields a cowl nozzle wall shorter than the body nozzle wall, shown in Fig.7.13. Additionally, most of the thrust is generated by the body nozzle wall even if the lengths 
of the body and cowl walls are equal. For most of the following simulations, only the inner nozzle flow (Region 1 and 2 in Fig.7.13) has been solved as it provides the overall performance of the nozzle. The only section that is missing is the region where the inner nozzle flow meets the outer cowl flow (Region 3 in Fig.7.13). This region only provides the final exit area of the nozzle. Once the best performing inner nozzle flow has been determined, the final region will be simulated for completeness.

\subsubsection{Case A: $T=309 K$}

\subsubsection{1 $15^{\circ}$ vert.}

The Case $\mathrm{A}$ at $15^{\circ}$ simulation used the vertical initial data line for the dual wall method. This case will be compared with the following case in which a slanted initial data line is used. Many planes in the span of the domain yielded initial data lines that created a cowl wall longer than the body wall, however the plane chosen had a longer body wall.

As can be seen in Fig.7.14, the shock from the wedge is smoothly expanded in the nozzle with the expansion occuring right where the shock hits the body wall. Several iterations need to be performed to achieve this by shifting the initial data line in the $\mathrm{x}$-direction. If the expansion occurs too late, the shock will hit the wall and cause a larger recirculation region. If the expansion occurs too early, then the flow will expand in the initial part of the nozzle before it gets compressed by the shock, and the initial nozzle section will have a low pressure force and a reduced thrust. 


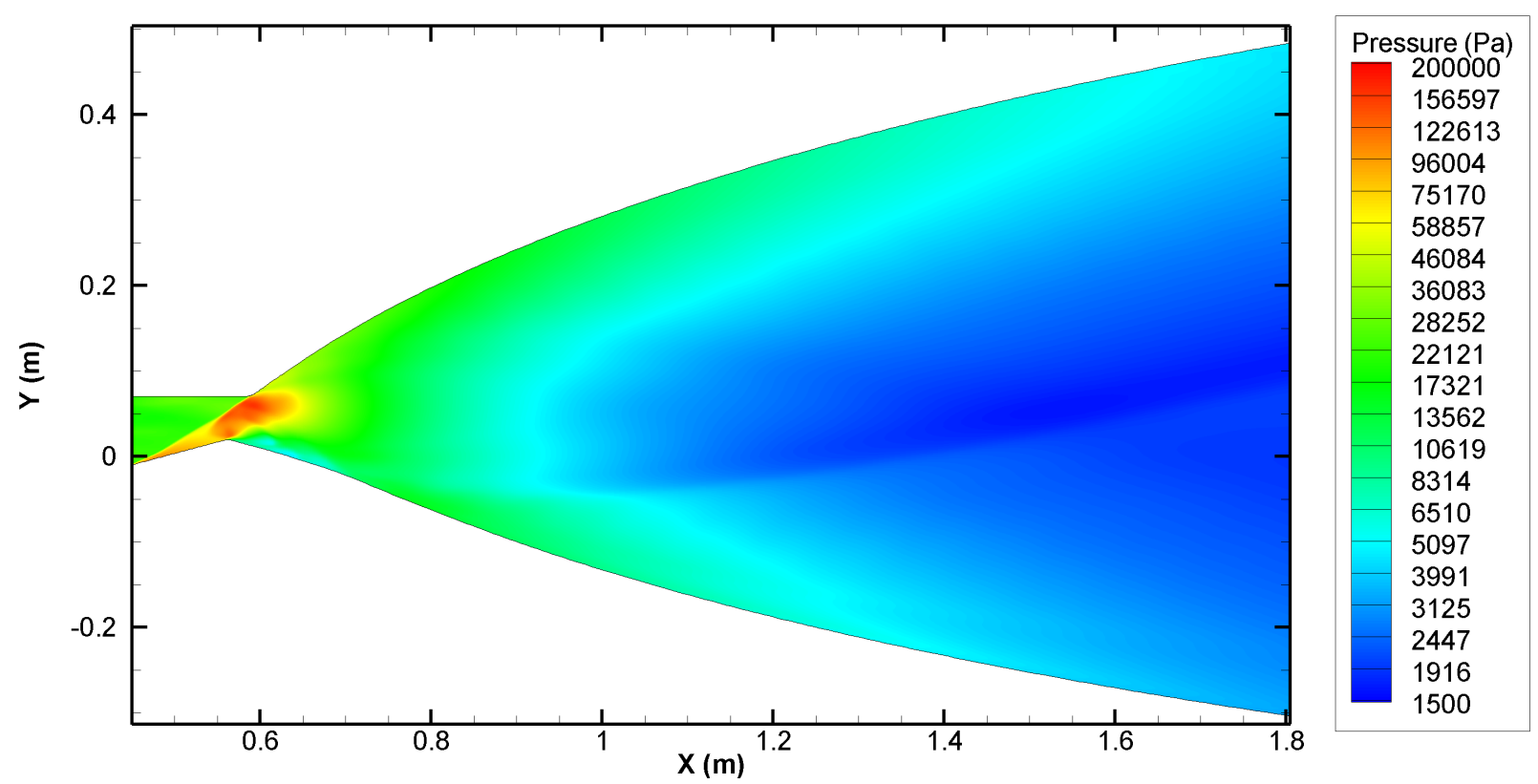

FIGURE 7.14: Case A $15^{\circ}$ nozzle pressure flowfield

\subsubsection{2 $15^{\circ}$ slant}

This case uses the same combustor flowfield as the previous case, however it uses the slanted initial data line instead of the vertical data line, shown in Fig.7.15. The result is a longer and more slender nozzle than before (only the inner nozzle flow is shown here). Additionally, all planes of the computational domain yields a body nozzle wall that is significantly longer than the cowl nozzle wall. Having a short and slimmer cowl nozzle wall will benefit in terms of the losses seen on the outer cowl wall. 


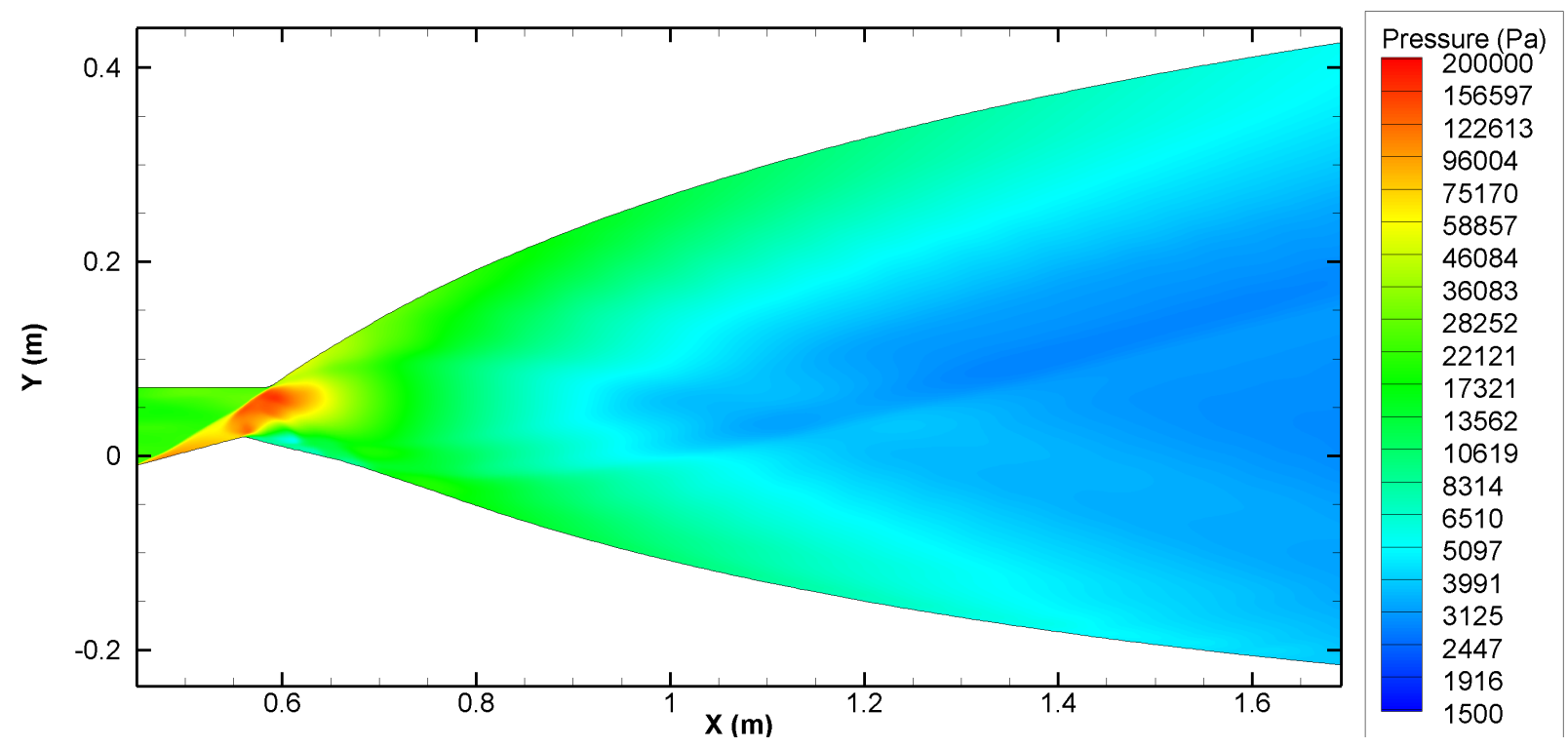

FIGURE 7.15: Case A $15^{\circ}$ slant nozzle pressure flowfield

\subsubsection{3 $15^{\circ}$ slant multitemp}

Another simulation of the Case A $15^{\circ}$ slant was performed with a different wall temperature. As noted earlier, the wall temperature of the shcramjet was set to $500 \mathrm{~K}$ and the comparison scramjet was set to $800 \mathrm{~K}$. The reason for using $500 \mathrm{~K}$ in the shcramjet was to lower the boundary layer temperature such that preignition does not occur ahead of the combustor. It was then decided to simulate the nozzle with the higher $800 \mathrm{~K}$ temperature to observe the difference it may cause as there is no issue of preignition after the combustor. It was seen to make very little difference in the overall thrust ( $1 \%$ ) with slightly lower friction but slightly less pressure force, shown in Table A.1.

\subsubsection{4 $18^{\circ}$ slant}

The $18^{\circ}$ slant simulation, shown in Fig.7.16, was performed to observe the overall vehicle performance when using a higher wedge angle that resulted in a higher pressure and temperature in the combustor. The drawback was the high pressure drag loss on the front face of the combustor. The overall vehicle performance using this high angle wedge was lower than using a low angle combustor, shown in Table A.1. Additionally, many planes in the span of the domain yielded unsmooth nozzle walls. This was due to the large fluctuations in flow properties along the initial data line. 


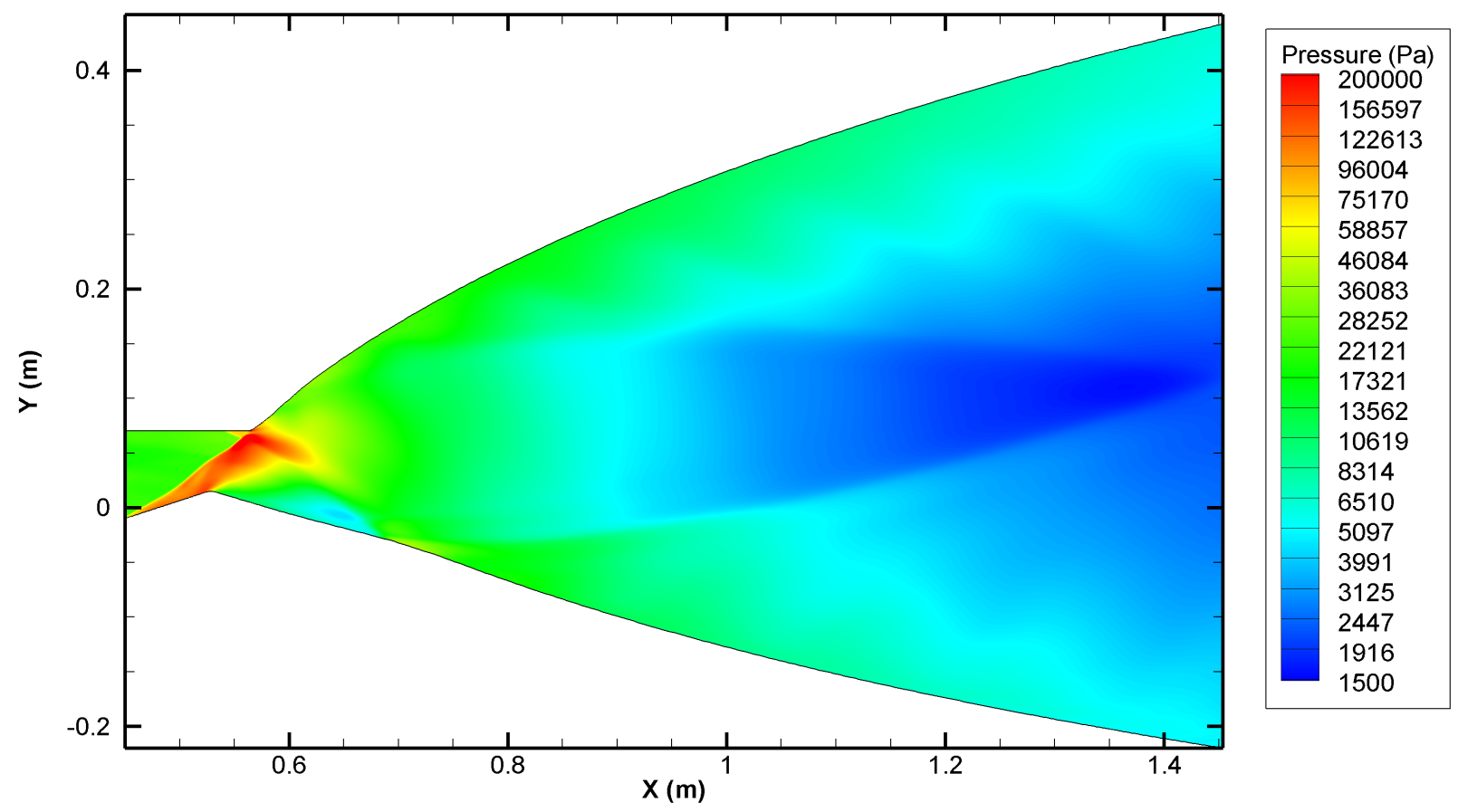

FIGURE 7.16: Case A $18^{\circ}$ slant nozzle pressure flowfield

\subsubsection{Case B: $T=250 \mathrm{~K}$}

\subsubsection{1 $13^{\circ}$ vert.}

For Case B, only the $13^{\circ}$ wedge was continued into the nozzle, shown in Fig.7.17. The nozzle flowfield is very similar to the other cases. The initial data line used in this case was the vertical line, which is the improper method. However, the cowl nozzle wall was still quite smooth. Due to the more even flow properties caused by the higher mixing efficiency, most planes in the domain yielded smooth nozzle walls where the body nozzle wall was longer than the cowl wall. 

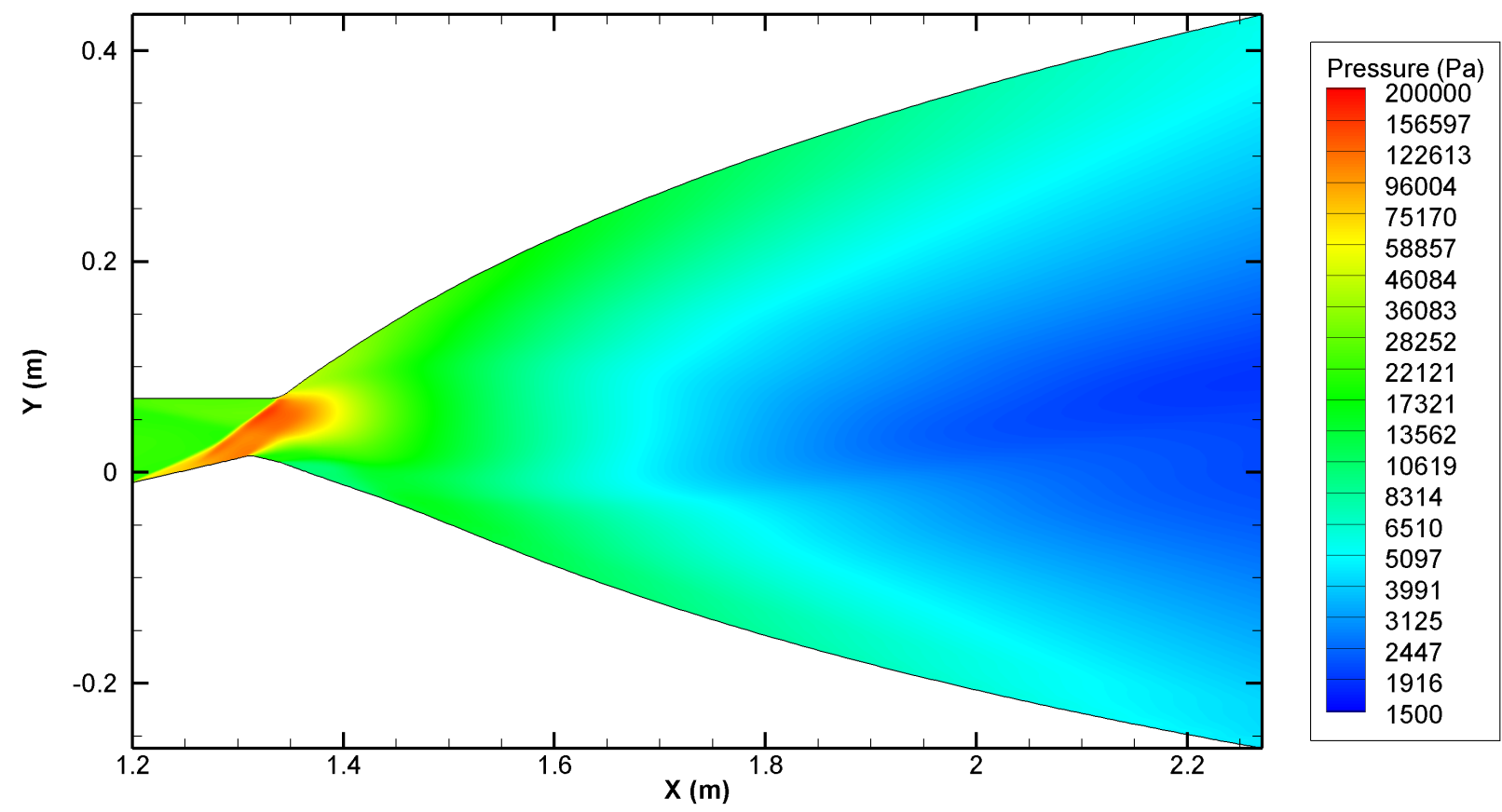

FIGURE 7.17: Case B $13^{\circ}$ nozzle pressure flowfield

\subsubsection{Case Comparison}

All nozzle simulations from both Case A and B are included in the flow properties comparison, shown in Fig.7.18. The plots are of mass flux averaged flow properties from the beginning of the combustor to the end of the inner nozzles. The Case B nozzle has been shifted from its combustor start at $1.2 \mathrm{~m}$ to Case A's $0.45 \mathrm{~m}$ start for better comparison. Looking at the thrust potential, Fig.7.18(a), all cases have a similar shape however Case A has a higher final value. Case A and B have a different initial value with Case B starting at a lower value due to the additional losses it accrued over its longer mixing duct. However the overall gain from combustion is higher, due to its higher mixing efficiency and therefore higher percentage of fuel burned, which is evident in Figs.7.18(b) and 7.18(c). Looking at Fig.7.18(d), all cases have nearly identical average pressure distributions. Another interesting point is the nearly identical Case A nozzles. Even with different nozzle geometries, all the flow properties appear to be nearly idential.

Looking at Table A.1, the integrated pressure and frictional forces for the entire vehicle is shown, which gives the actual performance of the vehicles. In Case B with $T_{f}=250 \mathrm{~K}$, it can be seen that the overall performance is quite poor. Due to the good mixing in this case, a lower 
combustor angle can be used that causes less drag. However, the longer mixing duct incurs much more frictional drag. Additionally, the longer vehicle incurs more drag on its outer surfaces.

Comparing the inner nozzle cases, it was decided to use the Case A $15^{\circ}$ slant nozzle. Case A nozzles had a higher $I_{s p}$ than Case B. Deciding between the Case A nozzles required further analysis using the integrated pressure and frictional forces over the entire vehicle from Table A.1. Taking into account the outer cowl wall pressure forces, it can be seen that the slanted $15^{\circ}$ cowl protruded less than the $15^{\circ}$ vert. case and had an overall better performance. Using a slanted initial data line instead of a vertical initial data line for the MOC resulted in a $6-8 \%$ improvement in performance.

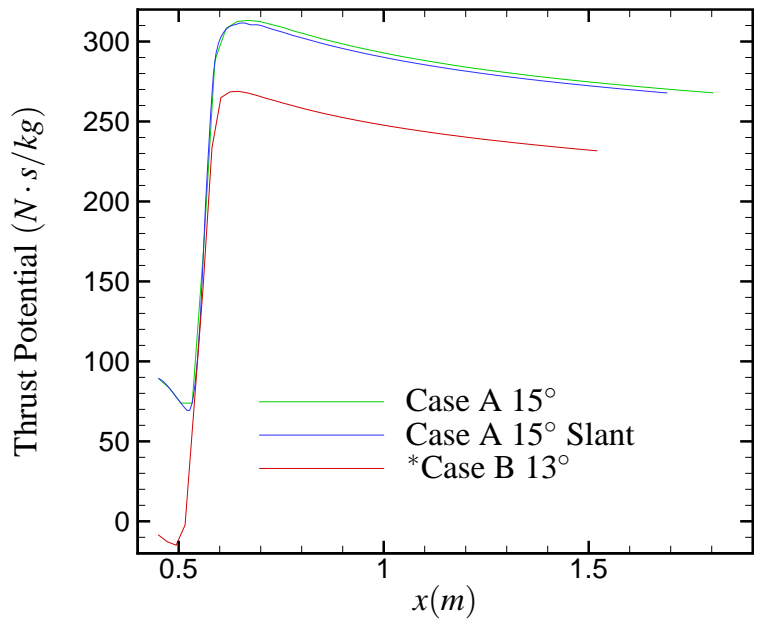

(a) Thrust Potential Comparison

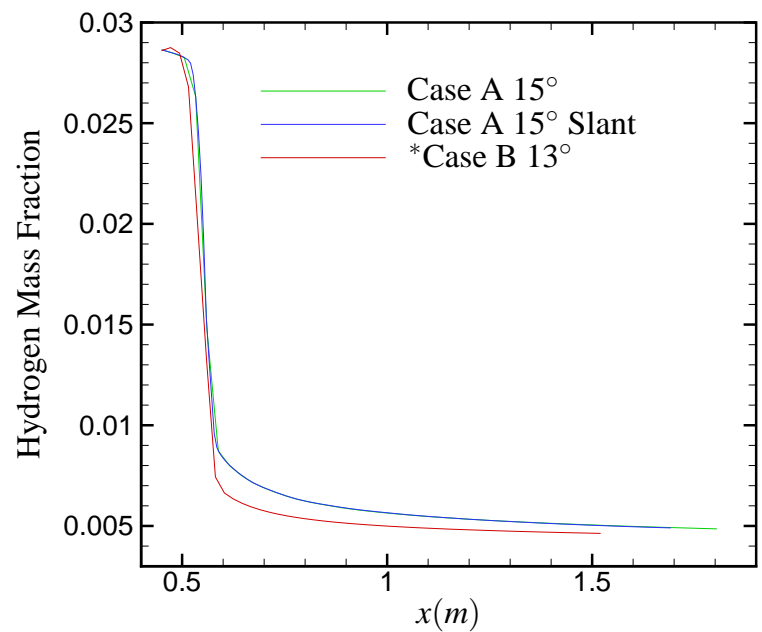

(c) Hydrogen Mass Fraction Comparison

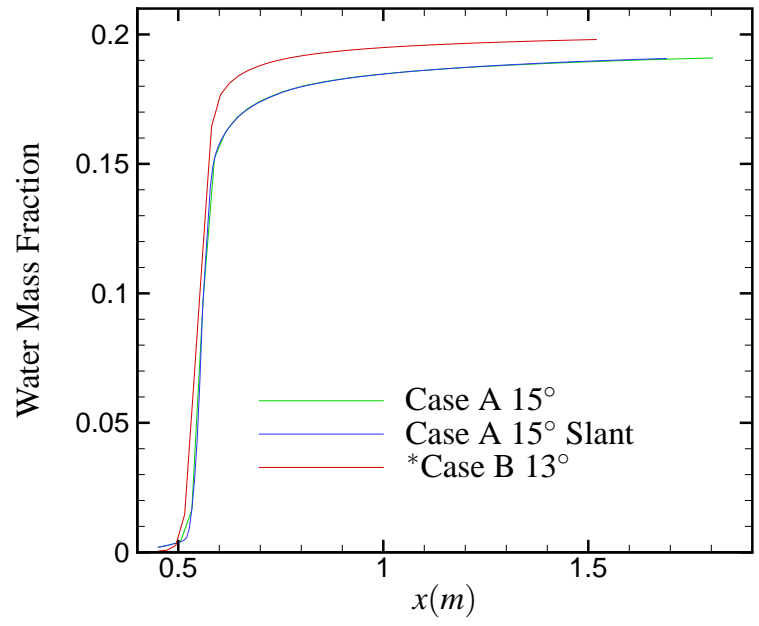

(b) Water Mass Fraction Comparison

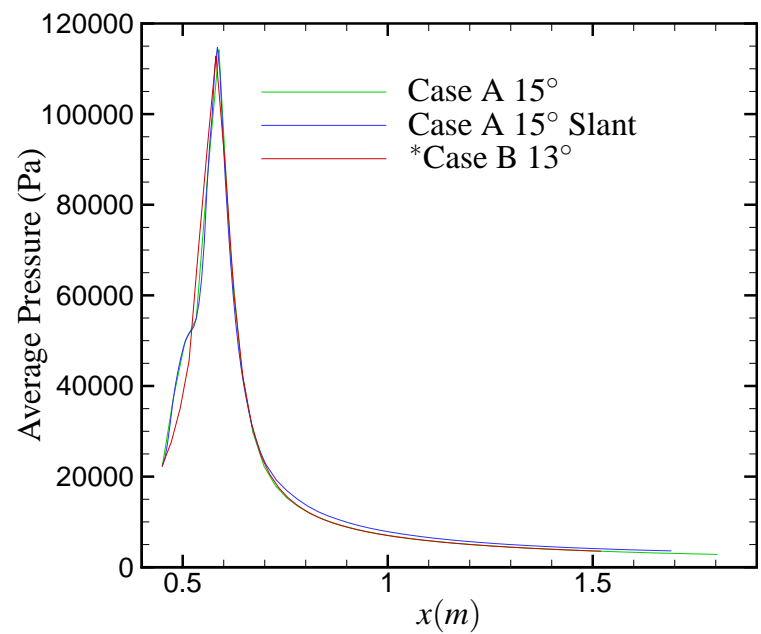

(d) Average Pressure Comparison

FIgURE 7.18: Nozzle flowfield properties comparison ( ${ }^{*}$ Case B shifted in $x$ to start with Case A) 


\subsubsection{Chosen Case}

With the chosen inner nozzle case (Case A $15^{\circ}$ slant), the full nozzle is simulated up to the end of the nozzle body wall in the x-direction (Regions 2 and 3 in Fig.7.13). The flow below the cowl and above the body top is simulated as well. These regions can be simulated in two dimensions except when the flow below the cowl comes in contact with the three dimensional flow from the inner nozzle (Region 3 in Fig.7.13). Solving this region allows us to find the exit area at the end of the nozzle. However, this region does not need to be solved in order to calculate the flight performance of the vehicle as the vehicle surfaces are contained in the remaining regions (ie. Region 2 can be solved with an outflow condition at the lower boundary). The region where the flow from the body top meets with the inner nozzle flow is not solved (ie. region behind the end of the nozzle). In reality, there may be a small recirculation region at the end of the body top from when the high pressure inner flow meets the low pressure outer flow. However this effect is extremely small and is not worth simulating.

\subsubsection{Cowl Length Optimization}

After the full nozzle has been simulated, an additional optimization can be performed with little effort. Currently the nozzle walls have been reduced to $95-98 \%$ of the thrust. The body nozzle wall ends flush with the inlet tip however the cowl nozzle wall extends into the air causing drag. Reducing the length of the cowl has the possibility of increasing the overall vehicle performance. With the full nozzle wall simulated, the pressure and friction forces required to determine the overall thrust can be generated on the inner nozzle cowl wall. Therefore the thrust generated by a shorter cowl wall is known. The outer cowl flow is two dimensional and can be simulated quickly for different cowl lengths. In the current case, various cowl lengths were tested and the optimum case resulted in a cowl nozzle wall that is reduced to $87 \%$ of the thrust $(30 \%$ shorter than the original reduced cowl), shown in Fig.7.19. This increased the total $I_{s p}$ from $1090 s$ to $1110 s$, shown in Table A.1. This is a $2 \%$ increase in $I_{s p}$ from a slight modification. The optimized cowl has also been performed on the Case A: $15^{\circ}$ vert., and has increased the $I_{s p}$ from $1006 s$ to $1050 s$, a $4 \%$ increase. 


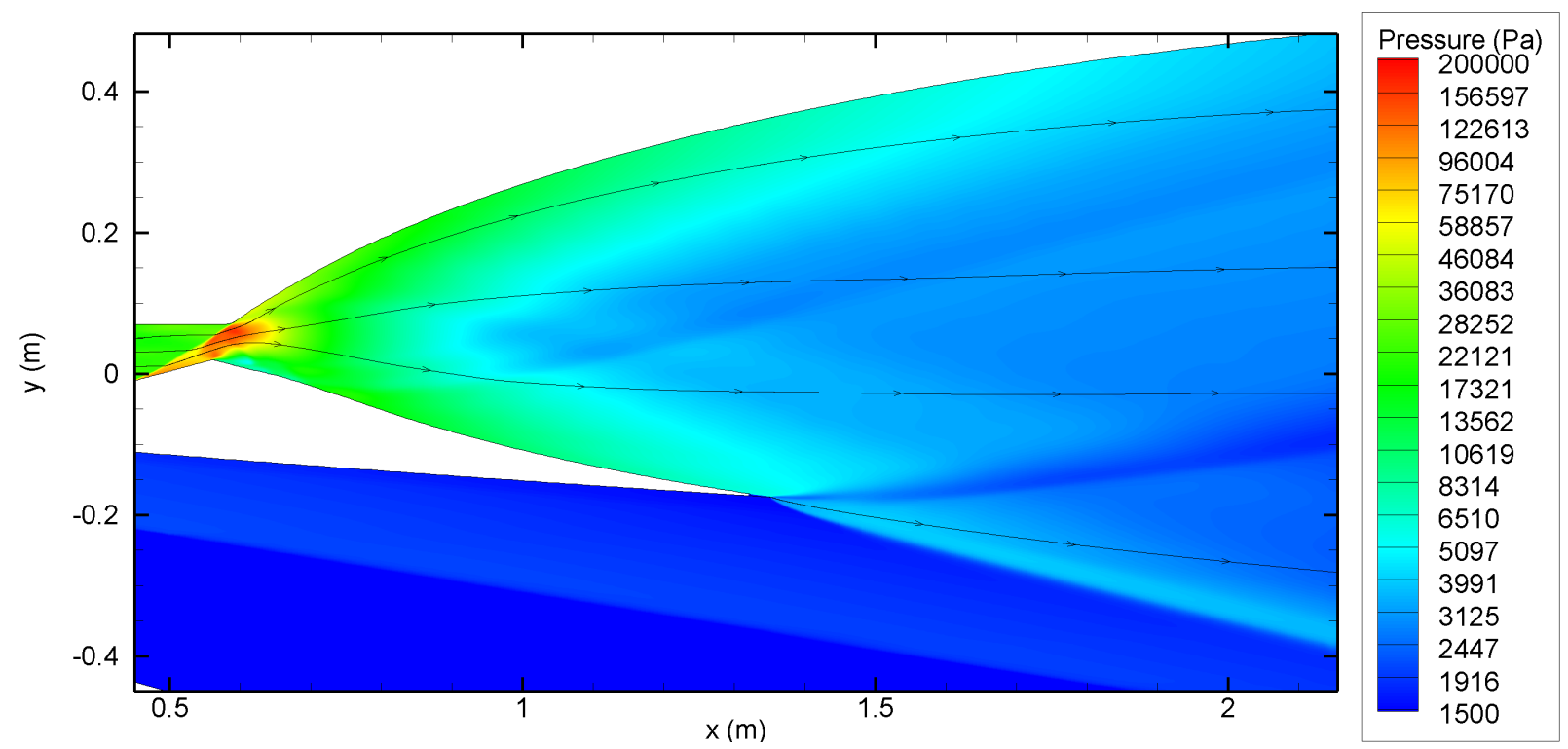

FIGURE 7.19: Case A $15^{\circ}$ slant nozzle pressure flowfield with optimized cowl

\subsection{Final Vehicle Configuration}

After the nozzle simulation is complete, all components of the vehicle have been simulated. Final thrust and specific impulse values can be generated as well, shown in Tables A.1 and A.2. With the final geometry chosen, the temperature flowfield is shown in Fig.7.20. 


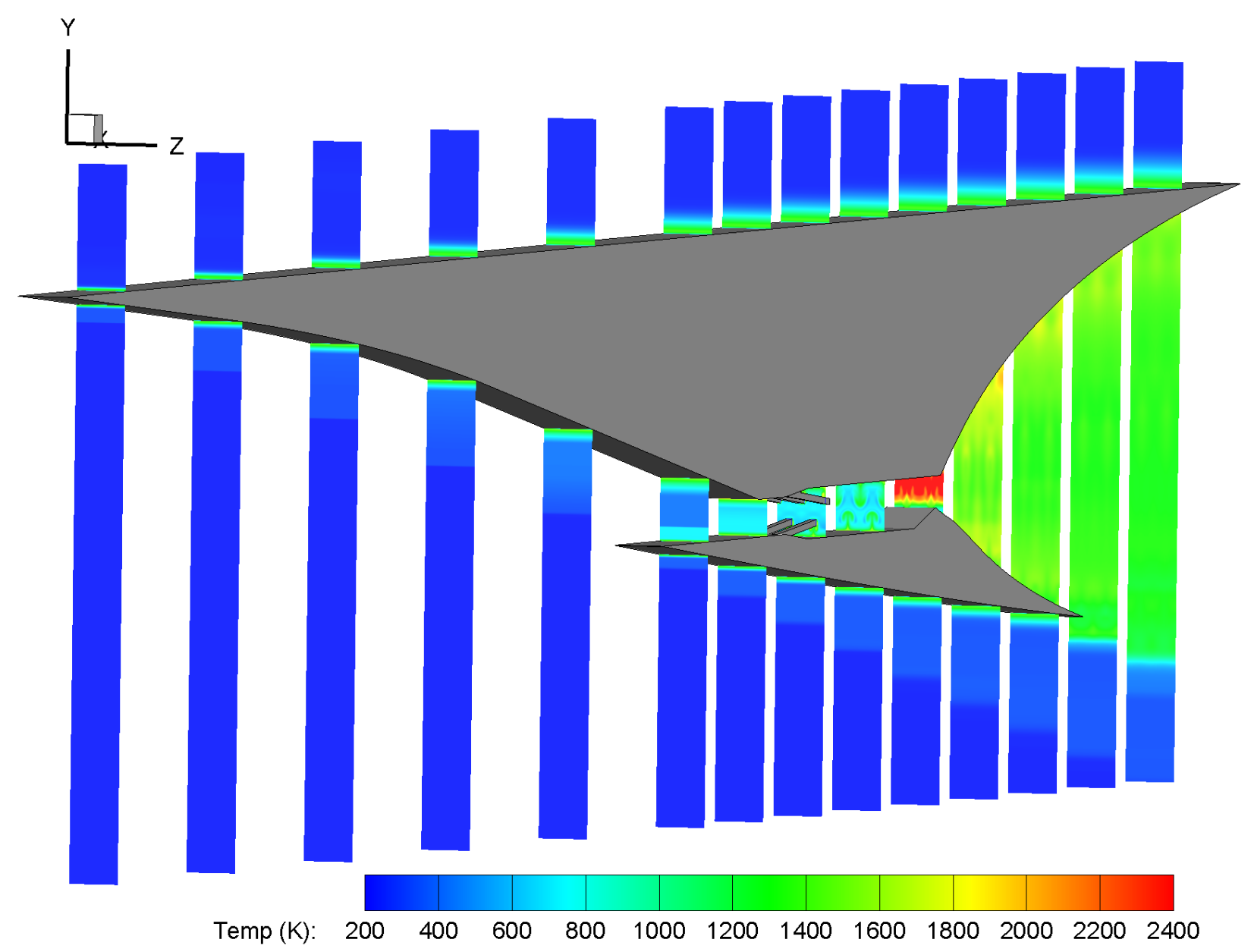

FIGURE 7.20: Full shcramjet vehicle temperature flowfield 


\section{Chapter}

\section{COMPARISON WITH SCRAMJET}

In this chapter, the overall performance of the shcramjet vehicle will be assessed. The performance parameters being used are described in Section .3.1. The comparison uses the optimal shcramjet configuration (Case A: $T=309 K 15^{\circ}$ slant, optimized cowl). This shcramjet will then be compared with a scramjet vehicle that is specifically designed for this comparison.

\subsection{Scramjet Configuration}

In this section, the design of the scramjet vehicle will be explained. For most components, the design procedure follows those previously mentionned for the shcramjet vehicle.

\subsubsection{Inlet}

The inlet for the scramjet has been designed in the same manner as the shcramjet as described in Section 4.1. The main difference is the inlet exit flow temperature. The choice of the inlet exit temperature, or burner entry flow temperature, for the scramjet is limited by material and air dissociation temperature considerations with no concern of premature ignition as in the shcramjet. The scramjet's inlet exit flow temperature is herein set to $1500 \mathrm{~K}$ as opposed to $800 \mathrm{~K}$ for the shcramjet. This results in using higher inlet angles (8 and $16.7 \mathrm{deg}$ ) compared to the shcramjet (4 and $8.7 \mathrm{deg}$ ), following Fig.4.2. 


\subsubsection{Injectors}

The fuel injectors used in the scramjet vehicle were the same cantilevered ramp fuel injectors as described in Section 5.1. Although other fuel injection systems could be more appropriate for a scramjet engine, for purposes of the present comparative analysis, they are employed in the scramjet engine as well. Fuel injector geometries are shown in Fig.8.1, and the fuel inflow properties for both the scramjet and shock-induced combustion ramjet are given in Table 8.1. The shcramjet has longer and taller injectors to deposit the fuel in the center of the air stream and to avoid premature ignition caused by fuel entering the hot boundary layers. While similar injectors are used for the scramjet, they are shorter as there is no requirement to avoid ignition. The injectors protrude less into the flow and are positioned in the center of the lower or upper half of the duct to maximize mixing with equal amounts of air above and below the fuel.

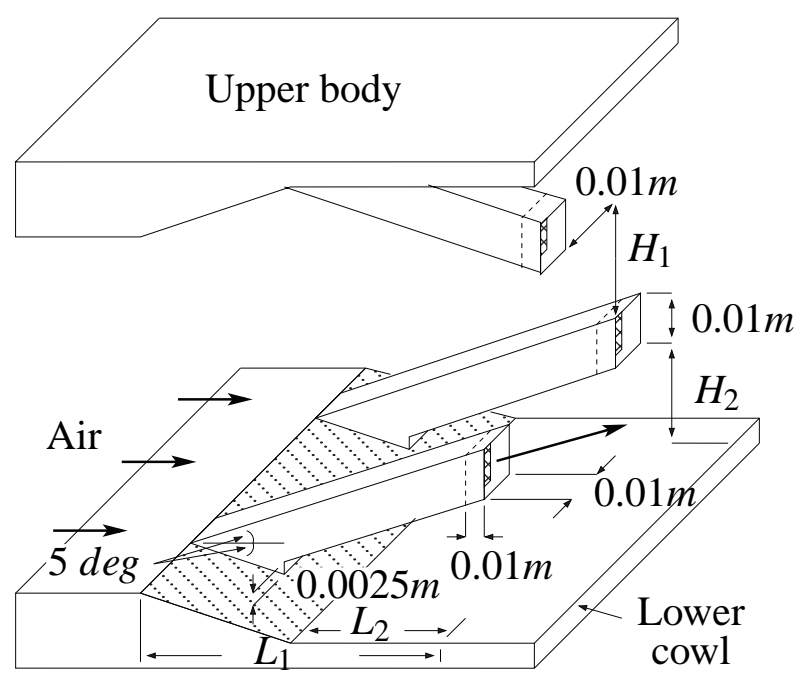

(a) Isometric view

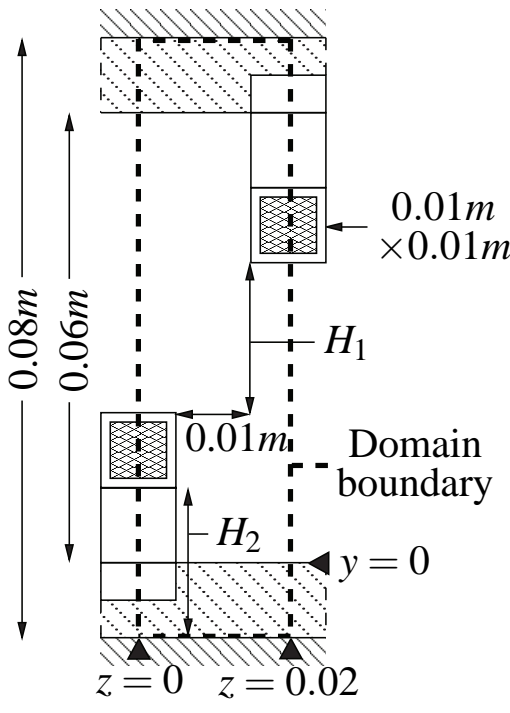

(b) $y-z$ domain

FIGURE 8.1: General cantilevered ramp injector array geometry

\subsubsection{Combustor}

The combustor is the main difference between the two vehicles and will have different geometries. The shcramjet vehicle used a wedge to produce shock-induced combustion. The combustor for the scramjet engine is simply a constant area duct for diffusive burning. The same cross-sectional area has been used for the shcramjet mixing duct. The length of the combustor will be determined by the thrust potential. The streamwise location for the end of the scramjet combustor is chosen as the 
TABLE 8.1: Fuel injection parameters

\begin{tabular}{|l|c|c|}
\hline Vehicle & Scramjet & Shcramjet \\
\hline$L_{1}(\mathrm{~m})$ & 0.169 & 0.226 \\
\hline$L_{2}(\mathrm{~m})$ & 0.057 & 0.111 \\
\hline$H_{1}(\mathrm{~m})$ & 0.015 & 0.02 \\
\hline$H_{2}(\mathrm{~m})$ & 0.03 & 0.02 \\
\hline Fuel velocity $(\mathrm{m} / \mathrm{s})$ & 5652 & 6229 \\
\hline Fuel temperature $(\mathrm{K})$ & 561 & 309 \\
\hline Fuel pressure $(\mathrm{Pa})$ & 95000 & 18000 \\
\hline Fuel Mach number & 3.156 & 4.657 \\
\hline Convective Mach number & 1.04 & 1.05 \\
\hline Fuel/air equivalence ratio & 1.0 & 1.0 \\
\hline Fuel stagnation temperature $(\mathrm{K})$ & 1620 & 1660 \\
\hline Fuel stagnation pressure $(\mathrm{Pa})$ & 4000000 & 6200000 \\
\hline
\end{tabular}

location where the thrust potential reaches a maximum, indicating the momentum addition from the combustion process is being overwhelmed by the friction in the duct. At this point the walls will be expanded into the nozzle.

\subsubsection{Nozzle}

The nozzle component for the two vehicles differs slightly in their wall contour generation method. In the shcramjet, the upward flow from the combustor generated a small cowl when using the dualwall method. In the scramjet, the flow from the combustor is exiting straight out. Therefore for the scramjet, the false-wall technique ${ }^{29}$ is used, which reduces the size of the cowl for straight flows.

\subsubsection{False-Wall Method}

This method is similar to the dual-wall method used for the shcramjet described in Section 7.1.2. This method has been created for the use of hypersonic vehicles in which a major concern of the nozzle design is to reduce the amount of drag from the outer vehicle geometry. As mentioned earlier, many compression systems will bring the flow to the lower region of the cross sectional area. While the flow exiting the combustor has room to expand upwards without causing additional drag, the flow expanding below will cause significant amounts of drag. With the straight flow exiting the scramjet combustor, the dual-wall method would result in a symmetric nozzle, shown in Fig.7.11(a). The false-wall method addresses this issue by constricting the expansion on the lower side.

The process of designing the walls begins with a larger imaginary nozzle generated using the 


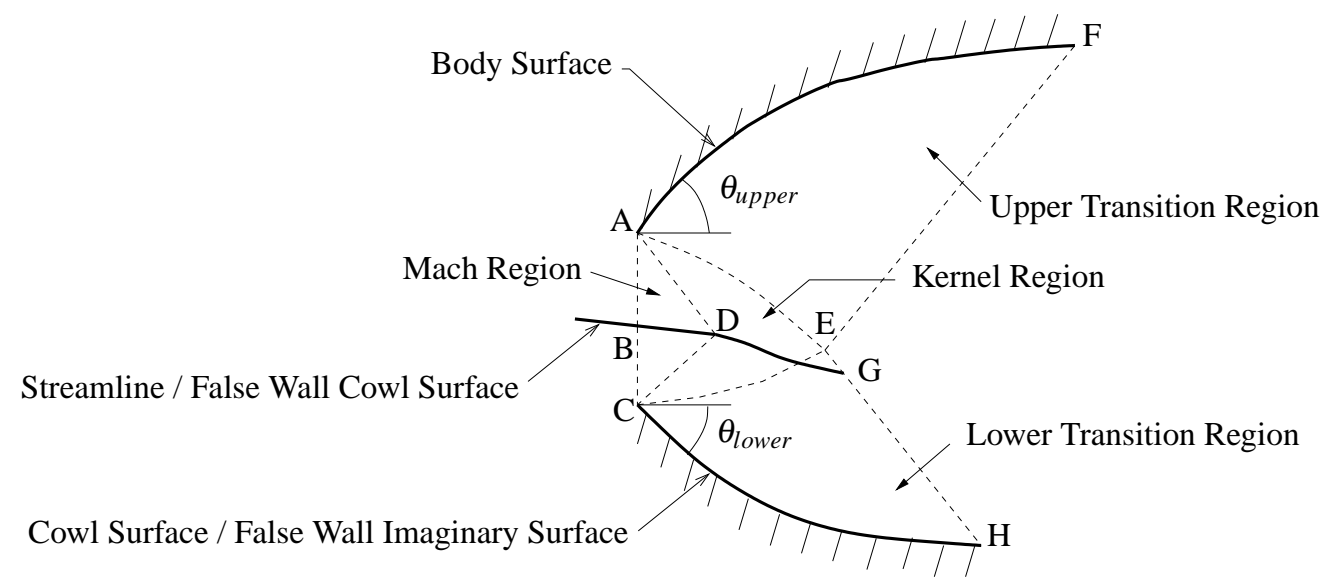

FIGURE 8.2: Schematic of nozzle design

dual-wall method, shown in Fig.8.2. This imaginary dual-wall method nozzle is constructed using an initial data line that is larger than the required data line. The top portion of the initial data line $(\mathrm{AB})$ will use the properties of the required data line while the bottom portion $(\mathrm{BC})$ can be initialized to any chosen properties. The length of the bottom portion (BC) and its flow properties can be varied and will affect the walls created using this method. Currently a line length equal to the top portion $(\mathrm{AB})$ is used and its properties are set equal to the lowest node in the upper portion. Using this initial data line, the dual wall method is used to generate the nozzle walls. From here, the streamline in this nozzle flow that begins at point B is chosen. The path of the streamline can now be used as the new cowl wall while retaining all the flow characteristics in the region ABGF, according to inviscid theory. Accordingly, the thrust generated on the body wall will theoretically be the same, however the cowl wall thrust will be reduced in exchange for a less protruding cowl wall. The limit of this process would be cutting a symmetrical nozzle in half and having a straight line cowl that would produce no thrust nor any drag on its outer surface.

The iterative procedure used in the shcramjet will be used here as well with the false wall method instead of the dual wall method. The MOC generated walls will be cut to $95 \%$ of their thrust for both the body and cowl walls and Edenfield's boundary layer growth correction terms will be used. The initial data line used for the scramjet is a vertical line at the end of the combustor shown in Fig.8.3. 


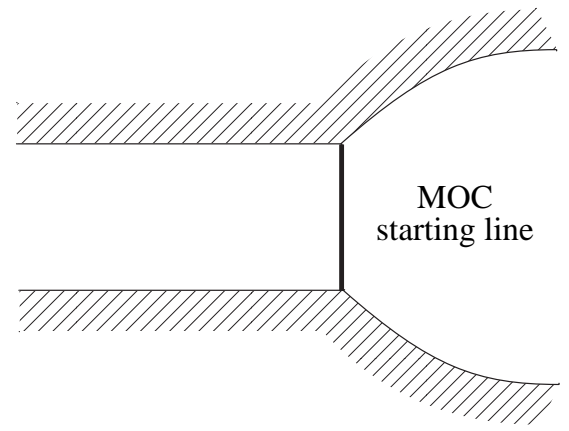

(a) Scramjet Nozzle

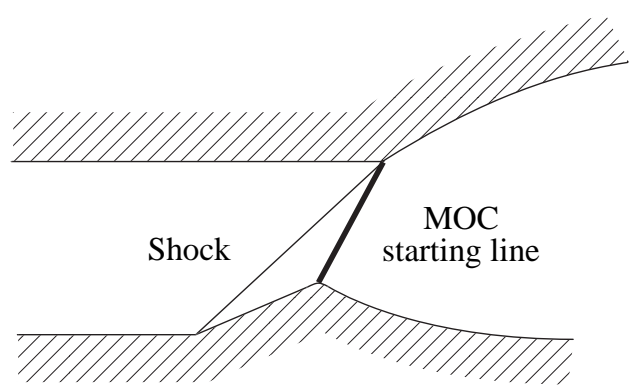

(b) Shcramjet Nozzle

FIGURE 8.3: Starting line of the nozzle expansion process

\subsection{Component Comparison}

In this section, the scramjet and the optimal shcramjet configuration will be compared component by component.

\subsubsection{Inlet}

The inlet flowfields from the scramjet vehicle is shown in Figs.8.4 and 8.5 and can be compared with the shcramjet inlet flowfields shown in Figs.4.3 and 4.4. The resulting inlet sizes and magnitudes of flow variables at the exit of the inlet for both vehicles are summarized in Table 8.2. Due to the higher exit temperature of the scramjet inlet and keeping the same exit area, the scramjet inlet is much larger than the shcramjet inlet. The compression ratio for the scramjet is 173 while the shcramjet is only 31 . Also the air mass flow rate for the scramjet is 2.64 times that of the shcramjet. Axial velocity distributions at the inlet exit, shown in Fig.8.6(a), exhibit a fairly uniform flow with boundary layer thicknesses of the order of $14.4 \mathrm{~mm}$ and $8.3 \mathrm{~mm}$ for the scramjet and 10.0 $\mathrm{mm}$ and $6.7 \mathrm{~mm}$ for the shcramjet for the upper and lower duct walls, respectively. The maximum temperatures found in the boundary layers are $2300 \mathrm{~K}$ and $2000 \mathrm{~K}$ for the scramjet and shcramjet, respectively. This temperature is high enough to dissociate oxygen but the amounts produced are negligible. The losses incurred by the inlet flow due to shocks and frictional forces on the internal walls are quantified by the concept of thrust potential. Figure 8.6(b) depicts their evolution for both engines. The scramjet inlet incurs more losses as it compresses the flow more than the shcramjet inlet. The majority of the compression is entropic and the losses are taken into account in the thrust potential. 


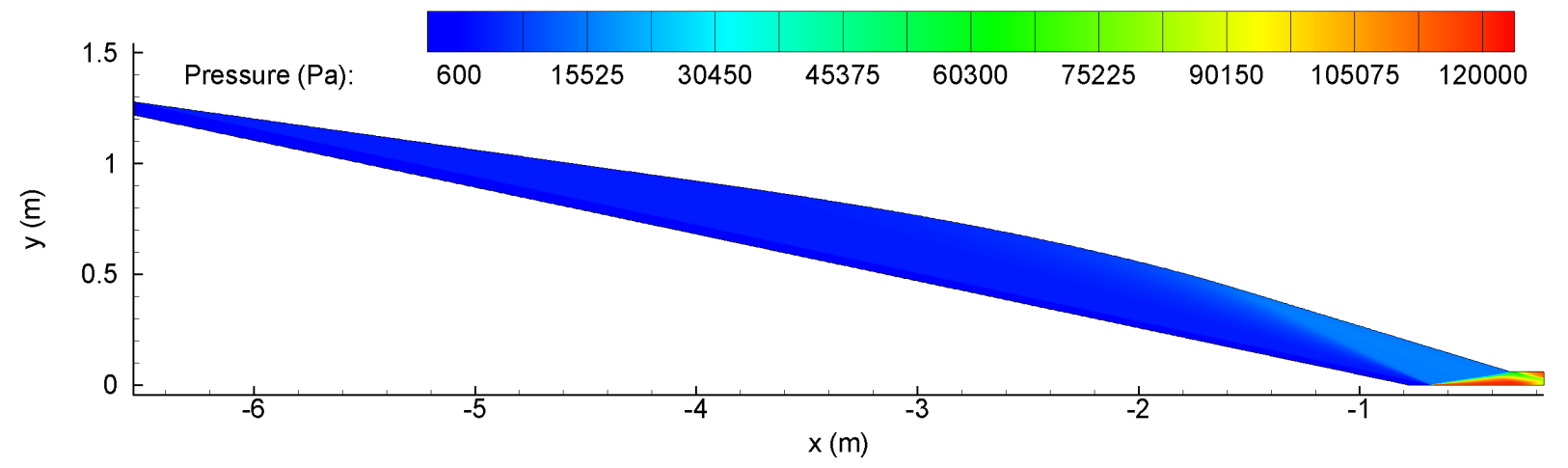

FIGURE 8.4: Scramjet inlet pressure flowfield

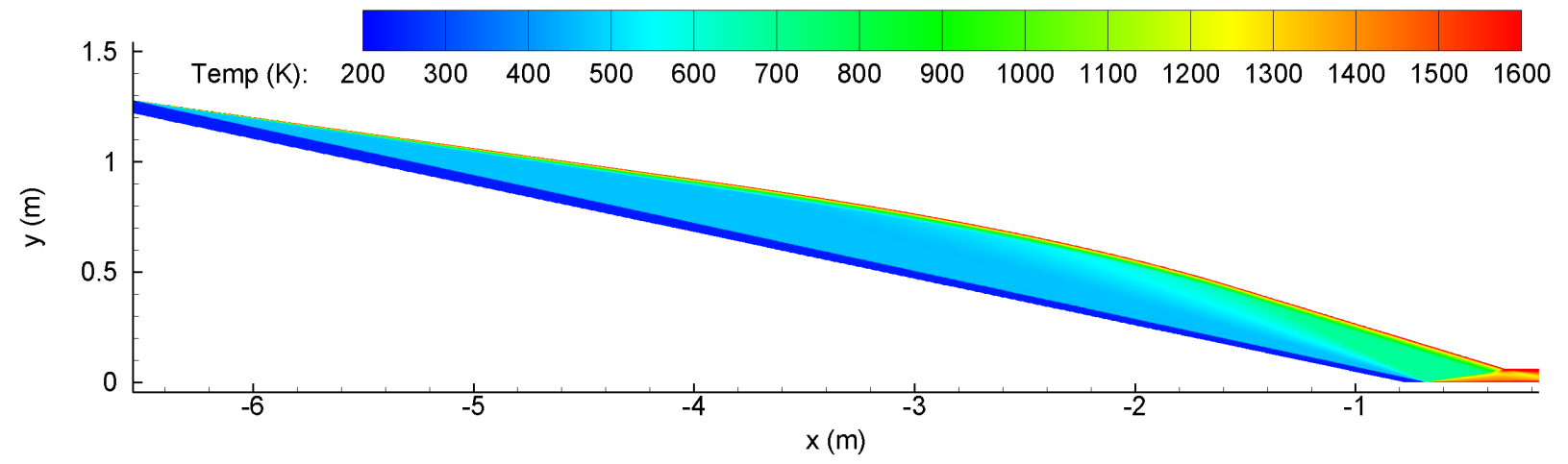

FIGURE 8.5: Scramjet inlet temperature flowfield

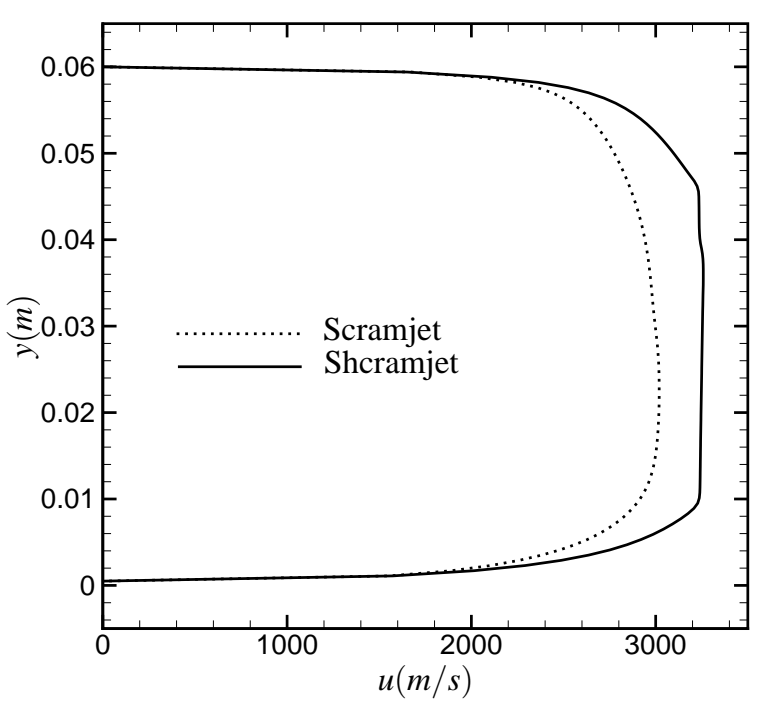

(a) Inlet Exit Velocity Profiles

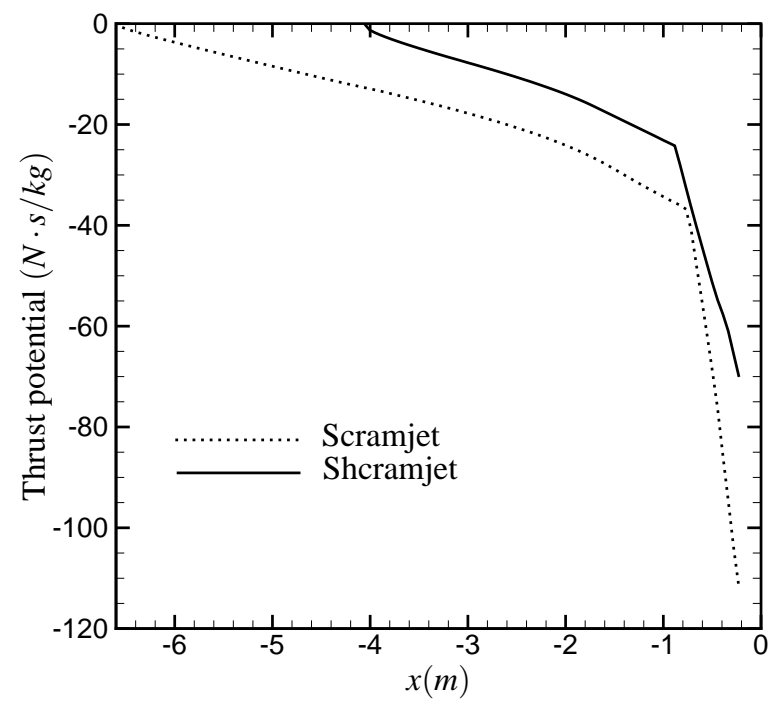

(b) Thrust Potential Losses in the Inlet

FIGURE 8.6: Inlet performance

\subsubsection{Combustor}

The scramjet combustor flowfields are shown in Figs.8.8 and 8.9 and can be compared with the shcramjet combustor shown in Figs.6.1 and 6.2. The Mach number flowfield and the Mach number 
TABLE 8.2: Inlet flow properties comparison

\begin{tabular}{|l|c|c|}
\hline & Scramjet & Shcramjet \\
\hline Air Intake Height $(\mathrm{m})$ & 1.278 & 0.484 \\
\hline Inlet Length $(\mathrm{m})$ & 6.375 & 3.834 \\
\hline Exit Height $(\mathrm{m})$ & 0.0595 & 0.0595 \\
\hline Contraction Ratio $\left(\mathrm{A}_{3} / \mathrm{A}_{0}\right)$ & 21.48 & 8.14 \\
\hline Air Mass Flow rate $\mathrm{kg} / \mathrm{s})$ & 0.770 & 0.292 \\
\hline Stoich Fuel Mass Flow Rate $\mathrm{kg} / \mathrm{s})$ & 0.02261 & 0.008798 \\
\hline Inlet Exit Pressure $(\mathrm{Pa})$ & 105000 & 18500 \\
\hline Inlet Exit Temperature $(\mathrm{K})$ & 1450 & 800 \\
\hline Inlet Exit Mach number & 3.72 & 5.58 \\
\hline Inlet Compression Ratio $\left(\mathrm{P}_{3} / \mathrm{P}_{0}\right)$ & 172.58 & 30.98 \\
\hline Exit thrust potential $(\mathrm{N} \cdot \mathrm{s} / \mathrm{kg})$ & -111.90 & -70.07 \\
\hline
\end{tabular}

of the normal component to the shock for the shcramjet combustor is shown in Fig.8.7. It can be seen that the normal component's Mach number is below 1 while the absolute Mach number is above 1, meaning it is an over-driven detonation wave. For the scramjet, no flameholding device is employed in the combustor. Rather the diffusive burning process of the stoichiometrically injected hydrogen is assumed to take place spontaneously at the thermogasdynamic conditions prevailing in the vicinity of the fuel injection region. The ignition delay is $0.02 \mathrm{~m}$ downstream of the injection point as seen in Fig.8.9. The combustor in these figures has been simulated to nearly $1 \mathrm{~m}$ in length but will be sized appropriately based on its thrust potential analysis. It can be seen in Fig.8.10, that the fuel is mixing and burning simultaneously. When it is first injected, the fuel/air interface burns first and then spreads to the center of the fuel injection. Approximately $0.5 \mathrm{~m}$ into the combustor, there is not much more combustion but the water mixes towards the walls of the duct.

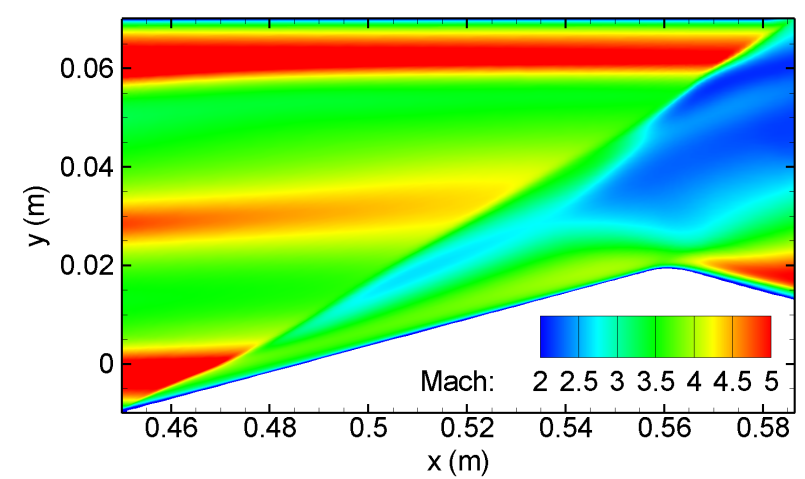

(a) Mach Number

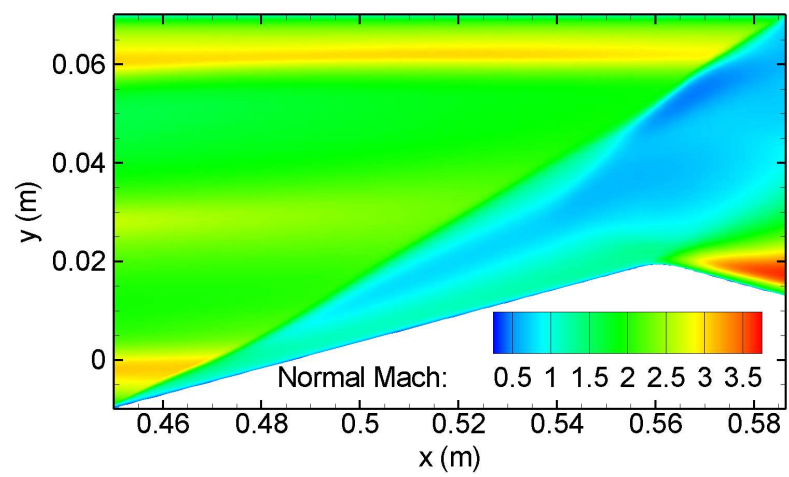

(b) Mach Number of Normal Component to Shock

FIGURE 8.7: Shcramjet combustor Mach number flowfields at $z=0.01 \mathrm{~m}$

The corresponding variation of flow properties in the scramjet combustor and shcramjet mix- 


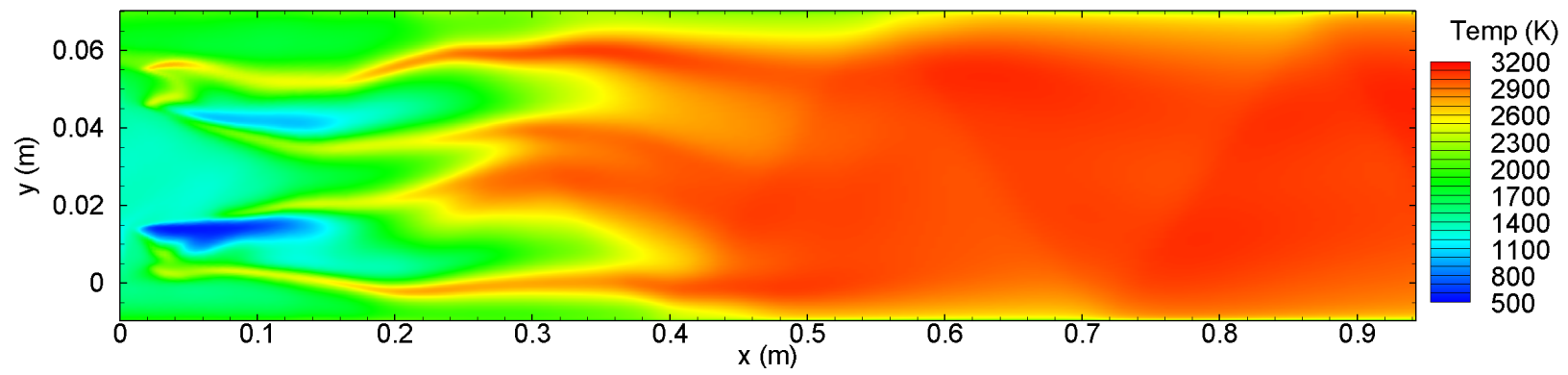

FIGURE 8.8: Temperature contour plots at $z=0.01 \mathrm{~m}$ in the scramjet combustor

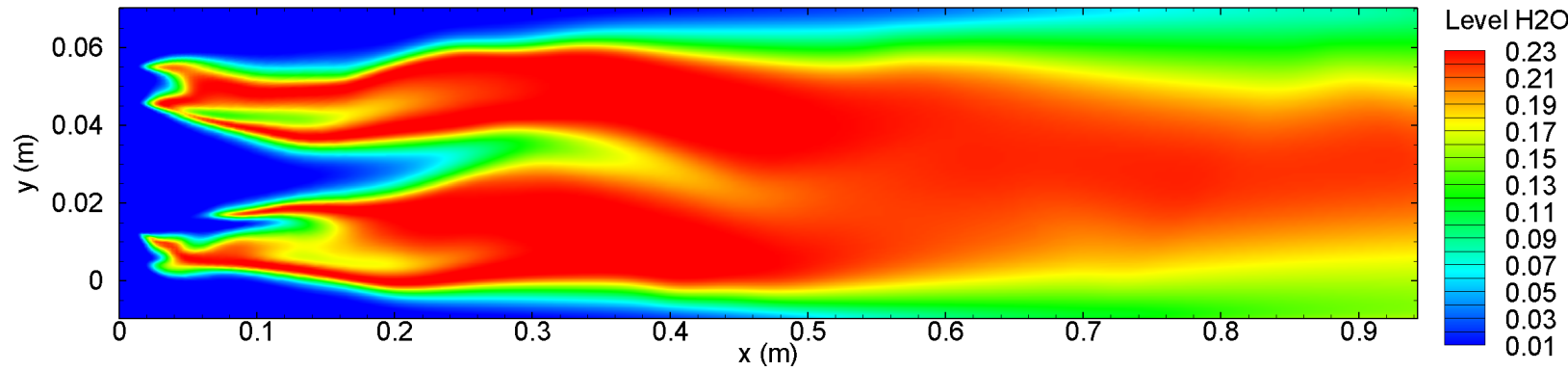

FIGURE 8.9: $\mathrm{H}_{2} \mathrm{O}$ mass fraction contour plots at $z=0.01 \mathrm{~m}$ in the scramjet combustor

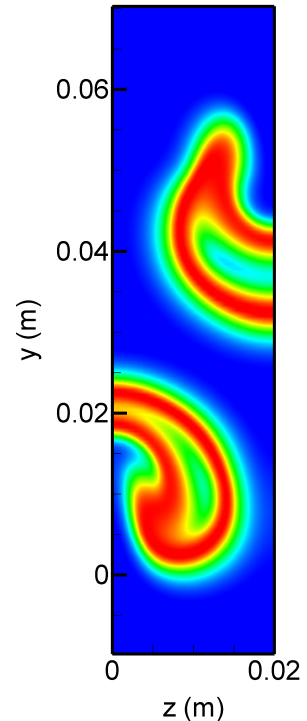

(a) $x=0.136 \mathrm{~m}$

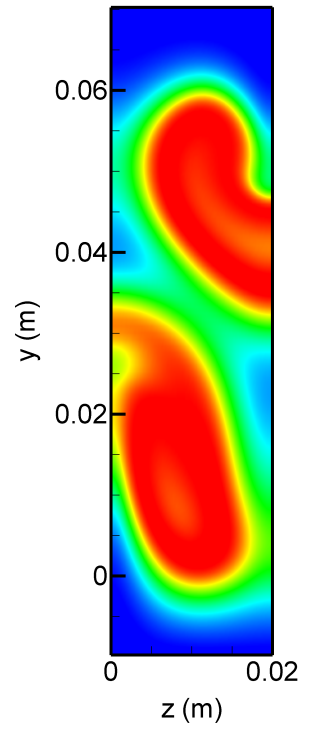

(b) $x=0.271 \mathrm{~m}$

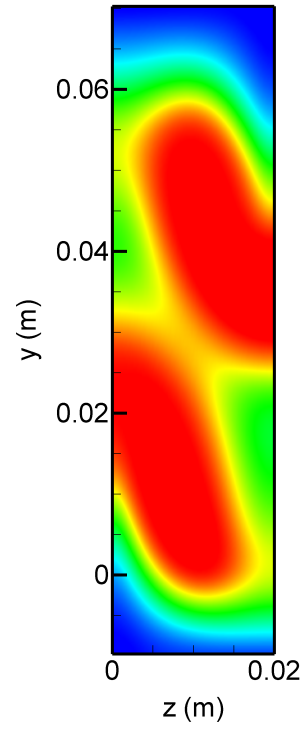

(c) $x=0.407 \mathrm{~m}$

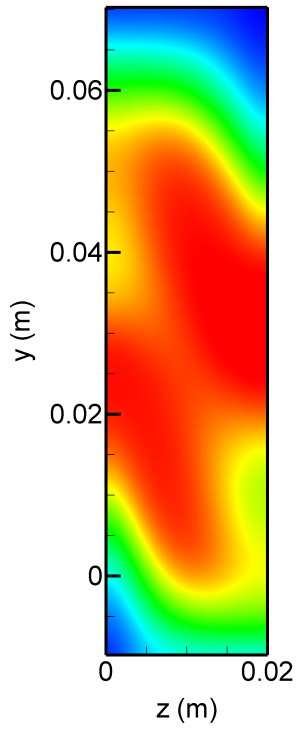

(d) $x=0.543 m$

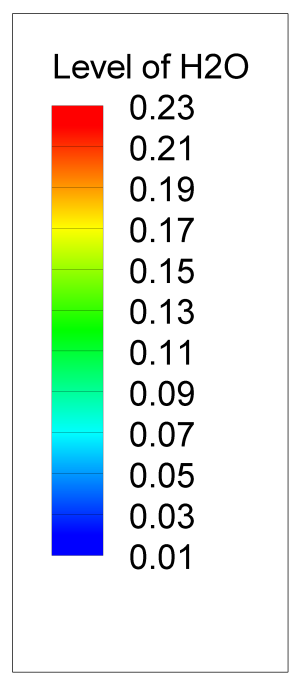

(e)

FIGURE 8.10: Water mass fraction contours in the scramjet combustor

ing duct/combustor are depicted in Fig.8.11. The scramjet combustor is plotted until $x=0.95 \mathrm{~m}$ although it will be cut shorter based on the thrust potential analysis. The mixing duct region for the shcramjet is also plotted such that both vehicles' flow properties begin after fuel injection. The shcramjet combustor flow is plotted until the $x$ location where the shock reaches the body wall.

The evolution of the thrust potential, $\mathscr{F}_{\text {pot }}$, is shown in Fig.8.11(a). The sharp increase in $\mathscr{F}_{\text {pot }}$ at the fuel exit plane, $x=0 \mathrm{~m}$, is due to the momentum of the injected hydrogen. For the 
TABLE 8.3: Combustor flow properties comparison

\begin{tabular}{|l|c|c|}
\hline & Scramjet & Shcramjet \\
\hline Combustor Height $(m)$ & 0.08 & 0.08 \\
\hline Combustor Length $(m)$ & 0.54 & 0.11 \\
\hline Amount of Fuel Burned $(\%)$ & 75.0 & 70.5 \\
\hline Temperature $(\mathrm{K})$ & 2880 & 2280 \\
\hline Pressure $(\mathrm{Pa})$ & 218000 & 115000 \\
\hline Friction Drag $(\mathrm{N})$ & 86.1 & 6.4 \\
\hline Pressure Drag $(\mathrm{N})$ & 0.2 & 54.5 \\
\hline
\end{tabular}

scramjet combustor, the $\mathscr{F}_{\text {pot }}$ is found to increase and then reach a maximum near $x=0.45 \mathrm{~m}$ which corresponds to the point where the gain due to combustion is overcome by mixing and frictional losses in the duct. The combustor was instead cut to $x=0.54 \mathrm{~m}$ but the difference in $\mathscr{F}_{\text {pot }}$ is small. Looking at the shcramjet mixing duct, the $\mathscr{F}_{\text {pot }}$ is decreasing due to friction and mixing losses. However the rate of decrease should be higher but the slight diffusive burning in the mixing duct offsets the losses. In the combustor region, the $\mathscr{F}_{\text {pot }}$ decreases rapidly due to the losses from the shock. After the induction distance, the combustion quickly raises the $\mathscr{F}_{\text {pot }}$ to a value near the scramjet.

Looking at the $\mathrm{H}_{2}$ and $\mathrm{H}_{2} \mathrm{O}$ levels in Figs.8.11(b) and 8.11(c), it can be seen that the shcramjet burns the fuel in a short distance whereas the scramjet burns it over a longer distance. However, the scramjet burns a larger percentage of the fuel injected. Finally in Fig.8.11(d), the average pressures in the $x$ planes are compared and the scramjet has a much higher value. However, this is slightly misleading as the average pressure along the $x$ planes in the shcramjet combustor always encompasses either unburned fuel regions or expanded flow regions as the nozzle expansion on the cowl side begins before the shock hits the body wall, completing the combustion process. However, taking this effect into account would still yield a much lower pressure in the shcramjet engine and this ultimately has an effect on the overall vehicle performance.

The combustor geometrical and flow properties are summarized in Table 8.3. Of particular interest is the difference in lengths of the combustor.

\subsubsection{Scramjet No Burning}

The scramjet combustor was resimulated without the chemical kinetics model activated. This was done to observe the mixing performance of the fuel injection in the scramjet combustor which cannot be measured when there is combustion. The mixing efficiency of this non-combusting 


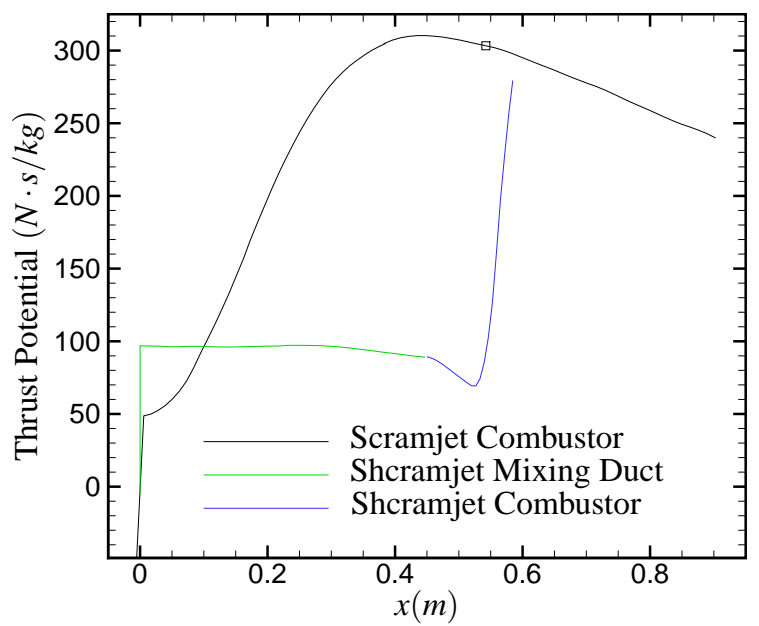

(a) Thrust Potential Comparison

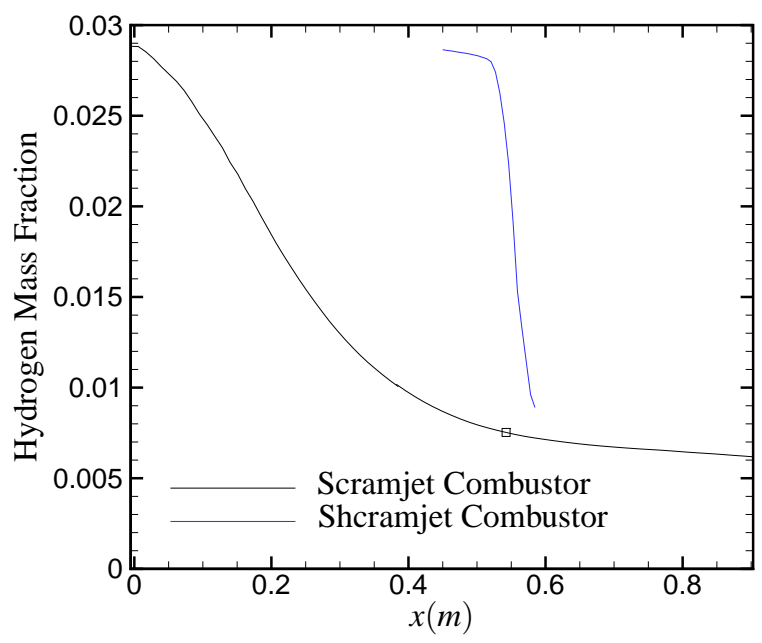

(c) Hydrogen Mass Fraction Comparison

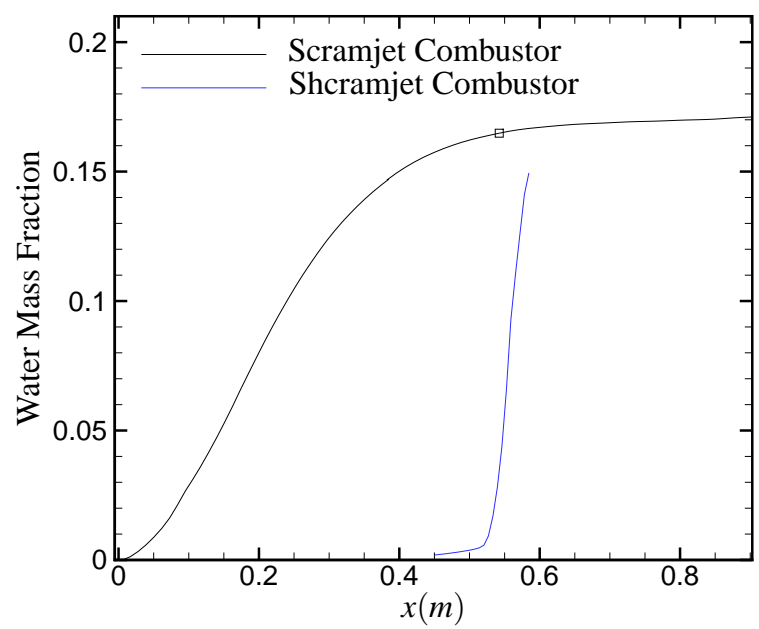

(b) Water Mass Fraction Comparison

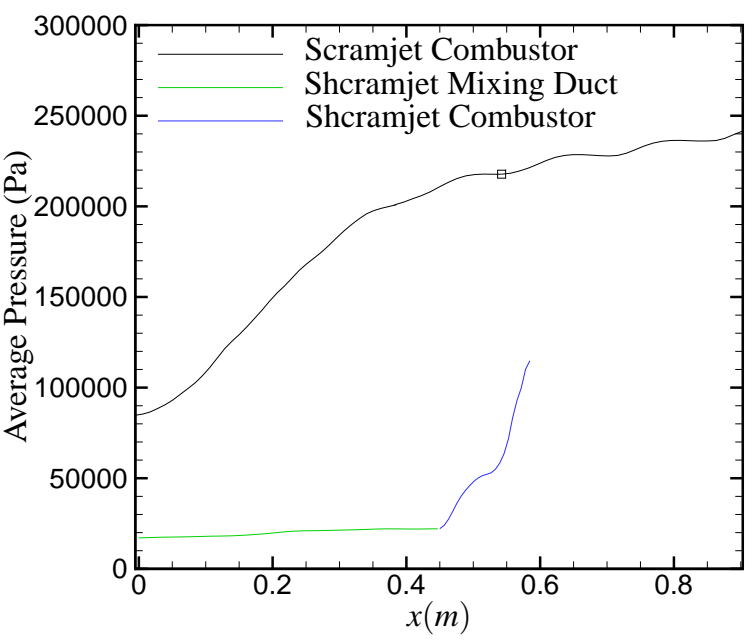

(d) Average Pressure Comparison

FIGURE 8.11: Combustor flowfield properties comparison

scramjet (the combustor becomes a mixing duct) is compared with the mixing duct in the shcramjet, shown in Fig.8.12. It can be seen that the scramjet case mixes much faster than the shcramjet case. This is mainly due to the higher pressures found in the scramjet (95000 $\mathrm{Pa}$ in the scramjet and $18000 \mathrm{~Pa}$ in the shcramjet). This confirms that the injector design used is a valid mixing mechanism for the scramjet engine. The shcramjet mixing duct has slight burning begining near $x=0.45 \mathrm{~m}$, which can be seen in Fig.5.3, and decreases the mixing efficiency. Therefore the mixing efficiency is no longer accurate past $x=0.45 \mathrm{~m}$. 


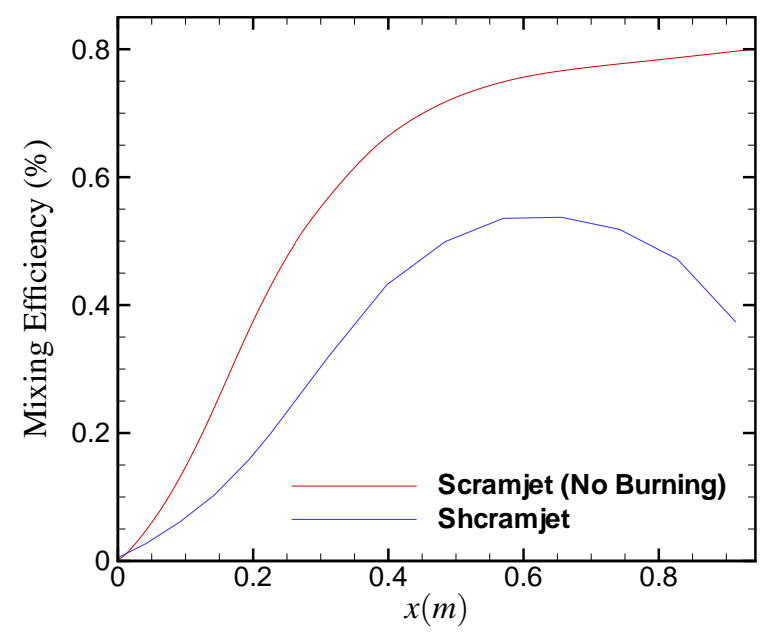

FIGURE 8.12: Scramjet (no burning) vs shcramjet mixing efficiency

\subsubsection{Nozzle}

The nozzle flowfields for the scramjet and shcramjet are shown in Figs.8.13 and 8.14. Due to significant pressure differences between the inner flow and the flow outside the cowl, a shock and expansion wave are formed at the trailing edge of the cowl. The mass flow through the interior of the engines reside above the shear layer originating from the end of the cowl, represented by the streamlines in the pressure flowfields, shown in Figs.8.16 and 8.17. For the shock-induced combustion ramjet, this flow covers a height of $0.77 \mathrm{~m}$ by the end of the engine, which is $58 \%$ larger than the inlet airflow capture height. In the scramjet, the flow through the interior of the engine covers a height of $1.77 \mathrm{~m}$ at the end of the nozzle, $38 \%$ larger than the inlet airflow capture height.

Looking at the $\mathrm{H}_{2} \mathrm{O}$ and $\mathrm{H}_{2}$ levels in both vehicles, it can be seen that diffusive combustion continues in the nozzles. For the scramjet nozzle, the remaining $\mathrm{H}_{2}$ level goes from $25.0 \%$ to $16.6 \%$ and for the shcramjet nozzle, the remaining $H_{2}$ level goes from $29.5 \%$ to $15.5 \%$.

For the shock-induced combustion ramjet, the Mach number at the nozzle exit is approximately 4.42 and the average nozzle exit velocity is $3498 \mathrm{~m} / \mathrm{s}$. Since the nozzle was truncated in length, the exit plane flow is not parallel to the $x$ axis, but expands outwards with angles ranging from -5.3 to $5.7 \mathrm{deg}$. In the scramjet, the exit Mach number is approximately 4.35 , the average nozzle exit velocity is $3503 \mathrm{~m} / \mathrm{s}$, and the flow expands outwards with angles ranging from -4.4 to $8.3 \mathrm{deg}$.

In the nozzle, combustion continues diffusively at the fuel/air interface as a large portion of the fuel is not burned in the combustor. Additionally, due to expansion in the nozzle, the chemical kinetics are driven by the new chemical equilibrium at the lower temperatures and pressures. Vari- 


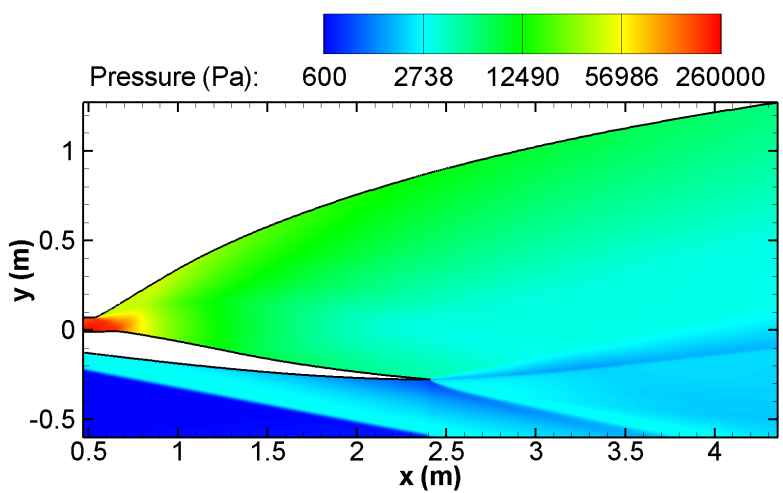

(a) Pressure Flowfield

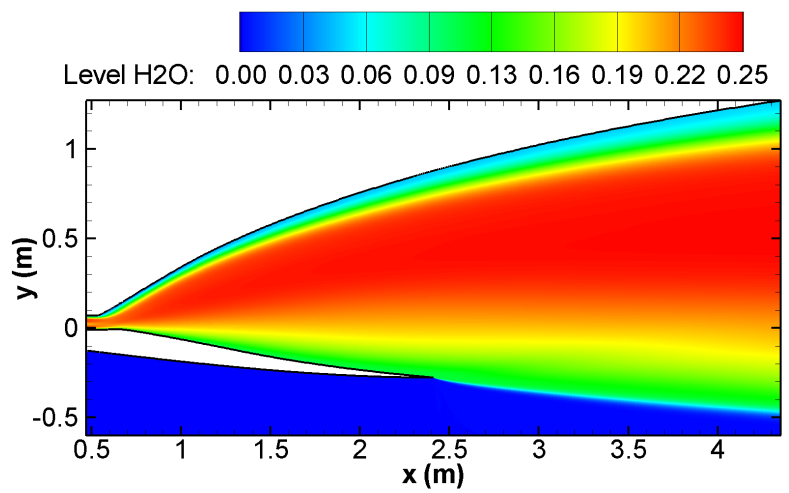

(c) Water Mass Fraction

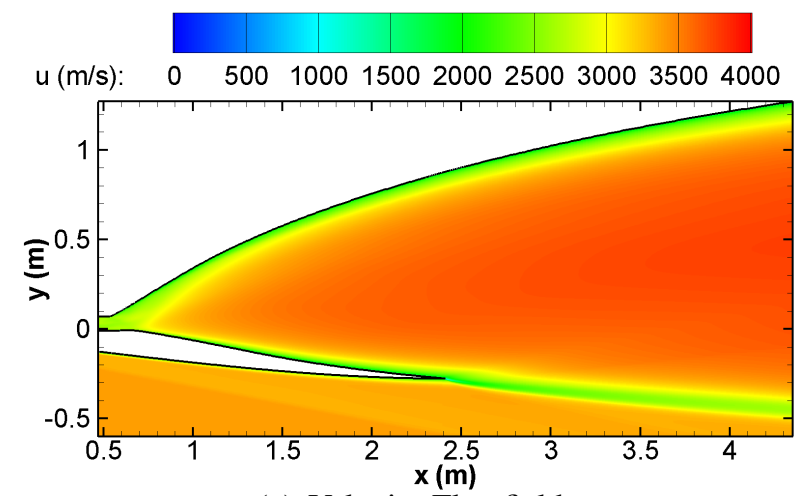

(e) Velocity Flowfield

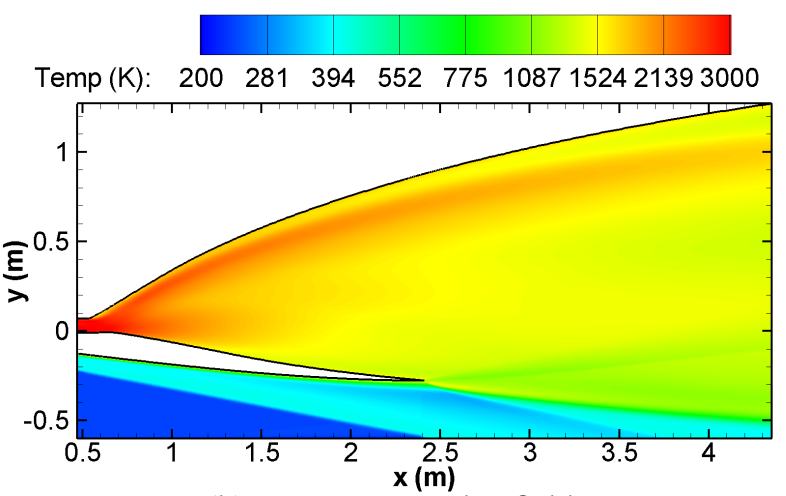

(b) Temperature Flowfield

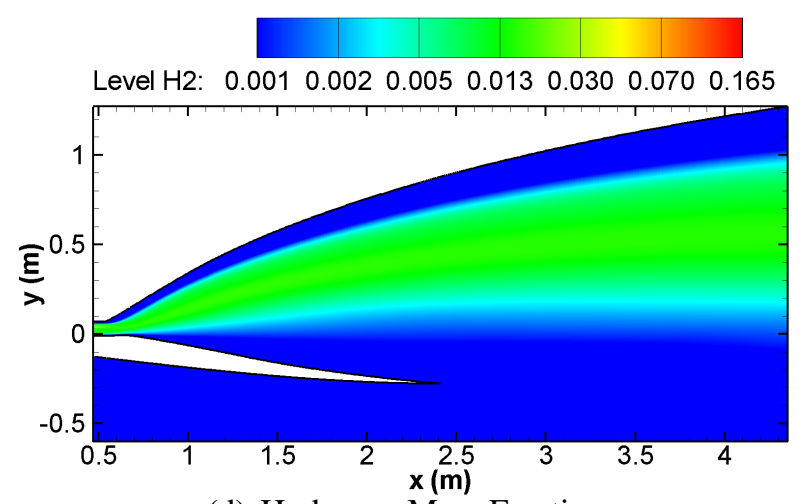

(d) Hydrogen Mass Fraction

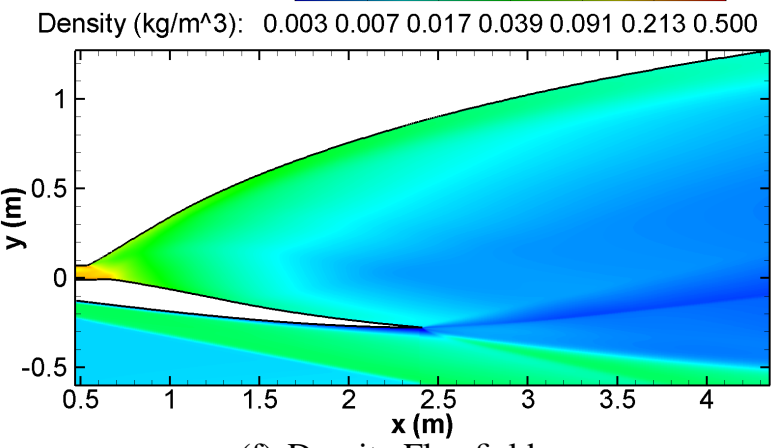

(f) Density Flowfield

FIGURE 8.13: Scramjet nozzle flowfields at $z=0.01 \mathrm{~m}$

ous species mass fractions in the nozzle for both the scramjet and shcramjet are plotted in Fig.8.15. Looking at the $\mathrm{H}_{2} \mathrm{O}$ and $\mathrm{H}_{2}$ levels in both vehicles, it can be seen that diffusive combustion continues in the nozzles. For the scramjet nozzle, the remaining $\mathrm{H}_{2}$ level goes from $25.0 \%$ to $16.6 \%$ and for the shcramjet nozzle, it from $29.5 \%$ to $15.5 \%$. For the scramjet nozzle the $\mathrm{H}_{2} \mathrm{O}$ mass fraction goes from 0.165 to 0.197 and for the shcramjet nozzle, it goes from 0.159 to 0.191 . 


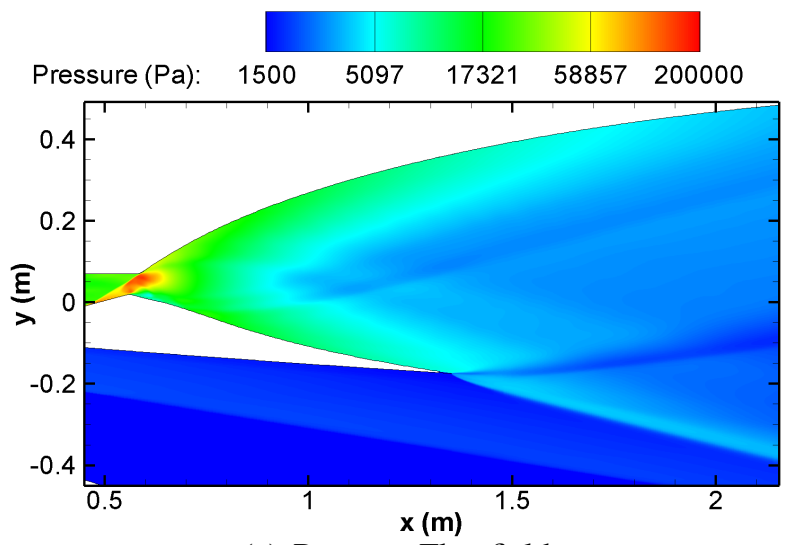

(a) Pressure Flowfield

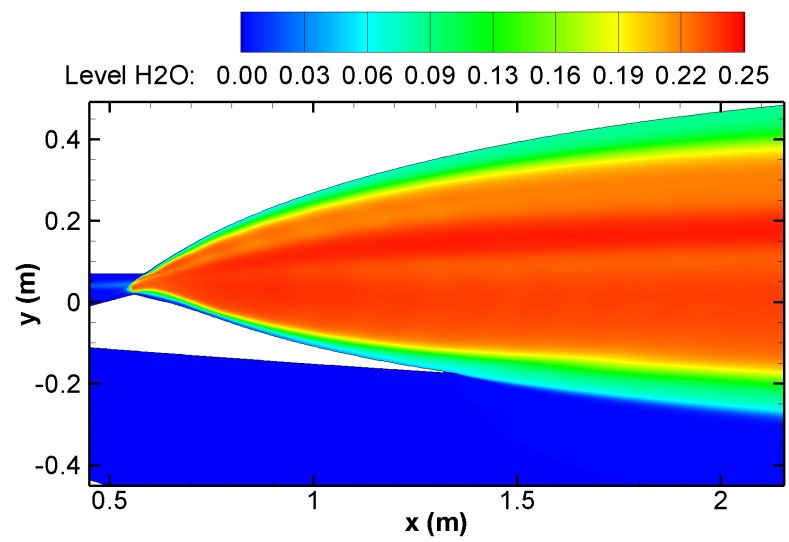

(c) Water Mass Fraction

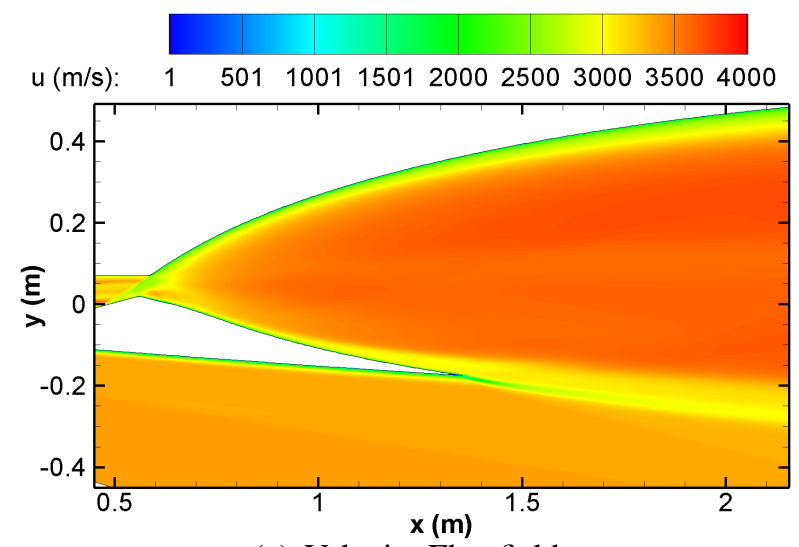

(e) Velocity Flowfield

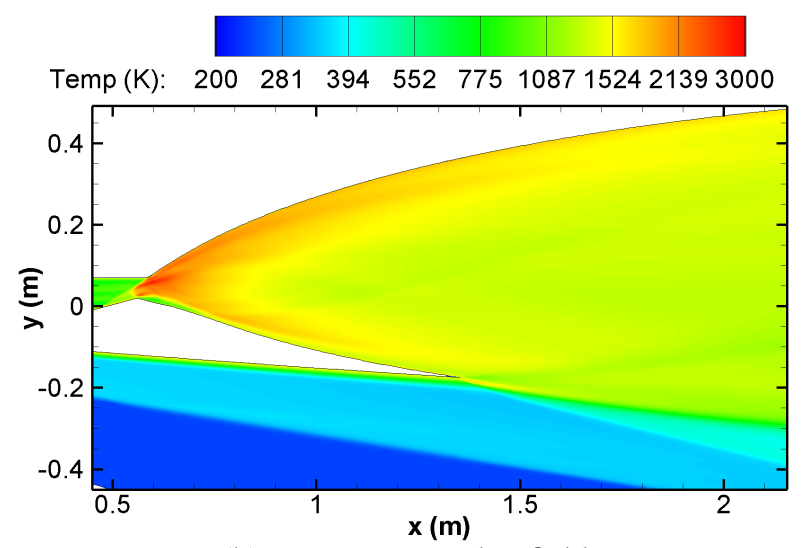

(b) Temperature Flowfield

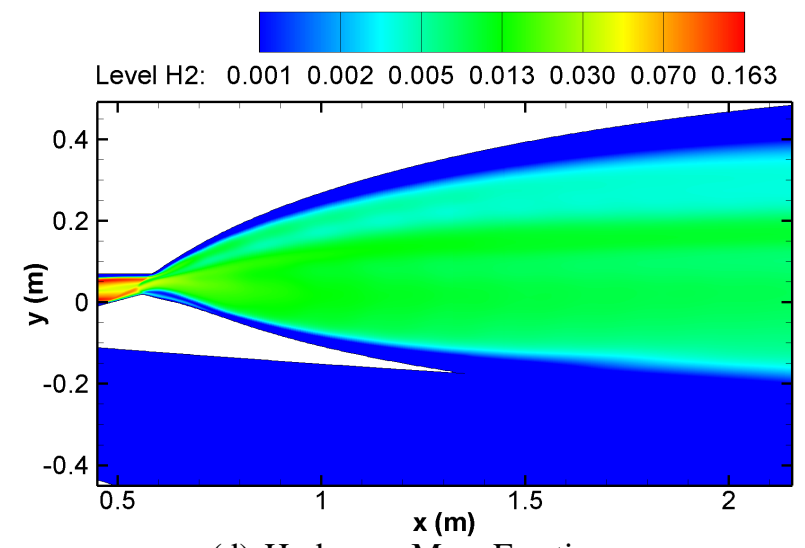

(d) Hydrogen Mass Fraction

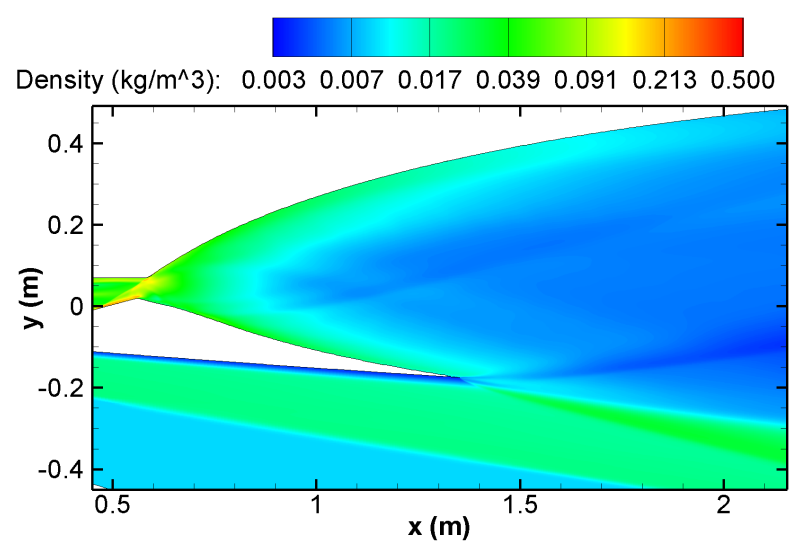

(f) Density Flowfield

FIGURE 8.14: Shcramjet nozzle flowfields at $z=0.01 \mathrm{~m}$ 


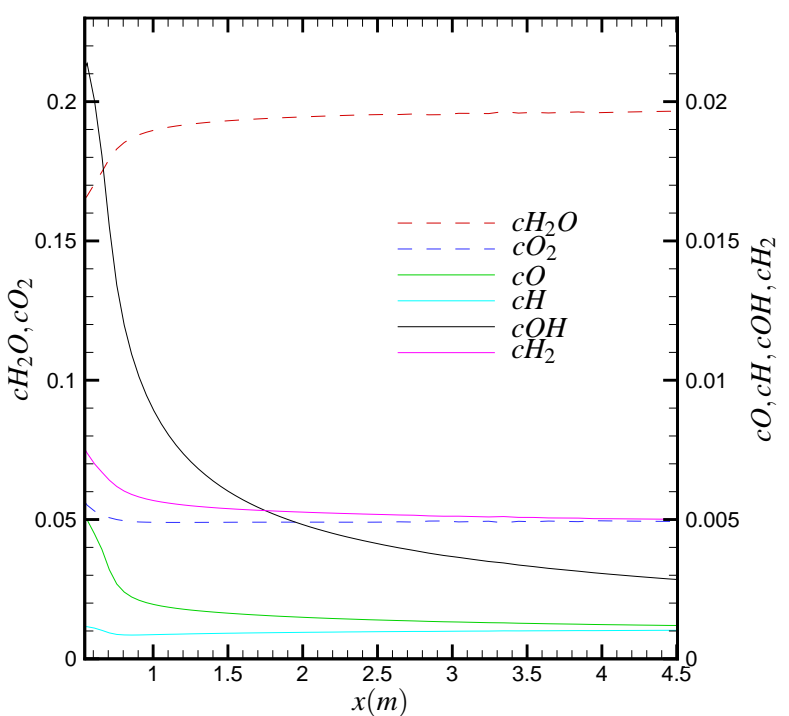

(a) Scramjet

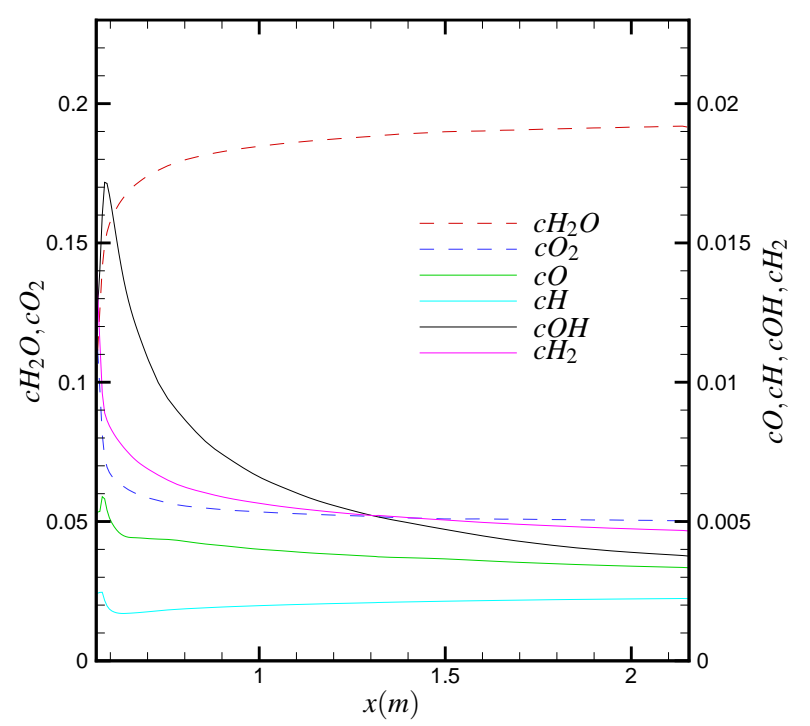

(b) Shcramjet

FIGURE 8.15: Nozzle species mass fractions

\subsection{Vehicle Comparison}

In this section the two complete vehicles will be compared and analyzed. Simulations of the flows in the engine components outlined above allow the performance characteristics of the entire vehicle to be analyzed. The total grid for the entire vehicle consist of 27.6 and 29.5 million nodes for the shcramjet and scramjet, respectively.

\subsubsection{Pressure Flowfields}

The pressure contours of the entire vehicle in the spanwise center domain, $z=0.01 \mathrm{~m}$, are shown in Figs.8.16 and 8.17. Both vehicles have been scaled down to the same plot length and have the same proportions, which allows for visual comparison. The scramjet has a relatively larger inlet and nozzle with a relatively smaller internal duct. It can also be seen that the shcramjet is much more slender, with a length to height ratio of 9.4 and 7.0 for the scramjet.

The level of pressures reached in both engine cycles is shown in Fig.8.18, where the pressure variations, mass-flux-averaged over $x$ planes, are depicted from the inlet cowl tip to the end of the nozzle. It can be seen that the maximum pressure level reached in the scramjet is higher than that of the shcramjet. However, as mentionned earlier, the maximum pressure reached in the shcramjet 


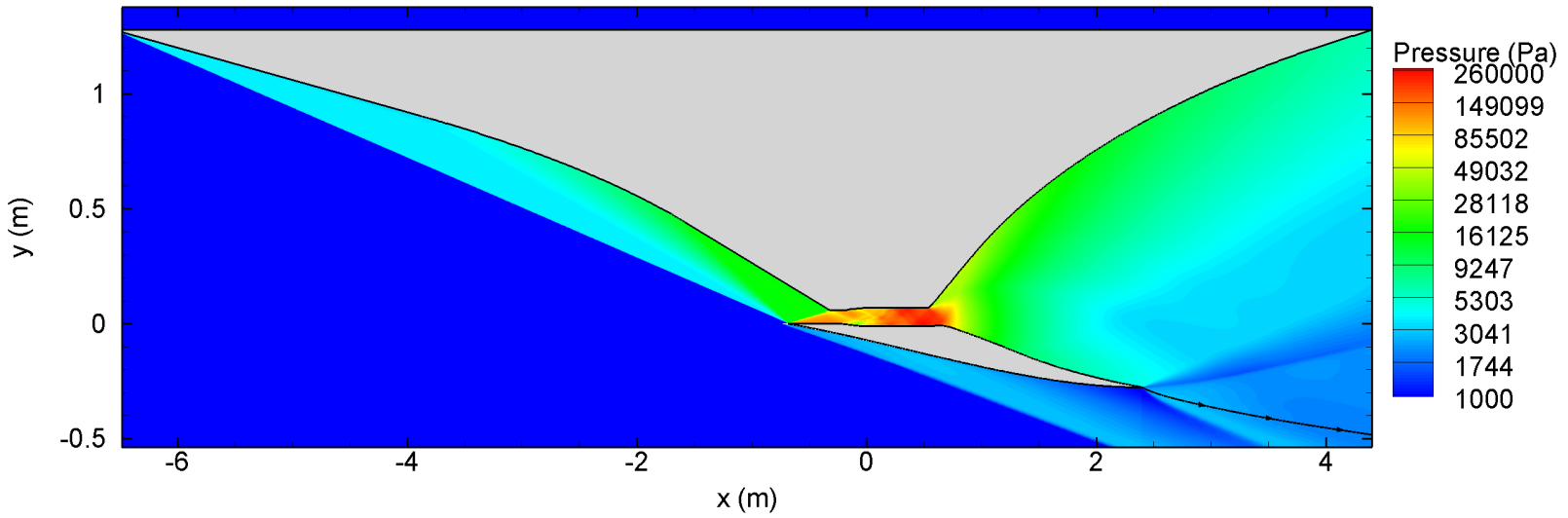

FIGURE 8.16: Scramjet vehicle pressure flowfield at $z=0.01 \mathrm{~m}$

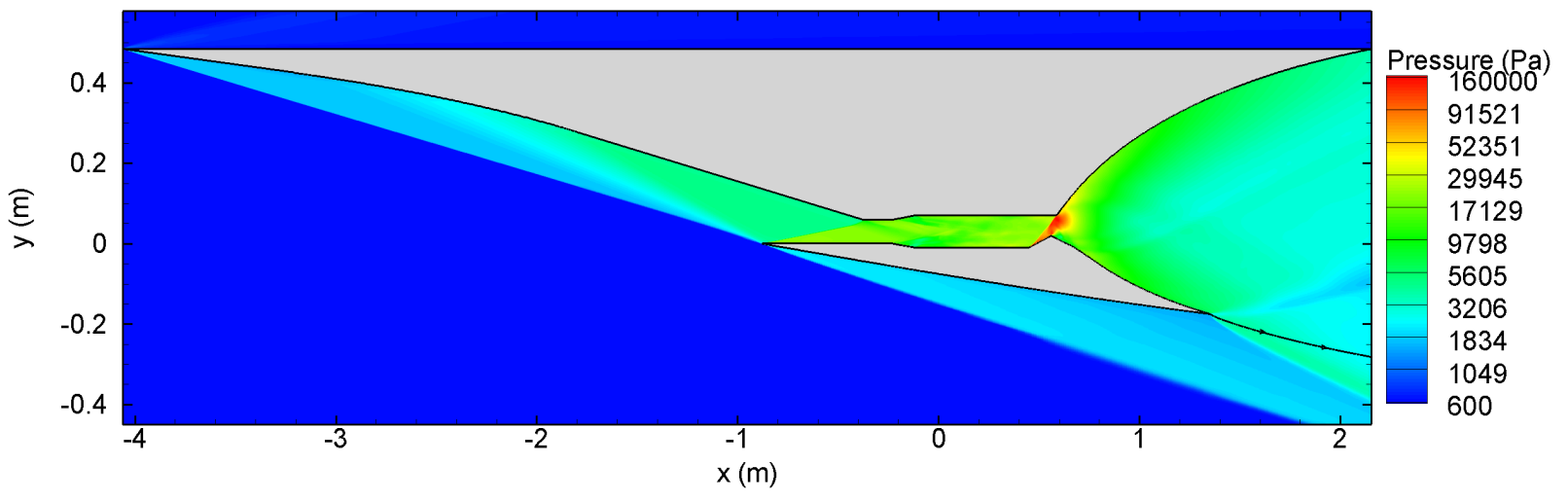

FIGURE 8.17: Shcramjet vehicle pressure flowfield at $z=0.01 \mathrm{~m}$

engine is understated.

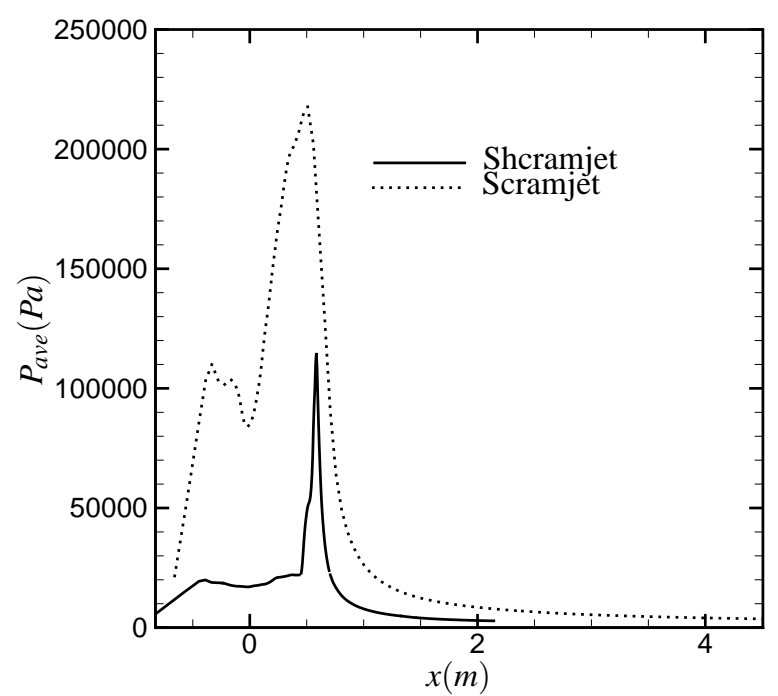

FIGURE 8.18: Mass-averaged pressure variations along the engine 


\subsubsection{Vehicle Surface Forces}

The variations of the cumulative pressure and frictional forces acting in the $x$-direction (the direction opposite to flight) on the internal walls of the engine (wetted by the propulsive flowpath) in both vehicles are presented in Figs.8.19 and 8.20. Note that the upstream face of the combustioninducing wedge in the shcramjet produces the largest rate (or amount per length) of friction and pressure drag in the engine, $64.6 \%$ of the pressure drag and $11 \%$ of the friction drag, which is $43.1 \%$ of the total drag while only being $1.8 \%$ of the total length of the engine. The effectiveness of such an engine is thus strongly dependent upon having a shock-generating device that assures combustion with minimal drag losses. The scramjet produces greater friction over its larger engine surfaces. Its combustor accounts for $46.0 \%$ of the total frictional drag while only being $4.9 \%$ of the total length of the vehicle.

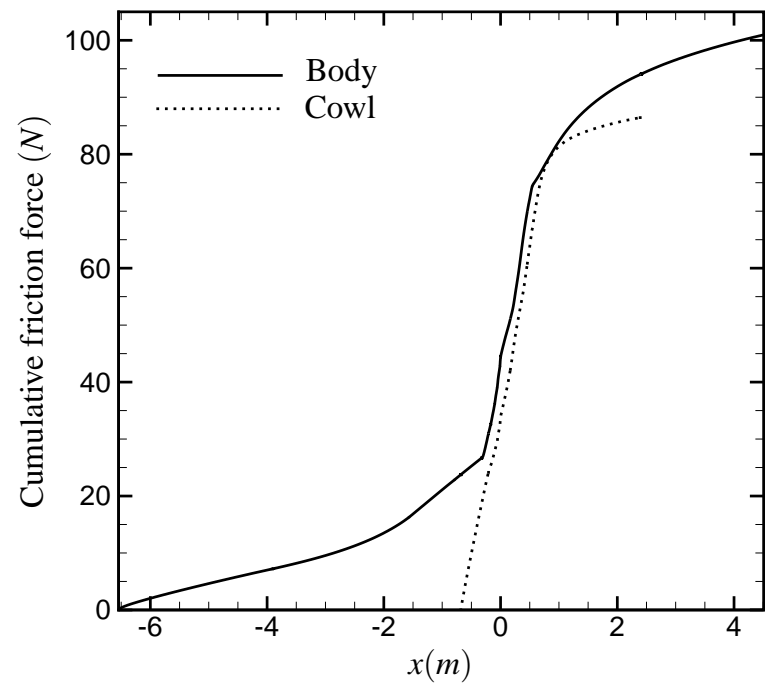

(a) $x$ friction forces

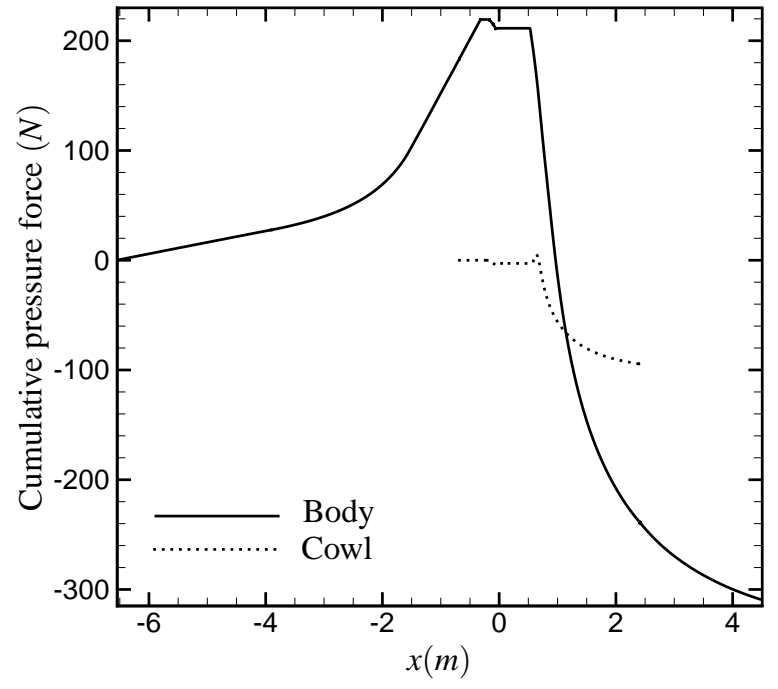

(b) $x$ pressures forces

FIGURE 8.19: Forces on scramjet inner wall surfaces

The frictional and pressure forces for every component on all surfaces for the two vehicles has been summarized in Table A.1 and converted to $I_{s p}$ for comparison in Table A.2. Additionally, several other sub-optimal variations of the shcramjet discussed previously have been included for comparison.

When looking through the data, it can be seen that the net force on the vehicle surfaces is a small fraction of the total forces. Using the optimal shcramjet configuration as an example, the frictional forces are $64.41 \mathrm{~N}$, the pressure drag forces are $91.43 \mathrm{~N}$ and the pressure thrust forces are $-195.07 \mathrm{~N}$. The net force is $-39.23 \mathrm{~N}$, which is only $11 \%$ of the total forces (350.91) acting 


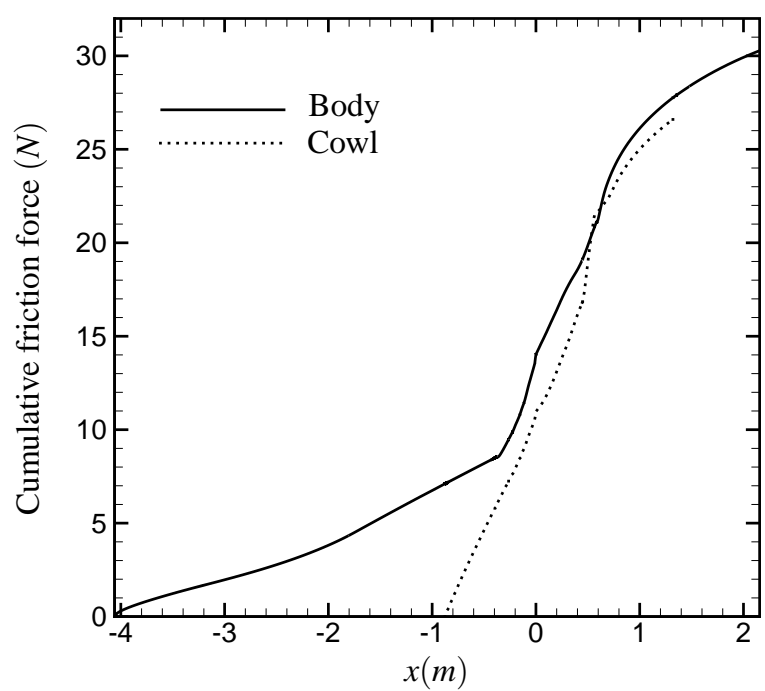

(a) $x$ friction forces

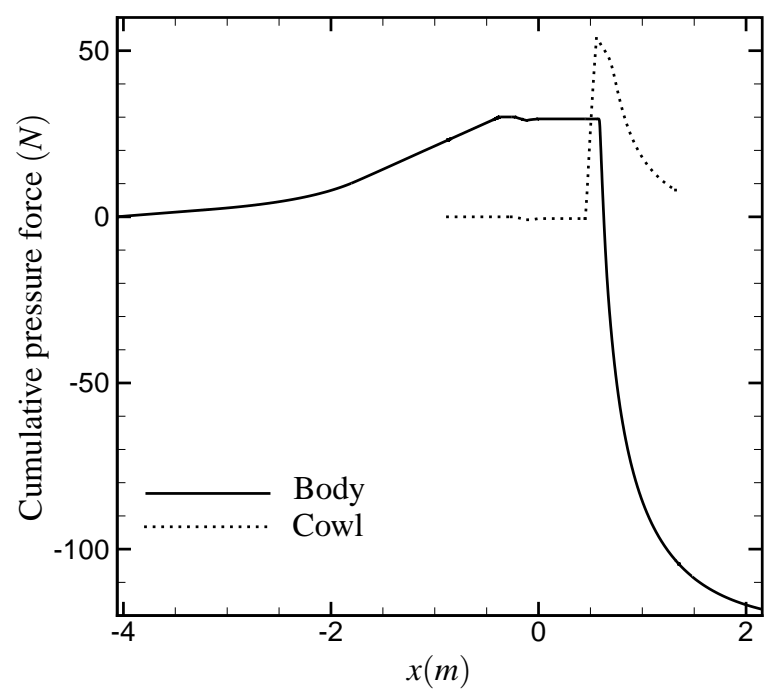

(b) $x$ pressures forces

FIGURE 8.20: Forces on shcramjet inner wall surfaces

on the surfaces. The fuel injection provides a thrust force of $-56.59 \mathrm{~N}$, bringing the total net force to $-95.82 \mathrm{~N}$. Because the net force is a balance between such large forces, any slight change can have dramatic effects on the overall performance. For example, if the nozzle performance could be improved by $10 \%$ (ie. produce $10 \%$ more thrust), then the overall $I_{s p}$ would increase by $20 \%$ to $1335 s$.

The performance of the scramjet and shcramjet is best compared in Table A.2, where the frictional and pressure forces are converted to $I_{s p}$ for normalization. Starting from the beginning, it can be seen that the scramjet has much more losses in the inlet due to its higher compression with $-1206 s$ compared to $-542 s$ in the shcramjet. However the shcramjet requires a mixing duct which incurs $-208 s$. Although the shcramjet combustor is shorter and incurs much less frictional losses, -75 $s$ compared to $-378 s$ for the scramjet, it has a compression component as well which incurs -631 s. Combining the compression, mixing and combustion components for each vehicle, the scramjet incurs $-1536 s$ while the shcramjet incurs -1456 s. However the nozzle performance of the scramjet $(2481 s)$ is significantly higher $(19 \%)$ than the shcramjet $(2079 s)$. The total friction for the entire vehicle is higher in the scramjet $(-872 s)$ than in the shcramjet $(-746 s)$. The specific impulse due to the fuel injection is slightly higher in the shcramjet (656s) than in the scramjet $(618 s)$.

One particular point of interest is the losses incurred on the body tops of both vehicles. Although both designs use a flat top that only causes frictional drag and the comparison uses $I_{s p}$ 
which normalizes the forces, the scramjet's body top incurs $-25 s$ while the shcramjet's body top incurs $-44 s$. The reason for the difference is that $I_{s p}$ is normalized using the fuel mass flow rate which is proportional to the total mass flow rate. As the mass flow rate is increased, the length of the vehicle will usually not increase proportionally.

Figure 8.21 shows the evolution of the specific impulse along the entire length of the scramjet and optimal shcramjet. The specific impulse is determined from the pressure and frictional forces on all four wetted surfaces of the vehicle and from the fuel injection. It can be seen that the shcramjet and the scramjet provide a specific impulse of $1110 s$ and $1450 \mathrm{~s}$, respectively.

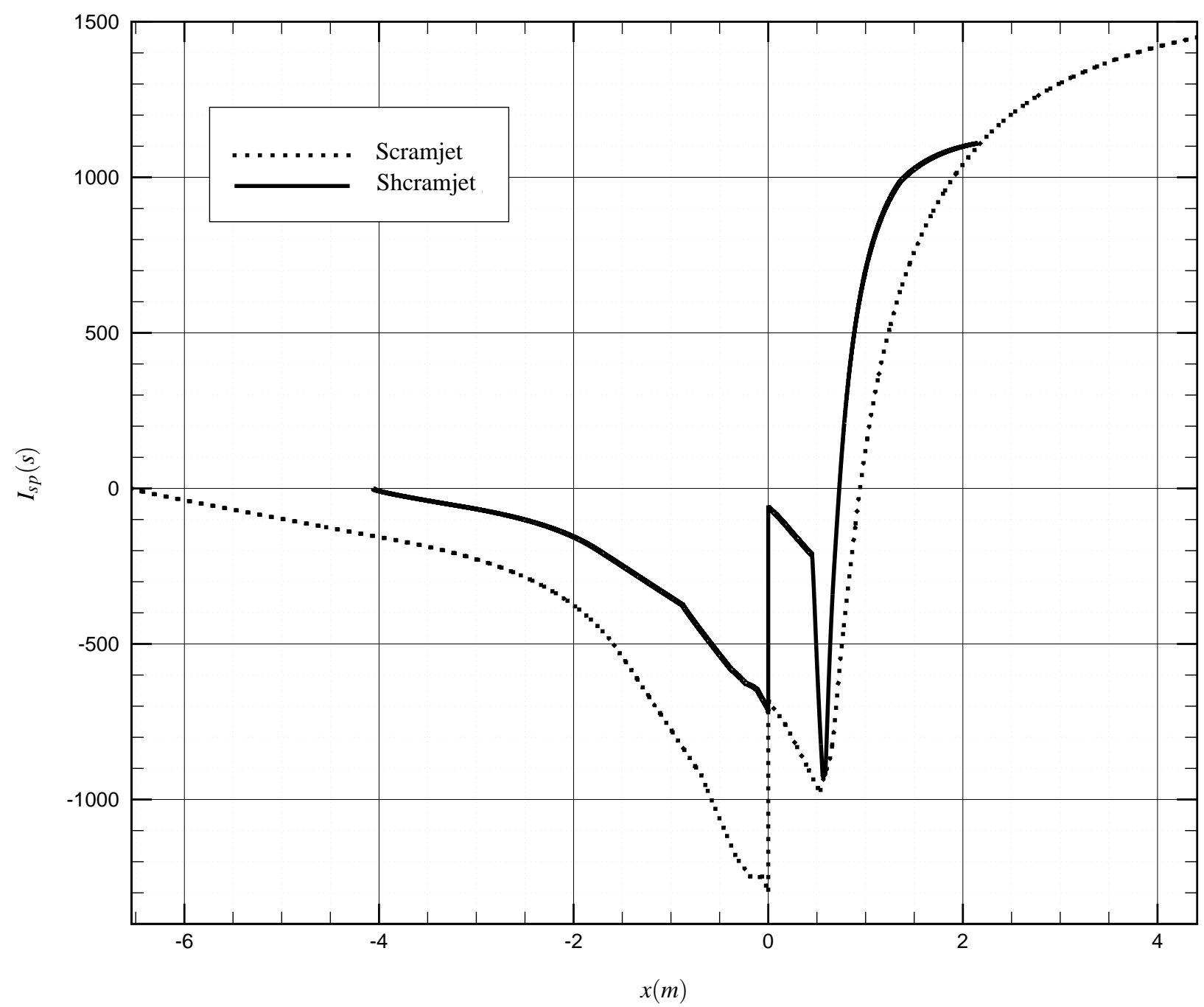

FIGURE 8.21: Variations of the fuel specific impulse along the vehicles 


\subsubsection{Summary}

The final aeropropulsive performances and relative sizes of the vehicles are summarized in Table 8.4. The scramjet is found to outperform the shcramjet with a final $I_{s p}$ of $1450 s$ compared to $1110 s$ for the shcramjet. However, the shcramjet is appreciably smaller and thus lighter than the scramjet with a length of $6.2 \mathrm{~m}$ and height of $0.66 \mathrm{~m}$ compared to $10.95 \mathrm{~m}$ and $1.56 \mathrm{~m}$, respectively for the scramjet. Note that the combustor lengths of the shcramjet and scramjet are $0.11 \mathrm{~m}$ and $0.54 \mathrm{~m}$, respectively, which would require the scramjet to have additional cooling. Both vehicles are plotted to scale in Fig.8.22.

TABLE 8.4: Overall vehicle performance characteristics

\begin{tabular}{|l|c|c|}
\hline Vehicle & Scramjet & Shcramjet \\
\hline Length $(m)$ & 10.95 & 6.2 \\
Height $(m)$ & 1.56 & 0.66 \\
Span $(m)$ & 0.02 & 0.02 \\
$\dot{m}_{\text {air }}(\mathrm{kg} / \mathrm{s})$ & 0.771 & 0.299 \\
$\dot{m}_{\text {fuel }}(\mathrm{kg} / \mathrm{s})$ & 0.02321 & 0.008797 \\
Combustor length $(\mathrm{m})$ & 0.54 & 0.11 \\
$\mathscr{F}_{\text {friction }}(N)$ & 198.7 & 64.38 \\
$\mathscr{F}_{\text {pressure }}(N)$ & -389.91 & -103.61 \\
$I_{s p}(s)$ & 1450 & 1110 \\
\hline
\end{tabular}

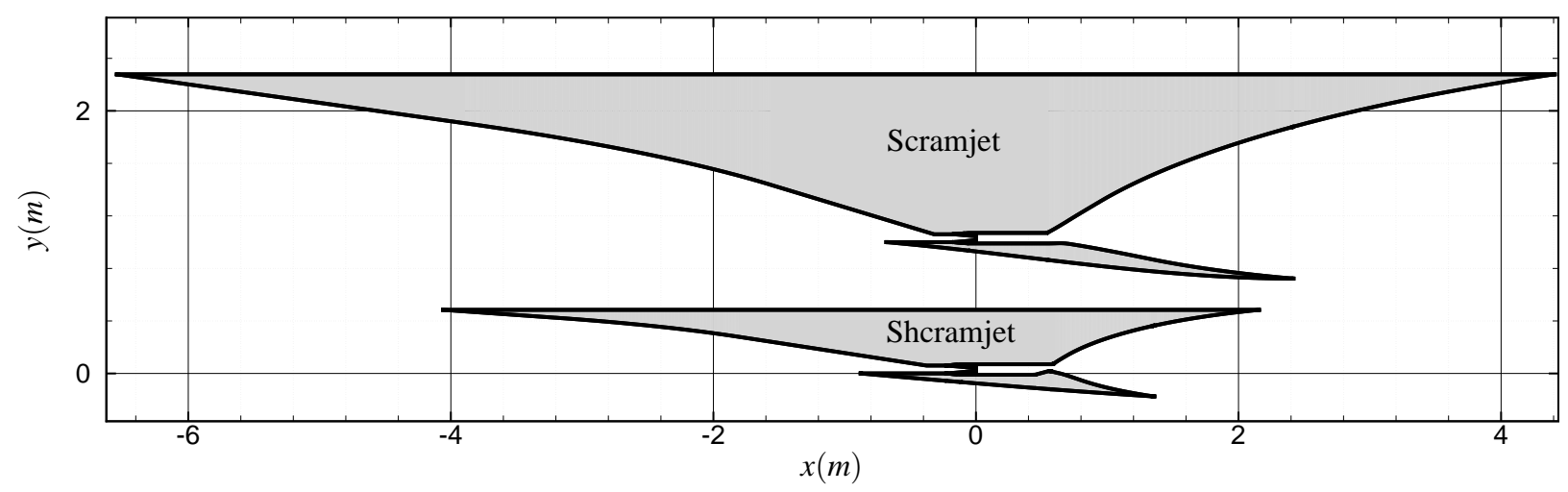

FIGURE 8.22: Scaled vehicle geometry comparison 


\section{CONCLUSIONS AND RECOMMENDATIONS}

The design of the shcramjet was completed while varying many parameters to yield a higher performance. It was found that although the mixing efficiency directly affects the performance of the combustor, to yield a high mixing efficiency requires longer distances which cause large amounts of frictional losses. Two cases were tested on either end of the spectrum with either a high mixing efficiency and a long duct or a low mixing efficiency with a short duct. It was found that the case with the lower mixing efficiency and a short duct performed better. Studies of the combustor were also performed with various wedge angles. It was found that lower wedge angles performed better as it has less losses from shocks and friction while still combusting the same amount of fuel as higher wedge angles. More focus should be made on minimum wedge angles and minimum wedge lengths. For the nozzle contour design using the MOC, it was found that using a slanted initial data line that goes from the end of the wedge combustor to the point where the shock hits the upper body wall performs better than a vertical initial data line that predetermines the cowl expansion. After the optimal shcramjet configuration was determined, it was compared with a scramjet at the same flight conditions and using many of the same components. It was shown that at Mach 11, the scramjet still outperforms the shcramjet with a specific impulse of $1450 s$ compared to $1110 s$ for the shcramjet. While keeping the main duct height the same, the scramjet vehicle was significantly larger with a length of $10.95 \mathrm{~m}$ and a height of $1.56 \mathrm{~m}$ compared to $6.2 \mathrm{~m}$ and $0.66 \mathrm{~m}$ for the shcramjet. Further studies comparing the shcramjet and scramjet should be made at higher Mach numbers at which point the benefits of the shcramjet should become more apparent.

The overall performance of hypersonic vehicles is highly dependent on each and every component and must be treated in an integrated manner. It was shown that the thrust produced is a 
small remainder of large forces acting on the vehicle. As such, any slight improvement in any area can have dramatic results on the overall performance. There is a large need for full vehicle, high accuracy analysis and optimization. Full vehicle optimization could easily produce much higher performance values. Although the simple geometry is well suited for shape optimization, solving the resulting flowfields is very time consuming. However, with the ever increasing computing power available, such tasks should be possible within the next decade.

Some other suggestions for improving the performance of the hypersonic vehicles include maximizing the thrust provided by fuel injection. It was shown that fuel injection provided about $43 \%$ and $59 \%$ of the thrust in the scramjet and shcramjet, respectively. The limits of the fuel injection system must be found and utilized. Another improvement would be to lower the equivalence ratio to $0.75-0.8$. Currently fuel is injected in stoichiometric proportions based on the air mass flowrate through the engine. However, fuel is injected in the center of the duct to avoid the boundary layers and therefore the local equivalence ratio is much higher than 1 . In the shcramjet engine, $29.5 \%$ of the fuel is not burned by the end of the combustor and $15.5 \%$ is not burned by the end of the nozzle. Additionally, the heat flux across the wall boundaries could have been calculated and compared had the wall temperatures been equal. This would help quantify the supposedly lower cooling requirements of the shcramjet due to its shorter combustor. 


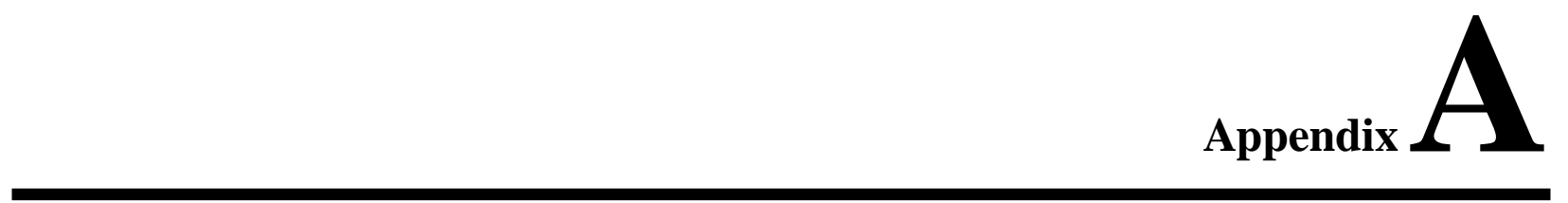

Vehicle Forces 
TABLE A.1: Overall vehicle performance (Thrust)

\begin{tabular}{|c|c|c|c|c|c|c|c|c|c|}
\hline & & Scramjet & $\begin{array}{c}\text { Shcramjet } \\
T_{f}=250 \\
13^{\circ} \text { vert. }\end{array}$ & $\begin{array}{r}\text { Shcramjet } \\
T_{f}=309 \\
15^{\circ} \text { vert. }\end{array}$ & $\begin{array}{c}\text { Shcramjet } \\
T_{f}=309 \\
15^{\circ} \text { vert. } \\
\text { opt. cowl }\end{array}$ & $\begin{array}{c}\text { Shcramjet } \\
T_{f}=309 \\
15^{\circ} \text { slant }\end{array}$ & $\begin{array}{c}\text { Shcramjet } \\
T_{f}=309 \\
15^{\circ} \text { slant } \\
\text { opt. cowl }\end{array}$ & $\begin{array}{r}\text { Shcramjet } \\
T_{f}=309 \\
15^{\circ} \text { slant } \\
\text { multitemp }\end{array}$ & $\begin{array}{c}\text { Shcramjet } \\
T_{f}=309 \\
18^{\circ} \text { slant }\end{array}$ \\
\hline \multirow{7}{*}{ Inlet } & Body Fric (N) & 30.98 & 9.47 & 9.47 & 9.47 & 9.47 & 9.47 & 9.47 & 9.47 \\
\hline & Cowl Fric (N) & 24.15 & 7.25 & 7.25 & 7.25 & 7.25 & 7.25 & 7.25 & 7.25 \\
\hline & Total Fric (N) & 55.13 & 16.72 & 16.72 & 16.72 & 16.72 & 16.72 & 16.72 & 16.72 \\
\hline & Body Pres (N) & 219.35 & 30.06 & 30.06 & 30.06 & 30.06 & 30.06 & 30.06 & 30.06 \\
\hline & Cowl Pres (N) & 0.00 & 0.00 & 0.00 & 0.00 & 0.00 & 0.00 & 0.00 & 0.00 \\
\hline & Total Pres (N) & 219.35 & 30.06 & 30.06 & 30.06 & 30.06 & 30.06 & 30.06 & 30.06 \\
\hline & Total (N) & 274.48 & 46.79 & 46.79 & 46.79 & 46.79 & 46.79 & 46.79 & 46.79 \\
\hline \multirow{7}{*}{ Mixing Duct } & Body Fric (N) & 0.00 & 18.44 & 9.56 & 9.56 & 9.56 & 9.56 & 9.56 & 9.56 \\
\hline & Cowl Fric (N) & 0.00 & 18.37 & 9.51 & 9.51 & 9.51 & 9.51 & 9.51 & 9.51 \\
\hline & Total Fric $(\mathrm{N})$ & 0.00 & 36.81 & 19.07 & 19.07 & 19.07 & 19.07 & 19.07 & 19.07 \\
\hline & Body Pres (N) & 0.00 & -0.60 & -0.60 & -0.60 & -0.60 & -0.60 & -0.60 & -0.60 \\
\hline & Cowl Pres (N) & 0.00 & -0.52 & -0.52 & -0.52 & -0.52 & -0.52 & -0.52 & -0.52 \\
\hline & Total Pres (N) & 0.00 & -1.12 & -1.12 & -1.12 & -1.12 & -1.12 & -1.12 & -1.12 \\
\hline & Total (N) & 0.00 & 35.69 & 17.95 & 17.95 & 17.95 & 17.95 & 17.95 & 17.95 \\
\hline \multirow{7}{*}{ Combustor } & Body Fric (N) & 43.38 & 1.83 & 1.93 & 1.93 & 1.93 & 1.93 & 1.93 & 1.12 \\
\hline & Cowl Fric (N) & 42.71 & 3.73 & 4.56 & 4.56 & 4.51 & 4.51 & 4.51 & 4.09 \\
\hline & Total Fric $(\mathrm{N})$ & 86.09 & 5.56 & 6.48 & 6.48 & 6.44 & 6.44 & 6.44 & 5.21 \\
\hline & Body Pres (N) & -8.00 & 0.00 & 0.00 & 0.00 & 0.00 & 0.00 & 0.00 & 0.00 \\
\hline & Cowl Pres (N) & -2.89 & 43.04 & 54.83 & 54.83 & 54.49 & 54.49 & 54.49 & 63.54 \\
\hline & Total Pres (N) & -10.89 & 43.04 & 54.83 & 54.83 & 54.49 & 54.49 & 54.49 & 63.54 \\
\hline & Total (N) & 75.20 & 48.59 & 61.31 & 61.31 & 60.92 & 60.92 & 60.92 & 68.75 \\
\hline \multirow{7}{*}{ Nozzle } & Body Fric (N) & 26.35 & 7.27 & 7.87 & 7.87 & 9.21 & 9.21 & 9.41 & 7.25 \\
\hline & Cowl Fric $(\mathrm{N})$ & 19.61 & 5.02 & 5.99 & 4.60 & 6.49 & 5.37 & 6.66 & 5.75 \\
\hline & Total Fric (N) & 45.96 & 12.29 & 13.86 & 12.47 & 15.71 & 14.58 & 16.07 & 13.00 \\
\hline & Body Pres (N) & -519.16 & -141.29 & -144.77 & -144.77 & -147.53 & -147.53 & -147.14 & -142.11 \\
\hline & Cowl Pres (N) & -91.64 & -54.79 & -53.85 & -46.63 & -50.46 & -46.43 & -50.38 & -52.55 \\
\hline & Total Pres (N) & -610.80 & -196.08 & -198.62 & -191.40 & -197.99 & -193.96 & -197.52 & -194.66 \\
\hline & Total (N) & -564.83 & -183.78 & -184.75 & -178.93 & -182.28 & -179.38 & -181.45 & -181.66 \\
\hline \multirow{7}{*}{ Total Engine } & Body Fric (N) & 100.72 & 37.01 & 28.83 & 28.83 & 30.18 & 30.18 & 30.38 & 27.40 \\
\hline & Cowl Fric (N) & 86.47 & 34.36 & 27.30 & 25.91 & 27.76 & 26.63 & 27.92 & 26.60 \\
\hline & Total Fric $(\mathrm{N})$ & 187.19 & 71.38 & 56.14 & 54.75 & 57.93 & 56.81 & 58.29 & 54.00 \\
\hline & Body Pres (N) & -307.81 & -111.82 & -115.30 & -115.30 & -118.06 & -118.06 & -117.67 & -112.65 \\
\hline & Cowl Pres (N) & -94.53 & -12.27 & 0.46 & 7.68 & 3.51 & 7.54 & 3.58 & 10.47 \\
\hline & Total Pres (N) & -402.33 & -124.09 & -114.84 & -107.63 & -114.55 & -110.52 & -114.09 & -102.18 \\
\hline & Total (N) & -215.15 & -52.72 & -58.71 & -52.88 & -56.62 & -53.72 & -55.79 & -48.18 \\
\hline \multirow{3}{*}{ Outer Body } & Body Fric $(\mathrm{N})$ & 5.66 & 4.00 & 3.66 & 3.66 & 3.83 & 3.83 & 3.83 & 3.58 \\
\hline & Body Pres (N) & 0.00 & 0.00 & 0.00 & 0.00 & 0.00 & 0.00 & 0.00 & 0.00 \\
\hline & Total (N) & 5.66 & 4.00 & 3.66 & 3.66 & 3.83 & 3.83 & 3.83 & 3.58 \\
\hline \multirow{3}{*}{ Outer Cowl } & Cowl Fric $(\mathrm{N})$ & 5.67 & 5.55 & 6.20 & 4.52 & 4.74 & 3.78 & 4.74 & 4.53 \\
\hline & Cowl Pres (N) & 14.40 & 12.60 & 18.64 & 10.71 & 10.51 & 6.88 & 10.51 & 10.43 \\
\hline & Total (N) & 20.07 & 18.15 & 24.84 & 15.23 & 15.26 & 10.66 & 15.26 & 14.95 \\
\hline \multirow{7}{*}{ Total Vehicle } & Body Fric (N) & 106.38 & 41.01 & 32.49 & 32.49 & 34.00 & 34.00 & 34.20 & 30.98 \\
\hline & Cowl Fric (N) & 92.14 & 39.91 & 33.50 & 30.43 & 32.50 & 30.41 & 32.66 & 31.12 \\
\hline & Total Fric (N) & 198.52 & 80.93 & 65.99 & 62.92 & 66.50 & 64.41 & 66.87 & 62.10 \\
\hline & Body Pres (N) & -307.81 & -111.82 & -115.30 & -115.30 & -118.06 & -118.06 & -117.67 & -112.65 \\
\hline & Cowl Pres (N) & -80.13 & 0.33 & 19.10 & 18.39 & 14.02 & 14.42 & 14.10 & 20.90 \\
\hline & Total Pres (N) & -387.93 & -111.49 & -96.20 & -96.92 & -104.04 & -103.64 & -103.57 & -91.75 \\
\hline & Total (N) & -189.41 & -30.57 & -30.21 & -33.99 & -37.53 & -39.23 & -36.71 & -29.64 \\
\hline Fuel Inj Thrust (N) & & -140.67 & -46.13 & -56.59 & -56.59 & -56.59 & -56.59 & -56.59 & -56.59 \\
\hline Total Thrust (N) & & -330.08 & -76.70 & -86.81 & -90.59 & -94.13 & -95.83 & -93.30 & -86.24 \\
\hline
\end{tabular}


TABLE A.2: Overall vehicle performance $\left(I_{s p}\right)$

\begin{tabular}{|c|c|c|c|c|c|c|c|c|c|}
\hline & & Scramjet & $\begin{array}{c}\text { Shcramjet } \\
T_{f}=250 \\
13^{\circ} \text { vert. }\end{array}$ & $\begin{array}{c}\text { Shcramjet } \\
T_{f}=309 \\
15^{\circ} \text { vert. }\end{array}$ & $\begin{array}{r}\text { Shcramjet } \\
T_{f}=309 \\
15^{\circ} \text { vert. } \\
\text { opt. cowl }\end{array}$ & $\begin{array}{r}\text { Shcramjet } \\
T_{f}=309 \\
15^{\circ} \text { slant }\end{array}$ & $\begin{array}{r}\text { Shcramjet } \\
T_{f}=309 \\
15^{\circ} \text { slant } \\
\text { opt. cowl }\end{array}$ & $\begin{array}{r}\text { Shcramjet } \\
T_{f}=309 \\
15^{\circ} \text { slant } \\
\text { multitemp }\end{array}$ & $\begin{array}{c}\text { Shcramjet } \\
T_{f}=309 \\
18^{\circ} \text { slant }\end{array}$ \\
\hline \multirow{7}{*}{ Inlet } & Body Fric (s) & -136.06 & -109.78 & -109.78 & -109.78 & -109.78 & -109.78 & $\begin{array}{l}-109.78 \\
\end{array}$ & -109.78 \\
\hline & Cowl Fric (s) & -106.09 & -83.98 & -83.98 & -83.98 & -83.98 & -83.98 & -83.98 & -83.98 \\
\hline & Total Fric (s) & -242.15 & -193.76 & -193.76 & -193.76 & -193.76 & -193.76 & -193.76 & -193.76 \\
\hline & Body Pres (s) & -963.44 & -348.38 & -348.38 & -348.38 & -348.38 & -348.38 & -348.38 & -348.38 \\
\hline & Cowl Pres (s) & 0.00 & 0.00 & 0.00 & 0.00 & 0.00 & 0.00 & 0.00 & 0.00 \\
\hline & Total Pres (s) & -963.44 & -348.38 & -348.38 & -348.38 & -348.38 & -348.38 & -348.38 & -348.38 \\
\hline & Total (s) & -1205.59 & -542.13 & -542.13 & -542.13 & -542.13 & -542.13 & -542.13 & -542.13 \\
\hline \multirow{7}{*}{ Mixing Duct } & Body Fric (s) & 0.00 & -213.68 & -110.83 & -110.83 & -110.83 & -110.83 & -110.83 & -110.83 \\
\hline & Cowl Fric (s) & 0.00 & -212.84 & -110.15 & -110.15 & -110.15 & -110.15 & -110.15 & -110.15 \\
\hline & Total Fric (s) & 0.00 & -426.51 & -220.98 & -220.98 & -220.98 & -220.98 & -220.98 & -220.98 \\
\hline & Body Pres (s) & 0.00 & 6.93 & 6.94 & 6.94 & 6.94 & 6.94 & 6.94 & 6.94 \\
\hline & Cowl Pres (s) & 0.00 & 6.03 & 6.03 & 6.03 & 6.03 & 6.03 & 6.03 & 6.03 \\
\hline & Total Pres (s) & 0.00 & 12.97 & 12.97 & 12.97 & 12.97 & 12.97 & 12.97 & 12.97 \\
\hline & Total (s) & 0.00 & -413.55 & -208.01 & -208.01 & -208.01 & -208.01 & -208.01 & -208.01 \\
\hline \multirow{7}{*}{ Combustor } & Body Fric (s) & -190.55 & -21.18 & -22.31 & -22.31 & -22.31 & -22.31 & -22.31 & -12.95 \\
\hline & Cowl Fric (s) & -187.58 & -43.20 & -52.84 & -52.84 & -52.26 & -52.26 & -52.26 & -47.45 \\
\hline & Total Fric (s) & -378.13 & -64.38 & -75.14 & -75.14 & -74.57 & -74.57 & -74.57 & -60.39 \\
\hline & Body Pres (s) & 35.15 & 0.00 & 0.00 & 0.00 & 0.00 & 0.00 & 0.00 & 0.00 \\
\hline & Cowl Pres (s) & 12.68 & -498.71 & -635.32 & -635.32 & -631.38 & -631.38 & -631.38 & -736.26 \\
\hline & Total Pres (s) & 47.83 & -498.71 & -635.32 & -635.32 & -631.38 & -631.38 & -631.38 & -736.26 \\
\hline & Total (s) & -330.30 & -563.09 & -710.46 & -710.46 & -705.95 & -705.95 & -705.95 & -796.65 \\
\hline \multirow{7}{*}{ Nozzle } & Body Fric (s) & -115.75 & -84.23 & -91.21 & -91.21 & -106.75 & -106.75 & -109.07 & -84.01 \\
\hline & Cowl Fric (s) & -86.13 & -58.19 & -69.43 & -53.29 & -75.26 & -62.19 & -77.13 & -66.61 \\
\hline & Total Fric (s) & -201.88 & -142.42 & -160.64 & -144.50 & -182.01 & -168.94 & -186.20 & -150.61 \\
\hline & Body Pres (s) & 2280.25 & 1637.17 & 1677.55 & 1677.55 & 1709.50 & 1709.50 & 1704.96 & 1646.75 \\
\hline & Cowl Pres (s) & 402.50 & 634.88 & 623.96 & 540.34 & 584.69 & 537.99 & 583.82 & 608.89 \\
\hline & Total Pres (s) & 2682.75 & 2272.05 & 2301.51 & 2217.89 & 2294.19 & 2247.49 & 2288.79 & 2255.64 \\
\hline & Total (s) & 2480.87 & 2129.63 & 2140.87 & 2073.39 & 2112.18 & 2078.55 & 2102.59 & 2105.03 \\
\hline \multirow{7}{*}{ Total Engine } & Body Fric (s) & -442.37 & -428.86 & -334.12 & -334.12 & -349.67 & -349.67 & -351.99 & -317.56 \\
\hline & Cowl Fric (s) & -379.79 & -398.21 & -316.40 & -300.26 & -321.65 & -308.58 & -323.52 & -308.19 \\
\hline & Total Fric (s) & -822.16 & -827.07 & -650.51 & -634.38 & -671.32 & -658.25 & -675.50 & -625.74 \\
\hline & Body Pres (s) & 1351.95 & 1295.73 & 1336.11 & 1336.11 & 1368.06 & 1368.06 & 1363.52 & 1305.31 \\
\hline & Cowl Pres (s) & 415.18 & 142.21 & -5.32 & -88.94 & -40.65 & -87.35 & -41.52 & -121.33 \\
\hline & Total Pres (s) & 1767.13 & 1437.94 & 1330.78 & 1247.17 & 1327.41 & 1280.71 & 1322.00 & 1183.98 \\
\hline & Total (s) & 944.98 & 610.87 & 680.27 & 612.79 & 656.09 & 622.46 & 646.50 & 558.24 \\
\hline \multirow{3}{*}{ Outer Body } & Body Fric (s) & -24.87 & -46.36 & -42.36 & -42.36 & -44.36 & -44.36 & -44.36 & -41.46 \\
\hline & Body Pres (s) & 0.00 & 0.00 & 0.00 & 0.00 & 0.00 & 0.00 & 0.00 & 0.00 \\
\hline & Total (s) & -24.87 & -46.36 & -42.36 & -42.36 & -44.36 & -44.36 & -44.36 & -41.46 \\
\hline \multirow{3}{*}{ Outer Cowl } & Cowl Fric (s) & -24.91 & -64.31 & -71.80 & -52.39 & -54.96 & -43.78 & -54.96 & -52.43 \\
\hline & Cowl Pres (s) & -63.26 & -146.00 & -216.02 & -124.12 & -121.83 & -79.71 & -121.83 & -120.85 \\
\hline & Total (s) & -88.17 & -210.31 & -287.81 & -176.51 & -176.79 & -123.49 & -176.79 & -173.28 \\
\hline \multirow{7}{*}{ Total Vehicle } & Body Fric (s) & -467.24 & -475.22 & $\begin{array}{l}-376.48 \\
\end{array}$ & -376.48 & -394.03 & -394.03 & -396.35 & -359.01 \\
\hline & Cowl Fric (s) & -404.70 & -462.51 & -388.19 & -352.65 & -376.61 & -352.36 & -378.47 & -360.62 \\
\hline & Total Fric (s) & -871.94 & -937.73 & -764.67 & -729.13 & -770.64 & -746.39 & -774.82 & -719.63 \\
\hline & Body Pres (s) & 1351.95 & 1295.73 & 1336.11 & 1336.11 & 1368.06 & 1368.06 & 1363.52 & 1305.31 \\
\hline & Cowl Pres (s) & 351.93 & -3.80 & -221.34 & -213.06 & -162.48 & -167.06 & -163.35 & -242.18 \\
\hline & Total Pres (s) & 1703.88 & 1291.93 & 1114.77 & 1123.05 & 1205.58 & 1201.00 & 1200.17 & 1063.14 \\
\hline & Total (s) & 831.94 & 354.20 & 350.09 & 393.92 & 434.94 & 454.60 & 425.35 & 343.50 \\
\hline Fuel Inj (s) & & 617.85 & 534.57 & 655.80 & 655.80 & 655.80 & 655.80 & 655.80 & 655.80 \\
\hline Total $I_{s p}$ & & 1449.79 & 888.77 & 1005.90 & 1049.72 & 1090.74 & 1110.41 & 1081.15 & 999.30 \\
\hline
\end{tabular}




\section{Bibliography}

1. Alexander, D. C. And Sislian, J. P., "A Computational Study of the Propulsive Characteristics of a Shcramjet Engine," Journal of Propulsion and Power, Vol. 24, No. 1, 2008, pp. 34-44.

2. Alexander, D. C., Hypersonic Mixed-Compression Inlet Shock-Induced Combustion Ramjets, Ph.D. thesis, University of Toronto, Toronto, ON, Canada, 2006, Graduate Department of Aerospace Science and Engineering.

3. Alexander, D. C., Sislian, J. P., And Parent, B., "Hypervelocity Fuel/Air Mixing in MixedCompression Inlets of Shcramjets," AIAA Journal, Vol. 44, No. 10, 2006, pp. 2145-2155.

4. Batten, P., Leschziner, M. A., And Goldberg, U. C., "Average-State Jacobians and Implicit Methods for Compressible Viscous and Turbulent Flows," Journal of Computational Physics, Vol. 137, No. 1, 1997, pp. 38-78.

5. Beam, R. M. And Warming, R. F., "An Implicit Factored Scheme for the Compressible NavierStokes Equations," AIAA Journal, Vol. 16, No. 4, 1978, pp. 393-402.

6. Burrows, M. C. And Kurkov, A. P., "Analytical and Experimental Study of Supersonic Combustion of Hydrogen in a Vitiated Air Stream,” TMX 2828, NASA, 1973.

7. Chang, C. L. And Merkle, C. L., "The Relation Between Flux Vector Splitting and Parabolized Schemes," Journal of Computational Physics, Vol. 80, 1989, pp. 344-361.

8. Coakley, T. J., Horstman, C. C., Marvin, J. G., Viegas, J. R., Bardina, J. E., Huang, P. G., AND Kussoy, M. I., “Turbulent Compressibility Corrections,” NASA TM 108827, may 1994. 
9. Coakley, T. J. And HuAng, P. G., “Turbulent Modelling for High-Speed Flows,” AIAA Paper 9204366, 1992.

10. Dimotakis, P. E., Turbulent Free Shear Layer Mixing and Combustion, American Institute of Aeronautics and Astronautics, Inc., Washington, DC, 1991, pp. 265-340.

11. Donohue, J. M., McDaniel, J. C., And Haj-Hariri, H., "Experimental and Numerical Study of Swept Ramp Injection into a Supersonic Flowfield," AIAA Journal, Vol. 32, No. 9, 1994, pp. 18601867.

12. Dudebout, R., Sislian, J. P., And Oppitz, R., "Numerical Simulation of Hypersonic ShockInduced Combustion Ramjets," Journal of Propulsion and Power, Vol. 14, No. 6, 1998, pp. 869-879.

13. Edenfield, E. E., "Design of a High Reynolds Number Mach Number 8 Contoured Nozzle for the Hypervelocity Wind Tunnel,” AEDC-TR 72-48, Arnold Engineering Development Center, August 1972.

14. Fusina, G., Sislian, J. P., And Parent, B., "Formation and Stability of Near Chapman-Jouguet Standing Oblique Detonation Waves,” AIAA Journal, Vol. 43, No. 7, 2005, pp. 1591-1604.

15. Gross, R. A. AND Chinitz, W., "A Study of Supersonic Combustion,” Journal of Aerospace Sciences, Vol. 27, No. 7, 1960, pp. 517-534.

16. JaChimowski, C. J., "An Analytical Study of Hydrogen-Air Reaction Mechanism with Application to Scramjet Combustion," NASA TP 2791, 1988.

17. Kailasanath, K., "Review of Propulsion Applications of Detonation Waves," AIAA Journal, Vol. 38, No. 9, 2000, pp. 1698-1708.

18. LeHr, H. F., "Experiments in Shock-Induced Combustion,” Astonautica Acta, Vol. 17, 1972, pp. 589597.

19. Mao, M., Riggins, D. W., And McClinton, C. R., Numerical Simulation of Transverse Fuel Injection, NASA, Lewis Research Center, Washington, DC, 1991, pp. 635-667, see N91-21062 13-02.

20. McBride, B. J. And Reno, M. A., "Coefficients for Calculating Thermodynamic and Transport Properties of Individual Species," TM 4513, NASA, 1993.

21. Migal, D., "Supersonic Annular Nozzles," Journal of Spacecraft and Rockets, Vol. 9, No. 1, 1972, pp. 3-6.

22. Nicholls, J. A., Dabora, E. K., And Gealev, R. L., Studies in Connection with Stabilized Detonation Waves, Butterworths, London, UK, 1959, pp. 766-772. 
23. Papamoschou, D. And Roshko, A., “The Compressible Turbulent Shear Layer: An Experimental Study," Journal of Fluid Mechanics, Vol. 197, 1988, pp. 453-477.

24. Parent, B., Sislian, J. P., And Schumacher, J., "Numerical Investigation of the Turbulent Mixing Performance of a Cantilevered Ramp Injector,” AIAA Journal, Vol. 40, No. 8, 2002, pp. 1559-1566.

25. Parent, B., Computational Study of Fuel Injection in a Shcramjet Inlet, Ph.D. thesis, University of Toronto, Toronto, ON, Canada, 2002, Graduate Department of Aerospace Science and Engineering.

26. Parent, B. And Sislian, J. P., "The Use of Domain Decomposition in Accelerating the Convergence of Quasihyperbolic Systems," Journal of Computational Physics, Vol. 179, 2002, pp. 140-169.

27. Parent, B. And Sislian, J. P., "Effect of Geometrical Parameters on the Mixing Performance of Cantilevered Ramp Injectors," AIAA Journal, Vol. 41, No. 3, 2003, pp. 448-456.

28. Parent, B. And Sislian, J. P., "Validation of Wilcox k- $\omega$ Model for Flows Characteristic to Hypersonic Airbreathing Propulsion,” AIAA Journal, Vol. 42, No. 2, 2004, pp. 261-270.

29. PARK, H.-K., Model of an Aero-space Plane Based on an Idealized Cone-derived Waverider Forebody, Ph.D. thesis, University of Oklahoma, Norman, Oklahoma, USA, 1990.

30. Riggins, D. W., McClinton, C. R., And Vitt, P. H., "Thrust Losses in Hypersonic Engines Part 1: Methodology," Journal of Propulsion and Power, Vol. 13, No. 2, 1997, pp. 281-289.

31. RoE, P. L., "Approximate Riemann Solvers, Parameter Vectors, and Difference Schemes," Journal of Computational Physics, Vol. 43, 1981, pp. 357-372.

32. Roy, M. M., "Moteurs Thermiques," Comptes Rendus de l'Academie des Sciences, Vol. 222, No. 1, 1946, see also Royal Aircraft + Establishment Library Translation 112, 1946.

33. Schwartzentruber, T. E., Sislian, J. P., and Parent, B., "Suppression of Premature Ignition in the Premixed Inlet Flow of a Shcramjet," Journal of Propulsion and Power, Vol. 21, No. 1, 2005, pp. 87-94.

34. Seiner, J. M., Dash, S. M., And Kenzakowski, D. C., "Historical Survey on Enhanced Mixing in Scramjet Engines," Journal of Propulsion and Power, Vol. 17, No. 6, 2001, pp. 1273-1286.

35. Settles, G. S., Vas, I. E., And Bogdonoff, S. M., "Details of a Shock-Seperated Turbulent Boundary Layer at a Compression Corner,' AIAA Journal, Vol. 14, No. 12, 1976, pp. 1709-1715.

36. Sislian, J. P. And Parent, B., "Hypervelocity Fuel/Air Mixing in a Shcramjet Inlet," Journal of Propulsion and Power, Vol. 20, No. 2, 2004, pp. 263-272. 
37. Sislian, J. P. And Schumacher, J., "A Comparative Study of Hypervelocity Fuel/Air Mixing Enhancement by Ramp and Cantilevered Ramp Injectors," AIAA Paper 99-4873, Nov. 1999.

38. Veen, R. V., Gentry, R., And Hoffman, J. D., "Design of Shrouded-Plug Nozzles for Maximum Thrust," AIAA Journal, Vol. 12, No. 9, 1974, pp. 1193-1197.

39. Waitz, I. A., Marble, F. E., And Zukoski, E. E., "Investigation of a Contoured Wall Injector for Hypervelocity Mixing Augmentation,” AIAA Journal, Vol. 31, No. 6, 1993, pp. 1014-1021.

40. Wilcox, D. C., "Reassessment of the Scale Determining Equation for Advanced Turbulence Models," AIAA Journal, Vol. 26, No. 11, 1988, pp. 1299-1310.

41. WILCOX, D. C., "Dilatation-Dissipation Corrections for Advanced Turbulence Models," AIAA Journal, Vol. 30, No. 11, 1992, pp. 2639-2646.

42. Yee, H. C., Klopfer, G. H., And Montagné, J. L., "High-Resolution Shock-Capturing Schemes for Invisid and Viscous Hypersonic Flows," Journal of Computational Physics, Vol. 88, 1990, pp. 3161.

43. Zucrow, M. J. And Hoffman, J. D., Gas Dynamics, Vol. 1, John Wiley and Sons, New York, New York, 1976. 